\title{
DISEÑO DE PROPUESTAS DE E-FORMACIÓN
}

\section{COLABORATIVA:}

\section{UN MODELO DESDE LA PERSPECTIVA DE}

\section{LA TEORÍA DE LA ACTIVIDAD}

\author{
Tesista: Gabriela R. Cenich \\ Directora: Dra. Graciela Santos
}

Codirectora: Mg. María Alejandra Zangara

Tesis presentada para obtener el grado de MAGISTER en TECNOLOGÍA INFORMÁTICA APLICADA EN EDUCACIÓN 
Dedicatoria

$\mathcal{A}$ mi familia 


\section{Agradecimientos}

Este trabajo fue realizado gracias a la colaboración y apoyo brindado por personas comprometidas con las Instituciones donde desarrollan su labor. Quiero expresar mi sincero agradecimiento:

A la Universidad Nacional del Centro de la Provincia de Buenos Aires (UNICEN), a la Secretaría de Ciencia, Arte y Tecnología por haber subsidiado mi Magíster a través del Programa de Apoyo a la Formación de Postgrado.

Al Postgrado de la Facultad de Informática de la Universidad Nacional de La Plata por brindarme la posibilidad de ampliar mi formación profesional, tanto por el tema específico como por la modalidad de enseñanza.

A la Facultad de Ciencias Exactas de la UNICEN, por su sostenido apoyo para consolidar el área de investigación en Educación Tecnológica.

Al Departamento de Formación Docente y Núcleo de Investigación en Enseñanza de Ciencia y Tecnología (NIECYT) de la Facultad de Ciencias Exactas de la UNICEN, por el apoyo a mi formación y por brindarme los recursos para la realización de la presente tesis.

A la Secretaría Académica de la UNICEN y al Centro de Investigación, Producción y Tecnología Educativa (CIPTE) de la UNICEN por el aval institucional y facilitarme el uso de la plataforma de Educación a Distancia "Software de Asistencia Virtual para Educación Remota” (SAVER).

A Director Lic. Mg. Tomás Landivar y Vicedirectora Prof. Mg. Silvia Gallarreta del colegio de Nivel Polimodal "Ernesto Sábato" dependiente de la UNICEN, por facilitarme el trabajo con los docentes de la Institución así como el acceso a los recursos humanos e instalaciones que requirió el desarrollo del trabajo.

A la Dra. Sonia Araujo por haberme asesorado en los contenidos específicos de la propuesta de formación online.

A los Docentes del colegio de Nivel Polimodal "Ernesto Sábato" dependiente de la UNICEN, por su compromiso en la participaron en la propuesta de formación online. 
Quiero agradecer también a aquellas personas que participaron en la construcción día a día de este trabajo:

A mi familia, por su comprensión y enorme paciencia.

A Chelita por guiarme en el trabajo, compartiendo con generosidad su entender y su experiencia.

A Alejandra, por su buena disposición en la orientación de este trabajo.

A Andrea, por el respaldo de su amistad y las charlas que ayudan a pensar.

A Silvia, Stella e Irene por las buenas palabras.

A Rita e Inés, por el apoyo y la contención brindados desde la primera hora. 


\section{ÍNDICE}

\section{CAPÍTULO I}

INTRODUCCIÓN.

\section{CAPÍTULO II}

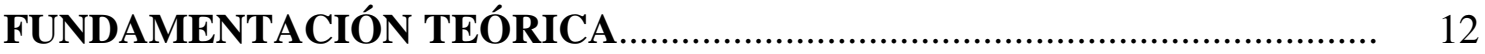

2.1 Concepción constructivista social del aprendizaje.......................................... 13

2.1.1 Teoría de la Actividad (TA).............................................................. 17

2.1.2 Aprendizaje basado en problemas........................................................ 19

2.1.3 Aprendizaje colaborativo.................................................................... 21

2.1.3.1 Factores que caracterizan el aprendizaje colaborativo............ 23

\section{CAPÍTULO III}

EDUCACIÓN A DISTANCIA, E-LEARNING Y FORMACIÓN

CONTINUA

3.1 Educación a Distancia e e-learning.

3.1.1 Formación continua en organizaciones escolares.................................. 29

3.1.2 Mediación pedagógica e instrumental................................................... 31

3.1.3 Plataformas de e-learning: características........................................... 35

3.1.3.1 Plataforma SAVER (Software de Asistencia Virtual para Educación Remota)............................................................ 36

3.1.3.1.1 Descripción general de la plataforma y herramientas

3.2 La dinámica del curso online según la Teoría de la Actividad.

\section{CAPÍTULO IV}

METODOLOGÍA PARA EL ESTUDIO DEL E-CURSO.

4.1 Introducción

4.2 Metodología a utilizar e instrumentos 


\section{CAPÍtULLO V \\ DISEÑO DEL E-CURSO “LA EVALUACIÓN: REFLEXIONANDO EN NUESTRA PRÁCTICA DOCENTE”,}

5.1 Descripción del diseño del e-curso............................................................ 52

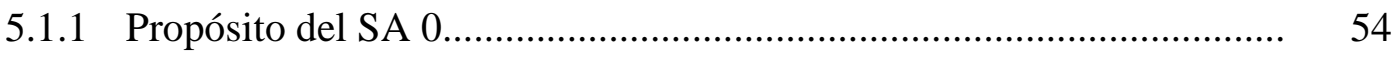

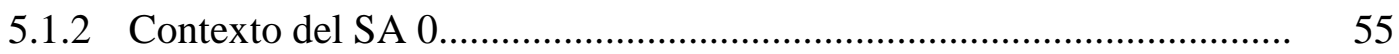

5.1.3 Descripción de los elementos del SA 0 según el modelo de Engeström (1987) ............................................................................ 56

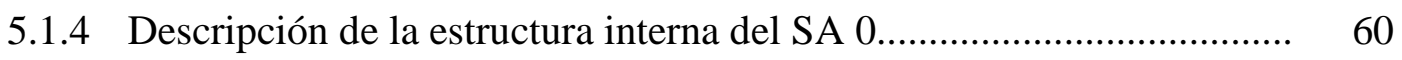

5.1.4.1 Descripción de los elementos de las actividades componentes del SA 0 según el modelo de Engeström (1987)

5.1.5 Evaluación integral del Sistema de Actividad. 72

\section{CAPÍTULO VI}

IMPLEMENTACIÓN Y SEGUIMIENTO DEL E-CURSO

6.1 Sistema de Actividad 0.1........................................................................... 75

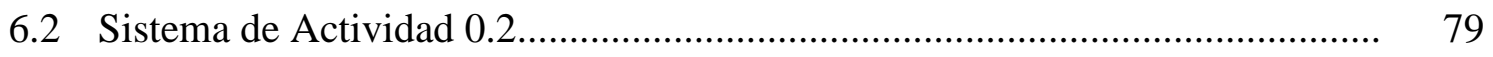

6.2.1 Análisis de los factores que caracterizan el desarrollo de procesos colaborativos (Ingram y Hathorn, 2004).......................................... 79

6.2.1.1 Participación..................................................................... 79

6.2.1.2 Interacción....................................................................... 81

6.2.2 Análisis holístico del SA 0.2 ......................................................... 81

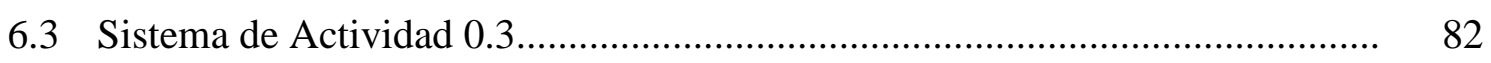

6.3.1 Análisis de los factores que caracterizan el desarrollo de procesos colaborativos (Ingram y Hathorn, 2004)............................................ 83

6.3.1.1 Participación...................................................................... 84

6.3.1.2 Interacción.......................................................................... 85

6.3.2 Análisis holístico del SA 0.3 .......................................................... 93

6.4 Sistema de Actividad 0.4.1.................................................................... 97 
6.4.1 Análisis de los factores que caracterizan el desarrollo de procesos colaborativos (Ingram y Hathorn, 2004)........................................... 97

6.4.1.1 Participación..................................................................... 97

6.4.2 Análisis holístico del SA 0.4.1....................................................... 99

6.5 Sistema de Actividad 0.4 ........................................................................... 101

6.5.1 Análisis de los factores que caracterizan el desarrollo de procesos colaborativos (Ingram y Hathorn, 2004)........................................... 102

6.5.1.1 Participación........................................................................... 102

6.5.1.2 Interacción........................................................................... 104

6.5.2 Análisis holístico del SA 0.4........................................................ 116

6.6 Sistema de Actividad 0.5 ................................................................... 121

6.6.1 Análisis de los factores que caracterizan el desarrollo de procesos colaborativos (Ingram y Hathorn, 2004)........................................... 122

6.6.1.1 Participación...................................................................... 122

6.6.1.2 Interacción.......................................................................... 122

6.6.2 Análisis holístico del SA 0.5 ........................................................... 124

6.7 Sistema de Actividad 0...................................................................... 125

6.7.1 Análisis de los factores que caracterizan el desarrollo de procesos colaborativos (Ingram y Hathorn, 2004)......................................... 127

6.7.1.1 Participación.................................................................... 127

6.7.1.2 Interacción....................................................................... 127

6.7.1.3 Síntesis.......................................................................... 129

6.7.2 Análisis holístico del SA 0............................................................... 130

\section{CAPÍTULO VII}

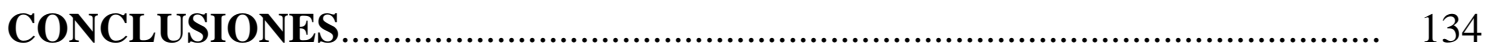

7.1 Presentación general de resultados.......................................................... 135

7.2 Modelo de "Diseño de propuestas de e-formación colaborativa".................... 136

7.3 Supuestos que sustentan la propuesta........................................................ 141

7.4 Proyección de este trabajo....................................................................... 142 
ANEXOS:

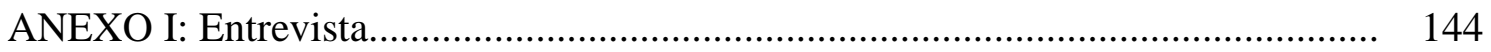

ANEXO II: Planteo de la situación problemática (SA 0.5.2)...................... 146

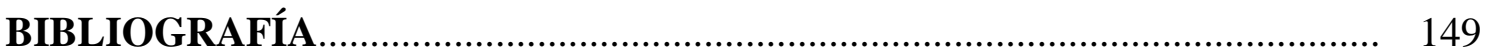


CAPÍTULO I

INTRODUCCIÓN 


\section{INTRODUCCIÓN}

Las innovaciones producidas en el área de las TIC (Tecnologías de la Información y la Comunicación) facilitan el almacenamiento, transferencia y procesamiento de la información, promoviendo cambios en las relaciones sociolaborales de las personas que deben readaptarse a nuevas situaciones organizacionales y personales. Los avances tecnológicos posibilitan la configuración de grupos humanos que interaccionan a través de redes para construir conocimientos en forma compartida y colaborativa. En este escenario, las organizaciones necesitan elaborar estrategias educativas y tecnológicas que les permitan adaptarse a los cambios que se generan en la sociedad.

En las instituciones escolares, la incorporación y utilización de las TIC, plantea la necesidad de formar al docente en aquellas capacidades y estrategias que le permitan participar colaborativamente en los nuevos entornos tecnológicos. Si se supone la construcción del conocimiento como contextual y pragmática, surgida a partir de la situación o de la propia práctica (Lewis, 2001) es imprescindible la consideración del contexto laboral en una propuesta de formación docente.

La mayoría de los estudios realizados sobre experiencias de aprendizaje colaborativo online, han puesto el énfasis en variables aisladas relacionadas con la construcción de conocimiento, la dimensión social, la interacción, el pensamiento crítico y la participación (Gunawardena y col., 1997; Kanuka y Anderson, 1998; Hew y Cheung, 2003). Los aspectos concernientes a las estrategias y habilidades necesarias para el desarrollo de procesos colaborativos, han sido más estudiados en el ámbito de situaciones de enseñanza presenciales (Johnson y Johnson, 1999). Sin embargo, son escasos los trabajos que estudian de manera holística el funcionamiento del grupo, desde una visión integradora de los aspectos antes mencionados. De esta manera, se hace necesario el desarrollo de investigaciones en este campo con el fin de indagar acerca de las variables presentes y sus interrelaciones para poder establecer lineamientos generales que orienten la práctica docente (Roberts, 2004).

El objetivo principal de esta propuesta, que se encuadra en la problemática de diseño de cursos e-learning para formación en organizaciones educativas, consiste en delinear un modelo de diseño de enseñanza basado en una visión constructivista social del aprendizaje que permita promover el aprendizaje colaborativo en un entorno virtual. 
Para ello, se parte de una propuesta inicial de diseño basada en la Teoría de la Actividad (Nardi, 1996), la cual es reformulada de manera iterativa desde una perspectiva holística para responder a las situaciones emergentes del curso en progreso. Para generar una aproximación a dicho modelo se estudiarán aspectos relevantes del funcionamiento sistémico de un curso de formación docente elaborado a partir de una demanda de formación planteada por la Dirección de la Escuela Polimodal "Ernesto Sábato" dependiente de la UNICEN. Se diseña e implementa un curso de formación online para desarrollar una tarea común con un objetivo compartido, utilizando la plataforma de la Universidad Nacional de Centro de la Provincia de Buenos Aires "Saver" ". Se propone incorporar una innovadora dinámica de trabajo entre los docentes de la institución escolar con el fin de promover el desarrollo de procesos colaborativos.

A continuación en el segundo capítulo se detallan bajo una perspectiva socioconstructivista, los lineamientos teóricos en los que se enmarca la propuesta. En el tercer capítulo se presenta la problemática de la incorporación del e-learning en la formación de docentes y la propuesta de la Teoría de la Actividad (TA) como heurística para el desarrollo de cursos colaborativos online. Desde un enfoque cualitativo, en el cuarto capítulo se propone utilizar métodos descriptivos de estudio de caso, aplicando la TA como metodología cualitativa para la estructuración y análisis de los datos. En el quinto capítulo se detalla el diseño del curso definido como un Sistema de Actividad (SA), describiendo sus componentes e interrelaciones. Se presenta en el sexto capítulo la implementación del curso de formación colaborativo online (e-curso), detallando el análisis y discusión de su evolución. En el capítulo siete se exponen las conclusiones y las proyecciones de este trabajo. Finalmente se incluye la bibliografía consultada y los anexos.

1 Plataforma "Saver", www.e-unicen.edu.ar/saver/ 


\section{FUNDAMENTACIÓN TEÓRICA}




\subsection{Concepción constructivista social del aprendizaje}

El campo de la educación ha experimentado cambios significativos acerca de la idea de aprendizaje y de las condiciones que favorecerían su progreso. Durante la primera mitad del siglo XX la psicología conductista fue el paradigma dominante. Las ideas iniciales de Thorndike y de Watson, y en especial de Skinner, limitaban el campo de trabajo a la conducta observable, ignorando cualquier posibilidad de que se indagase acerca de los sujetos que aprendían en tanto sujetos, o por su contexto social, o por el significado de lo que aprendían. El hecho de no considerar estos aspectos originó las principales críticas del conductismo como teoría del aprendizaje en las que se lo señala como ahistórico y asocial (Rodríguez Illera, 2004).

Las teorías cognitivistas surgen como una nueva perspectiva que emplea ideas del procesamiento de la información y enfatiza el procesamiento mental activo por parte del estudiante. Sin embargo, al igual que el conductismo sigue respondiendo a la tradición objetivista en la cual el conocimiento se cree que existe independientemente del aprendiz y es objetivo (Applefield y col., 2001). Desde la perspectiva objetivista el rol de la educación es ayudar a los estudiantes a aprender acerca del mundo real. Se afirma que hay un cuerpo particular de conocimiento que necesita ser transmitido al alumno, el aprendizaje entonces se considera como la adquisición y acumulación de un conjunto finito de habilidades y hechos (Tam, 2000). Autores como Gagné y Novak han influido en cómo pensar la educación, particularmente desde el punto de vista del profesor, al proponer formas y técnicas de representación de los conocimientos aplicables en la práctica educativa (Rodríguez Illera, 2004).

Contrariamente a estas ideas acerca de aprendizaje y conocimiento el constructivismo considera que los individuos viven en el mundo de sus propias experiencias personales y subjetivas. Siendo el individuo quien impone significado sobre el mundo, en vez del mundo imponerle su significado, construyendo una visión personal de la realidad (Karagiorgi y Symeou, 2005). De acuerdo a estas nociones, ..."el aprendizaje es un fenómeno de construcción personal antes que un proceso de transmisión” (Rodríguez Illera, 2004), destacándose el rol activo del alumno.

La construcción del conocimiento depende de lo que el aprendiz ya sabe, vinculado a la clase de experiencias que ha tenido, cómo ha organizado aquellas 
experiencias en estructuras de conocimiento, y las creencias que utiliza para interpretar objetos y eventos que encuentra en el mundo. A través de la interpretación de nuestras experiencias en el mundo, construimos nuestra propia realidad (Jonassen, online consultado 28/03/06).

El constructivismo social (Vygotsky, 1930/ 1978), argumenta que la cultura y el contexto son importantes en la formación del conocimiento. En este paradigma, el aprendizaje no es un proceso puramente interno, sino un constructo social mediado por el lenguaje utilizado en el discurso social, donde el contexto en el cual ocurre constituye el centro del aprendizaje mismo. La naturaleza de conocer y el proceso de construcción de conocimiento se originan en la interrelación social de personas que comparten, comparan y discuten ideas. Es a través de este proceso altamente interactivo que el alumno construye su propio conocimiento. De esta manera, el constructivismo social capta la perspectiva del constructivismo más general existente a través del énfasis en la importancia de los intercambios sociales para el desarrollo cognitivo y el impacto del contexto cultural e histórico en el aprendizaje (Applefield y col., 2001). Desde esta perspectiva se postula un sujeto social que no sólo es activo sino, ante todo, interactivo. El aprendizaje consiste en la internalización progresiva de los instrumentos mediadores en un proceso de enseñanza y aprendizaje, donde se considera al que aprende, al que enseña y la relación social entre ellos (Castorina y col., 1999).

El constructivismo considera que el educador actúa como un facilitador cuya función principal es ayudar a los estudiantes a convertirse en participantes activos de su aprendizaje y a realizar conexiones significativas entre el conocimiento existente, el nuevo conocimiento y los procesos involucrados en el aprendizaje (Tam, 2000). Desde esta visión se resalta el desempeño del educador como guía que posibilita el alcance por parte del aprendiz de habilidades cada vez más complejas, hasta llegar al logro de competencias independientes (Applefield y col., 2001). Esta perspectiva se encuentra relacionada con un concepto muy importante del constructivismo social: la zona de desarrollo próximo (ZDP). Vygotsky (1930/ 1978) la definía como "la distancia entre el nivel real de desarrollo, determinado por la capacidad de resolver independientemente un problema, y el nivel de desarrollo potencial, determinado a través de la resolución de un problema bajo la guía de un adulto o en colaboración con otro compañero más capaz". Así, un estudiante que no pudiera llevar a cabo de manera satisfactoria una tarea solo, podría lograrlo con la asistencia del docente o de un par más avanzado, los cuales 
permitirían al aprendiz lograr un nivel más alto de realización de la tarea (Marsh II y Ketterer, 2005). Este concepto se encuentra considerado en numerosas situaciones laborales reales, donde un individuo aprende una actividad trabajando en contacto con un experto, el cual modela comportamientos y proporciona feedback, permitiendo gradualmente al novato ejercitar independientemente las habilidades propias de la profesión (Applefield y col., 2001). El aprendizaje intencional se apoya frecuentemente en tareas de aprendizaje bastante específicas creadas por los profesores para proporcionar contextos a la acción realizada por el estudiante y que producen nuevas experiencias mediante las cuales puede tener lugar el aprendizaje. De esta manera el docente favorece no sólo la construcción de nuevo conocimiento, sino además, la reestructuración del existente mediante las acciones de andamiaje de compañeros y profesores (Lewis, 1998).

La actividad en la cual el estudiante construye conocimiento es una parte integral del aprendizaje, las situaciones son co-productoras del conocimiento a través de la actividad (Brown y col., 1989). La noción de cognición situada sostiene que la cognición comienza desde la base de la interacción con la situación para posteriormente internalizar los conceptos. Pensamiento y acción no pueden separarse. El aprendizaje podría tener lugar en una situación problemática o en un contexto real, contribuyendo a su motivación la definición de objetivos dirigidos en un contexto específico (Hung, 2002). El problema debería estar definido o estructurado en forma insuficiente, de manera que algunos aspectos de la situación problemática resulten inesperados y puedan ser definidos por los alumnos estableciendo y defendiendo juicios sobre el problema, el cual puede comprender múltiples soluciones, líneas de solución o ninguna solución (Jonassen, 2000). La resolución de problemas es una actividad compleja que involucra distintos componentes cognitivos, tales como conceptos, reglas y principios relacionados con el dominio de conocimiento (Jonassen, 1997).

Teniendo en cuenta la naturaleza contextual del conocimiento se destaca como una parte importante del contexto humano la interacción social con otras personas. Lewis (1998) propone un modelo donde destaca que ciertas partes del conocimiento nuclear de cada persona se solapa con el de otros y donde considera además, que la ZDP de una persona se solapa con el conocimiento nuclear de otros. De esta manera, cada persona podría contribuir al desarrollo cognitivo del grupo brindando ayuda a otros para desempeñar tareas que requieran de su conocimiento para poder ser realizadas de 
manera autónoma. Vygotsky considera la importancia de la intervención de los miembros del grupo como mediadores entre la cultura y el individuo, para promover los procesos interpsicológicos que posteriormente serán internalizados (Castorina y col., 1999).

Uno de los principios fundamentales que subyace en el constructivismo es el concepto de "conflicto sociocognitivo". Este mecanismo para el aprendizaje, derivado del trabajo de Piaget y sus discípulos, surge a través de la dinámica del intercambio social cuando el estudiante realiza una actividad que promueve una contradicción entre su conocimiento existente y lo que está experimentando. Los constructivistas sostienen que el mejor ambiente para crear tales conflictos, es aquél en el cual se plantea un problema, surgen preguntas y se presentan perspectivas alternativas (Applefield y col., 2001). Estos conflictos son productivos para el avance cognoscitivo al facilitar la toma de conciencia de los integrantes de un grupo de las respuestas distintas aportadas por otros miembros, en las cuales pueden presentarse características e información que no habrían sido consideradas y promoverían un incremento de la actividad intelectual ante la necesidad de llegar a un acuerdo (Castorina y col., 1999).

El diseño de situaciones de enseñanza y aprendizaje se ve afectado por el hecho de que el constructivismo es una teoría de aprendizaje y no una teoría de diseño instruccional (Karagiorgi y Symeou, 2005). En concordancia con sus postulaciones no prescribe un conjunto particular de actividades y procesos a llevar a cabo con el fin de lograr aprendizajes intencionales. En cambio, destaca el diseño de ambientes de aprendizaje dirigidos hacia la construcción de conocimiento, tarea que se ve dificultada debido a cierto grado de impredictibilidad de los resultados y complejidad en el proceso de construcción de conocimiento (Applefield y col., 2001).

Willis (citado en Tam, 2000) propone un modelo de diseño instruccional constructivista que se caracteriza por un proceso de diseño recursivo, una planificación integral, reflexiva y colaborativa, objetivos que emergen del diseño y el desarrollo de la actividad, y una enseñanza que destaca el aprendizaje en contextos significativos. Algunos ejemplos de ambientes de aprendizaje constructivista incluyen cognición situada en contextos del mundo real, flexibilidad cognitiva brindando ejemplos relacionados que ofrecen diversidad de puntos de vista y de perspectivas sobre el caso de estudio o proyecto a resolver (Jonassen, 2000), y aprendizaje colaborativo permitiendo a los estudiantes desarrollar, comparar, proponer, negociar, favoreciendo el 
entendimiento de múltiples perspectivas sobre un tema (Tam, 2000).

Desde esta perspectiva, el rol del docente implicaría un cuidadoso seguimiento del proceso de enseñanza y la construcción del aprendizaje del alumno (Applefield y col., 2001). Por otra parte, el diseño y desarrollo de situaciones de enseñanza y aprendizaje supondría contemplar de manera pragmática y desde una visión holística, nociones tales como la concepción de enseñanza y aprendizaje, el rol del alumno, el rol del docente, la interacción social, el contexto, la situación problemática a resolver, la colaboración, las herramientas mediadoras, con el fin de favorecer la construcción de ambientes colaborativos de aprendizaje que no sólo potencien las virtudes de los componentes anteriores, sino también sus interrelaciones, respetando la concepción de que el todo es más que la suma de las partes.

\subsubsection{Teoría de la Actividad (TA)}

Las teorías de aprendizaje que reconocen que el aprendizaje sólo ocurre en el contexto significativo de la actividad consideran que es importante analizar la actividad y el contexto como parte del proceso de diseño educativo. Así, cuando se estudia la actividad humana se debe analizar no sólo los tipos de actividades en los que las personas se comprometen sino quién se compromete con tal o cual actividad, cuáles son sus objetivos e intenciones, qué objetos o productos resultan de esa actividad, cuáles son las reglas y normas que circunscriben tal actividad y en qué comunidad ocurre la actividad.

La TA (Activity System Theory o simplemente Activity Theory) nació como un enfoque filosófico para analizar diferentes formas de la práctica humana como procesos de desarrollo, tanto a nivel individual como grupal. Es una poderosa lente socio-cultural y socio-histórica a través de la cual se pueden analizar la mayoría de las actividades humanas. Esta teoría fue desarrollada por Leont'ev (1978) en base al concepto de herramienta de mediación (Vygotsky, 1930/ 1978), la noción de actividad y la mediación de los aspectos sociales y culturales en la actividad humana.

Desde esta perspectiva teórica las actividades son las interacciones humanas con el mundo objetivo, siendo las actividades conscientes una parte de estas interacciones. Más que aprender antes de actuar, como prescriben las teorías tradicionales, la TA 
considera a priori que la mente humana emerge y existe como un componente especial de interacciones con el entorno, de manera que la actividad -sensorial, mental o físicaes precursora del aprendizaje.

Las acciones humanas son consideradas situadas en un contexto, enfatizando la interacción de la conciencia humana con la actividad dentro de un contexto relevante, diferenciando entre la acción individual y la actividad colectiva introducida por la división de labores. Se propone que, para entender completamente las acciones humanas, la unidad de análisis básica debe incluir tanto las acciones como el mínimo contexto significativo: "la actividad".

Es decir, la actividad consiste en una jerarquía de acciones, desarrolladas en forma consciente y dirigidas hacia una meta. Las acciones se utilizan para transformar el objeto y requieren cadenas de operaciones. Es importante tener en cuenta que todas las operaciones son acciones cuando se desarrollan por primera vez, porque requieren de un esfuerzo consciente. Con la práctica y la internalización las actividades devienen en acciones y eventualmente en operaciones cuando se hacen más automáticas dado que requieren menos esfuerzo consciente.

Engeström (1987) desarrolló un modelo para analizar las actividades realizadas por un sujeto cuando orienta sus acciones hacia un objeto para obtener ciertos resultados deseables. El objeto no es precisamente un objetivo o una meta, sino algo que el sujeto necesita y que construye guiado por la fuerza movilizadora presente en la cultura. La actividad es influenciada por las herramientas de mediación utilizadas, la comunidad a la que pertenece el sujeto y el tipo de colaboración establecida dentro de la comunidad, guiada por reglas y normas y la división del trabajo para reflejar la naturaleza colectiva y colaborativa de la actividad humana.

La producción de una actividad involucra un sujeto, el objeto de la actividad, las herramientas que se utilizan en la actividad, y las acciones y operaciones que afectan al resultado. Dichos componentes son organizados en un Sistema de Actividad, que se centra en la producción de algún objeto pero la unidad de análisis más apropiada es la actividad. De esta manera, se enfatizan los factores sociales y la interacción entre sujetos y sus ambientes explicando por qué el principio de "herramientas de mediación" tiene un papel central dentro de esta aproximación. Primero, porque considera que las herramientas informan los modos en que los humanos comienzan a interactuar con la 
realidad y segundo porque las herramientas reflejan las experiencias de otras personas, quienes han probado de resolver problemas similares con anterioridad y han inventado y modificado las herramientas para hacerlas más eficientes. Dicha experiencia es acumulada en las propiedades estructurales de las herramientas (forma, material, etc.), así como también el conocimiento de cómo la herramienta debe ser utilizada. Las herramientas son creadas y transformadas durante el desarrollo mismo de la actividad llevando con ellas una cultura particular -un remanente histórico de tal desarrollo. Así el uso de herramientas es un medio para la acumulación y transmisión del conocimiento social, influyendo tanto sobre el comportamiento externo como en el funcionamiento mental de los individuos.

El sujeto de una actividad es el individuo o grupo de actores comprometidos con la misma. El objeto de la actividad es el producto físico o mental que se busca conseguir. El sujeto actúa sobre el objeto, configurando la interacción que motiva la actividad, y el objeto no es invariable, se transforma en el curso de la actividad. Las herramientas son "alguna" cosa que se utiliza en el proceso de transformación, y pueden ser de carácter físico, como la computadora, o mental, como un modelo o una heurística. El uso de herramientas específicas de la cultura forma lo modos en que la gente actúa y piensa. Las herramientas alteran la actividad pero, a su vez, son alteradas por la actividad.

En síntesis, esta perspectiva enfatiza la relación dinámica entre conciencia y actividad donde el conocimiento es socialmente construído sobre la base de la intencionalidad, la historia, la cultura y las herramientas de mediación que se utilizan en el proceso. La consciencia es el resultado de la práctica diaria, y el proceso de significación consciente que realiza una persona o grupo en una red de trabajo que emerge y se sustenta en la actividad o en la reflexión consciente sobre dicha actividad.

\subsubsection{Aprendizaje basado en problemas}

Los problemas proveen el contexto para que los alumnos apliquen sus conocimientos, estimulando, en algunos casos, la exploración y reflexión necesaria para la construcción de conocimiento (Tam, 2000). La resolución de problemas es una actividad muy compleja que incluye componentes cognitivos relacionados con el 
dominio de conocimiento (información proposicional, conceptos, reglas, principios), conocimiento estructurado (redes conceptuales, modelos mentales, mapeo semántico) y estrategias metacognitivas (propuesta de objetivos, asignación de recursos cognitivos, evaluación del conocimiento anterior), que deberían ser abordados desde un enfoque holístico por el alumno (Jonassen, 1997).

David Jonassen (1997) distingue dos tipos de problemas principales: aquéllos a los que denomina "bien estructurados" y los que designa "mal estructurados". Los primeros abarcan aquellos problemas con soluciones convergentes que requieren la aplicación de un número limitado de reglas y principios con parámetros bien definidos. Greeno (1978 en Mergendoller J. y col., 2006) llama a este tipo de problemas de transformación, comienzan con un estado inicial bien definido (lo que se conoce), hay una clara identificación del objetivo (la solución), y un procedimiento reconocido para la transformación del estado inicial al estado meta. Los segundos, en cambio, poseen múltiples soluciones e incertidumbre acerca de qué conceptos, reglas y principios son necesarios para alcanzar una de las posibles soluciones y cuál de ellas sería la mejor. Los problemas "mal estructurados", desde una visión constructivista, promoverían la participación activa de los estudiantes en su propio proceso de aprendizaje y construcción de conocimiento (Neo \& Neo, 2001).

Los problemas se caracterizan tradicionalmente por un dominio, un tipo, un proceso de solución y una solución. El dominio del problema está constituido por aquellos conceptos, reglas y principios que definen los elementos del problema. El tipo de problema describe la combinación de conceptos y reglas, y los procedimientos para actuar sobre ellos con el fin de resolverlos. El espacio o esquema del problema se compone de la interpretación y representación del tipo de problema por parte de la persona que se propone resolverlo, la comprensión del estado actual del problema y el estado a alcanzar como meta, junto con un conjunto de operadores que permitirían pasar del estado inicial al estado objetivo. La solución al problema representa el objetivo de la persona comprometida a resolverlo. La solución puede ser convergente, una sola y conocida, o divergente, una entre varias soluciones aceptables. Un atributo crítico en la resolución de problemas es que la solución no es fácilmente identificable en el enunciado del problema; de esta manera el alumno debe identificar no sólo la naturaleza del problema, sino también una solución aceptable y un proceso que le permita llegar a ella. Los tipos de problemas no representan una clasificación rígida, sino más bien un 
continuo desde problemas descontextualizados con soluciones convergentes hasta problemas muy contextualizados con múltiples soluciones (Jonassen, 1997).

Los avances en las telecomunicaciones y tecnologías de la información requieren de los individuos habilidades que les permitan comunicarse, colaborar con otros, tomar decisiones y ser capaces de resolver problemas de manera crítica y creativa (Lee, 1999). Acorde a esta realidad, la enseñanza necesitará tener lugar en un contexto rico que refleje el mundo real y el cual estará estrechamente relacionado a aquellas situaciones en las cuales el conocimiento será utilizado (Petraglia, 1998).

\subsubsection{Aprendizaje colaborativo}

Trabajo y aprendizaje tienen una importante característica en común: dependen de individuos implicados en la realización de una tarea. Pero hay muchos aspectos que los distinguen, en particular, los objetivos básicos, las motivaciones individuales y el contexto. (...) Como las siglas indican, la investigación sobre $\mathrm{ACAO}^{1}$ se refiere a los denominados "aprendices" y esto implica que el aprendizaje es la primera intención de su actividad, por lo general en una institución formal o al menos con un currículum específico de estudio y con metas personales individuales. En cambio, el $\mathrm{TCAO}^{2}$ se refiere a personas cuya meta principal es el trabajo y este objetivo se alcanza en una comunidad con metas compartidas... (Lewis, 1998: 191).

Tomando esta cita y de acuerdo a los objetivos planteados en el capítulo uno, el énfasis en este trabajo estará puesto en el aprendizaje colaborativo.

La mayoría de los estudios acerca de trabajo colaborativo han sido llevados a cabo en el contexto académico, en el marco de enfoques pedagógicos tradicionales que han tendido a descontextualizar el conocimiento y las habilidades, eliminando los vínculos

\footnotetext{
${ }^{1}$ Aprendizaje Cooperativo Apoyado por Ordenador. Computer Supported Collaborative Learning (CSCL) en el original.

2 Trabajo en Colaboración Apoyado por Ordenador. Computer Supported Collaborative Working $(\mathrm{CSCW})$ en el original.
} 
con las aplicaciones en el mundo real (McLoughlin, 2002).

La colaboración es un método de enseñanza que utiliza la interacción social como medio de construcción del conocimiento (Paz Dennen, 2000). Centra la mayor parte de la responsabilidad de aprender en los estudiantes, requiriendo de ellos conceptualizar, organizar, poner a prueba las ideas, en un proceso continuo de evaluación y reconsideración de las mismas, asistidos por el profesor como facilitador del proceso de enseñanza y aprendizaje (Biesenbach-Lucas, 2004).

En primer lugar sería conveniente establecer una distinción entre aprendizaje cooperativo y colaborativo (McInnerney y Roberts, 2004):

El aprendizaje cooperativo implica esfuerzo individual, agrupa a los estudiantes para trabajar en problemas y cuestiones específicas bien definidas y bien estructuradas, para los cuales hay soluciones o respuestas claras y correctas (Jonassen, 1997). Por lo general los estudiantes trabajan con reglas bien definidas y permanecen bajo la dirección y control del profesor. A menudo el proceso involucra una clase de división del trabajo, en la cual los estudiantes se ayudan mutuamente para dominar el cuerpo de conocimientos apropiado, que es diseñado y predeterminado por el profesor. El aprendizaje se observa como un esfuerzo individual que se facilita por la participación en grupo.

El aprendizaje colaborativo comparte varias de las características del aprendizaje cooperativo. Difiere principalmente en la naturaleza de las tareas asignadas, dónde reside el control total del proceso de aprendizaje, la naturaleza del conocimiento y la concepción de aprendizaje. En el aprendizaje colaborativo, los grupos se enfrentan a situaciones de la vida real complejas, mal estructuradas y sin una clara y única solución correcta. El objetivo de la metodología de aprendizaje colaborativo es cambiar el lugar de control de la clase, del profesor a los grupos de alumnos, considerando a los estudiantes como co-constructores del conocimiento más que consumidores de él (Brufee, 1999 en Dirkx y Smith, 2004).

La evaluación de aprendizaje colaborativo online ha sido definida por los autores Gunawardena, Carabajal y Lowe (2001 en Treleaven, 2004) como:

"Una investigación sistemática e intencional que incluye la colección, análisis e informe de datos relacionados con la eficiencia, pertinencia, efectividad y la valoración de las características operacionales y de los resultados de un procedimiento, programa, 
proceso o producto."

\subsubsection{Factores que caracterizan el aprendizaje colaborativo}

Los autores Ingram y Hathorn (2004) definen que la colaboración consta de tres elementos decisivos: participación, interacción y síntesis. La participación es importante, porque la colaboración no puede tener lugar dentro de un grupo a menos que haya una intervención más o menos igualitaria entre sus miembros. La interacción requiere que los participantes del grupo respondan activamente unos con otros, explicitando ideas y generando devoluciones. Finalmente el producto creado por el grupo debe representar una síntesis de ideas de todos los miembros del grupo.

Para decidir si ha ocurrido colaboración en un grupo estos autores sugieren evaluar la cantidad y la naturaleza de las interacciones entre participantes. Consideran que en un foro las interacciones ocurren cuando los miembros del grupo refieren explícita o implícitamente mensajes anteriores en una discusión, mientras permanezcan en tema. Esto es distinto a la participación, la cual se mide por el número total y la extensión de los mensajes enviados y recibidos por todos los miembros del grupo. Así, todas las respuestas contribuyen a la participación en la discusión, pero sólo la discusión continua de la tarea cuenta como interacción (Ingram y Hathorn, 2004).

La colaboración puede ser difícil conocer cuándo ocurre, cuán efectiva es, cómo estimularla o qué la está impidiendo. El producto final es verdaderamente un producto grupal en el cual es difícil o imposible identificar las contribuciones individuales.

En general, se encuentran estudios de interacción acerca del feedback generado por la computadora a nivel de tarea y sólo apenas algunas exploraciones a nivel de interacción de grupo. Aunque la interacción y la comunicación son cruciales en el aprendizaje basado en proyecto, la mayoría de los enfoques que implementan PBL (Problem Based Learning) en un entorno de aprendizaje basado en red no ofrecen al alumno propuestas para soportar dichas estrategias de enseñanza. La mayoría de los estudios realizados sobre experiencias de aprendizaje colaborativo online, han puesto el énfasis en factores relacionados con la construcción de conocimiento, la dimensión social, la interacción, el pensamiento crítico y la participación (Gunawardena y col., 1997; Kanuka y Anderson, 1998; Hew y Cheung, 2003). Los aspectos concernientes a 
las estrategias y habilidades necesarias para el desarrollo de procesos colaborativos, han sido más estudiados en el ámbito de situaciones de enseñanza presenciales (Johnson y Johnson, 1999).

El objetivo del aprendizaje colaborativo es "crear situaciones en las cuales se generen interacciones productivas entre los aprendices" (Ronteltap y Eurelings, 2002). Esta noción de productividad, qué producen los estudiantes juntos, necesariamente involucra evaluar los diferentes contextos, procesos y resultados que facilitan y soportan tal interactividad. La evaluación en estos nuevos contextos cambia los enfoques tradicionales y requiere nuevos marcos teóricos que guíen el análisis y la interpretación.

La colaboración online basada en texto puede ser fácil de administrar y efectuar su seguimiento, porque las comunicaciones son todas escritas, y se puede guardar registro de lo ocurrido en las sesiones online. Las herramientas de comunicación asincrónicas, como el foro de discusión, proveen un espacio propicio para llevar a cabo discusiones focalizadas en la cual un concepto se desarrolla o se resuelve un problema, y en donde se requiere llegar a una conclusión. Son menos efectivas para generar ideas, para cambios rápidos de información y para discusiones que no están tan orientadas a estos objetivos.

En la discusión asincrónica los estudiantes pueden participar en cualquier tiempo y desde cualquier lugar, sin observar lo que están haciendo otros participantes. CMC (Computer-mediated communications) asincrónicas permiten a los participantes contribuir a la discusión más igualitariamente porque ninguna de las limitaciones habituales impuestas por un profesor ni horarios de clase se aplican. Las discusiones asincrónicas permiten más tiempo para considerar opiniones (Kaye, 1992 en Ingram y Hathorn, 2004) y son más efectivas para la discusión profunda de ideas (Smith, 1994 en Ingram y Hathorn, 2004). Los mensajes normalmente permanecen en el sitio de discusión durante todo el período; de esta manera los participantes pueden releer los mensajes previos y agregar nuevas ideas. El uso de los mensajes basados en texto permite la reflexión y el replanteo del conocimiento previo a medida que los estudiantes plantean preguntas y discuten ideas con otros en el grupo. Se favorece el aprendizaje a través de la reflexión y la interacción no sólo leyendo lo que otros escriben, sino influyendo en el desarrollo de las respuestas mediante la interacción de unos con otros.

Los programas de discusión basados en la Web cuentan con poderosas 
herramientas para facilitar la implementación de estrategias donde los estudiantes resuelven situaciones complejas basadas en situaciones del mundo real. En la utilización de estas estrategias se espera que el aprendizaje tenga lugar a medida que los estudiantes adquieren nuevo conocimiento y la habilidad de aplicarlo al proyecto. Comunicación y colaboración son esenciales para resolver estos problemas.

Considerando que la colaboración en entornos online se compone de participación, interacción y síntesis, se presenta la necesidad de indagar sobre los diferentes grados de colaboración en un grupo trabajando en la resolución de una actividad. Se requiere de un significado compartido de la tarea y las posibles soluciones, implicando compromiso y activa participación de los miembros. Dado que la presencia de estos tres elementos puede darse en diferentes niveles no es posible crear una sola regla de decisión que nos permita categorizar definitivamente a los grupos como colaborativos o no colaborativos. En cambio, se puede considerar un continuo desde grupos altamente colaborativos hasta escasamente colaborativos (Ingram y Hathorn, 2004). De esta manera, sería posible categorizar a los grupos para establecer niveles de colaboración y establecer alguna correlación con el producto obtenido por el grupo. 
EDUCACIÓN A DISTANCIA,

\author{
E-LEARNING Y
}

FORMACIÓN CONTINUA 


\subsection{Educación a Distancia e e-learning}

El surgimiento de la World Wide Web generó grandes expectativas en los sectores educacionales y organizacionales acerca de su uso como medio para facilitar el aprendizaje (Bowles, 2004). La educación a distancia, surgida con el objetivo de hacer llegar la educación a todo aquel que la necesitara, se caracterizó a lo largo de su evolución por utilizar como mediadores en los procesos de enseñanza y aprendizaje diversos medios tecnológicos. Destacándose en la incorporación de las Tics el concepto de interacción que permite considerar nuevos planteamientos pedagógicos (Sangrà Morer, 2002), que van más allá de pensar a Internet como un repositorio disponible y accesible de información.

En un principio, la interacción fue considerada en dos relaciones profesor-alumno y alumno-materiales de estudio. Así se distribuían materiales prearmados en formato de CD o a través de redes, promoviendo una visión atomizada de los alumnos y sin considerar el contexto social en el cual tenía lugar la experiencia educativa. La incorporación de nuevas tecnologías permitieron reflexionar sobre las posibilidades pedagógicas de considerar interacciones entre profesor-alumno y alumno-alumno tanto sincrónica como asincrónicamente (Bowles, 2004), favoreciendo la integración de metodologías de aprendizaje colaborativo (Sangrà Morer, 2002).

Se destacan como formas de comunicación sincrónicas el chat, basado en comunicación textual y audiovisual online en tiempo real; “el salón de clases virtual”, que trata de emular a un salón de clases tradicional, utilizando herramientas como la video-conferencia o las pizarras electrónicas que permiten compartir, crear y modificar materiales en tiempo real.

La utilización de herramientas asincrónicas proporciona a los alumnos una flexibilidad horaria que les permite adecuar los tiempos de estudio a sus compromisos personales o laborales. Entre los medios más utilizados de este tipo se encuentran el $e$ mail, el foro y las aplicaciones que permiten desarrollar un trabajo colaborativamente, promoviéndose la interacción entre alumnos, alumno-profesor y de los alumnos con los materiales de estudio, a través de actividades colaborativas que tienden a favorecer la discusión y negociación de significados (Bowles, 2004).

Cabero (2006) reconoce el papel mediador de las tecnologías, pero resalta que su 
utilización en el e-learning no constituye el factor principal ni determinante. Propone como variables críticas del sistema los contenidos, en cuanto a su calidad, su cantidad y estructuración; la disponibilidad de herramientas para la comunicación, tanto las que propician una comunicación sincrónica como asincrónica; el papel del profesor, como diseñador, orientador y tutor de situaciones mediadas de aprendizaje; el rol del alumno, considerado como receptor activo y consciente de la acción educativa; los aspectos organizativos, que suelen ser más complejos que en la situación presencial; las estrategias didácticas desde las referidas a la acción educativa individual hasta las que buscan el trabajo colaborativo a través de e-actividades propiciando la formación de una comunidad virtual. La consideración de estas variables en cuanto a su identificación y definición no debería ser en forma aislada, sino acompañada de una reflexión que permita percibir sus interacciones.

Las nuevas formas de interacción promueven procesos de reflexión sobre los roles del alumno y del profesor tendientes a lograr una integración de los nuevos medios y su potencial educativo a los procesos de enseñanza y aprendizaje.

Desde el surgimiento del e-learning han ido sucediendo diversas definiciones que han intentado limitar el concepto, sin embargo, el hecho de que el e-learning intersecta numerosos campos de pensamiento y práctica, y su estrecha relación con la tecnología que le da soporte, dificulta establecer acuerdos al respecto.

Urdan \& Weggen (citados en Wentling y col., 2000) consideran que el e-learning abarca un amplio conjunto de aplicaciones y procesos que incluyen CBL (ComputerBased Learning), WBL (Web-Based Learning), aulas virtuales y colaboraciones digitales, en los cuales la distribución de contenidos se realiza a través de medios electrónicos incluidos Internet, intranets, transmisión satelital, material de audio y video, TV interactiva y CD-ROM. Distinguen al e-learning de la educación a distancia señalando que esta última incluye los cursos basados en texto y distribuidos por correspondencia.

Rosemberg (2001) circunscribe al e-learning al ámbito de Internet, distinguiendo los siguientes criterios fundamentales:

*E-learning se implementa en una red, lo cual hace que sea capaz de actualización instantánea, almacenamiento y recuperación, y permite compartir enseñanza e información. Tan importantes son estas capacidades que rápidamente se convirtieron en 
un requerimiento indispensable del e-learning. Si bien los CD-Roms y DVDs presentan ventajas en la distribución de información e implementación de simulaciones, carecen de las características de un entorno de red, donde la distribución y actualización de la enseñanza e información se realiza en forma instantánea, por lo cual no deberían ser clasificados como e-learning.

*Se distribuye al usuario final a través de la computadora utilizando tecnología de Internet standard.

*Se enfoca en una visión más amplia del aprendizaje que va más allá de los paradigmas tradicionales de formación.

Williams y col. (1999) consideran que la educación a distancia se refiere al proceso de enseñanza y aprendizaje en el cual el alumno y el profesor están separados por la geografía y el tiempo. Los sistemas de educación a distancia en su evolución a través del tiempo, se caracterizan fundamentalmente por el tipo de tecnología que adoptan. Así se distinguen, la Enseñanza por Correspondencia, la Enseñanza Basada en la Comunicación de Masas, la Enseñanza Multimedia a Distancia y los Sistemas Interactivos Abiertos (Chacón, 1996). Teniendo en cuenta las características de elearning antes expuestas se podría decir que el e-learning es una forma de educación a distancia pero la educación a distancia no es necesariamente e-learning (Rosemberg, 2001).

El surgimiento y evolución de las tecnologías móvil, wireless y satelital, conllevan a una reflexión acerca de las potencialidades que la tecnología podría aportar al proceso educativo. Así, considerando el estado de permanente cambio en el cual se encuentran las Tics y su influencia en el e-learning, se adopta en el presente trabajo la definición propuesta por Bowles (2004): “una experiencia de aprendizaje que involucra la adquisición o transferencia de conocimiento distribuídos o intercambiados a través de medios electrónicos”. De esta manera, no se restringe el término a conexiones de Internet a través de computadoras en red, sino que se amplía su alcance a nuevas formas emergentes de comunicación.

\subsubsection{Formación continua en organizaciones escolares}


El avance de las nuevas tecnologías influye en la relación de las personas con el conocimiento, el interés se mueve desde la acumulación de saberes a la adquisición de estrategias y capacidades que permitan generar procesos para compartir, debatir y comunicar el conocimiento. Los conocimientos, las habilidades y los conceptos aprendidos durante la infancia y juventud en la familia, la escuela, la formación profesional, el instituto o la universidad no son suficientes para el desarrollo de la vida profesional. Una integración más decidida del aprendizaje en la vida adulta es un componente esencial del proceso de facilitación del aprendizaje permanente, aunque es sólo una parte de un todo. El aprendizaje permanente considera todo el aprendizaje como un proceso continuo e ininterrumpido durante todo el ciclo vital (SEC, 2000).

Las organizaciones escolares deben adaptarse a las nuevas situaciones que se generan en la sociedad impulsadas por cambios tecnológicos, económicos y científicos a través de la formación continua de los docentes. Tiempo y lugar educativo se multiplican en la sociedad actual, las personas acceden a través de otras formas a la educación (Huberman, 2000), para lo cual necesitan capacidades y estrategias que favorezcan el desarrollo de procesos de aprendizaje que les permitan adaptarse críticamente a los cambios.

La incorporación de las Tics a la vida cotidiana como herramientas que permiten la comunicación, almacenamiento y distribución de información plantean formas diferentes de interacción con el entorno que involucran a las personas en nuevas experiencias que requieren elaborar, comparar y lograr consenso con los otros sobre nuevos significados generando a su vez procesos de resignificación (Sánchez Ilabaca, 2004).

Según Huberman (2000) los docentes necesitan una formación continua para dar respuesta a nuevos interrogantes que plantea la realidad social en la que se encuentra inserta la escuela. A partir de esta idea se puede interpretar que la formación no debería ser descontextualizada, sino encontrar en el ámbito de trabajo la aplicación de los nuevos conocimientos favoreciendo procesos de aprendizaje y de colaboración en el contexto real de la práctica cotidiana. Se hace necesaria una reflexión en el accionar que permita a los docentes evaluar y mejorar su práctica, adaptándose a los cambios actuales y posibilitando enriquecer las situaciones de enseñanza y aprendizaje para favorecer que sus alumnos desarrollen experiencias de aprendizaje significativas (Huberman, 2000). 
La formación docente tiene una fuerte relación con la formación continua, es un proceso que requiere un trabajo sostenido en el tiempo y cuyos resultados son progresivos. La misma demanda un esfuerzo permanente y reflexivo por parte de todos los actores involucrados para encontrar respuestas de adaptación a los continuos cambios contextuales en los que se desarrolla la práctica docente. Considerar al elearning (Internet- enabled learning) en este contexto requiere pensarlo como una estrategia tendiente a optimizar la integración de la tecnología dentro de una cultura organizacional que necesita preparación para incorporarlo (Rosemberg, 2001).

\subsubsection{Mediación pedagógica e instrumental}

Las tecnologías informáticas están introduciendo cambios radicales en el mundo del trabajo, la cultura, las relaciones interpersonales, la forma de compartir conocimiento, el proceso de enseñanza y aprendizaje. El modelo hipertextual posibilita la construcción de redes semánticas dinámicas, con múltiples puntos de acceso y enlaces, construídas por el usuario según sus necesidades. Las herramientas que proporcionan las tecnologías de la información y comunicación permiten flexibilizar tiempos y espacios, posibilitando la creación de nuevos entornos virtuales para la enseñanza y aprendizaje. Para acompañar y promover el aprendizaje en entornos virtuales se destacan el tratamiento de los contenidos y la comunicación como parte del proceso de mediación pedagógica, es decir: “Los signos e instrumentos mediadores proporcionados por la cultura y el medio social son interiorizados por la persona en sus relaciones interpersonales múltiples a través de una serie de transformaciones, donde los significados externos se reconstruyen en significados interiores” (Fainholc, 1994).

Una de las características más difundidas con respecto a la tecnología es la transferencia y consumo mas que la comprensión de saberes (Prieto Castillo, 1999). En las actividades que involucran la utilización de Tics se pueden distinguir dos tipos de efectos cognitivos, uno que se obtiene “en conjunción con” la tecnología, basado en la posibilidad de colaboración capaz de ampliar el rendimiento intelectual del usuario, y otro "procedente de" la tecnología, en términos del residuo cognitivo transferible, tras la forma de un mayor dominio de habilidades y estrategias (Salomon y col., 1992). Los efectos de la tecnología son más los efectos a largo plazo que el aprendizaje concreto en 
una sesión o curso, mientras que aprender con la tecnología se refiere a los efectos cognitivos que se producen por el hecho mismo de utilizar determinadas tecnologías. Es la metáfora de la tecnología como herramienta, considerada desde el punto de vista de la integración entre la herramienta y la persona que la utiliza. Jonassen y col. (1998) distingue las herramientas de construcción del conocimiento que posibilitan que los estudiantes aprendan con ellas, no de ellas. De esta manera, las aplicaciones informáticas operan como herramientas de la mente promoviendo procesos de reflexión para interpretar y organizar conocimiento personal. Desde una visión socio constructivista que reconoce la importancia de la negociación social de significados en los procesos de aprendizaje, se distinguen herramientas de comunicación tanto sincrónicas (Chat, video conferencia, etc.) como asincrónicas (foro, e-mail, etc.) cuya utilización favorecería el desarrollo de procesos colaborativos.

Rodríguez Illera (2004) se refiere además a otro aspecto fundamental, en la idea de aprender con tecnología y es la conexión que establece con el mundo del trabajo. En la vida cotidiana diversas tareas se realizan utilizando computadoras en distintos ámbitos de la vida laboral. Fuera de las instituciones educativas se trabaja con las herramientas. Según el autor debido al rápido avance de las tecnologías, en un futuro gran parte de la enseñanza se vehiculará a través de las computadoras y de Internet, por lo que llegará un momento en que se aprenderá con computadoras y de computadoras simultáneamente.

Los autores Adell Segura y Sales Ciges (online consultado 03/08/07), reflexionando sobre los conceptos y procesos fundamentales de la educación en general y al considerarlos en su aplicación a la formación virtual, reconocen que los retos en este ámbito no son prioritaria o exclusivamente tecnológicos, sino esencialmente pedagógicos.

La incorporación de las nuevas tecnologías a la educación debe considerarse a partir de las posibilidades que ofrecen para mejorar los procesos de enseñanza y aprendizaje, para lo cual los docentes y la institución, deben conocer y comprender las nuevas tecnologías para integrar los beneficios de su mediación pedagógica. Esto permitirá pensar en situaciones de enseñanza donde se propongan ambientes de representación de conocimiento flexibles, en los que se exploten al máximo las potencialidades de las nuevas tecnologías en cuanto a representación de información no secuencial, integración de la información, enlaces asociativos, caminos, interactividad, 
dinamismo en el abordaje de la información e integración de medios, favoreciendo de esta manera, las actividades de aprendizaje de los estudiantes.

Las nuevas tecnologías aportan la capacidad de definir "saltos” en la lectura como “enlaces” o "hiperenlaces”, produciendo en el lector la sensación de acceso instantáneo a la nueva información. Se promueve de esta manera la creación de textos ricos en vínculos que serán materiales mediadores facilitadores del aprendizaje en la medida que sus enlaces representen relaciones potencialmente significativas entre las distintas partes del texto. Los hipertextos enlazan información con una determinada organización que influye en la sistematización de la misma; a medida que el procedimiento crece y evoluciona la propia estructura de la información se modifica (Burbules y Callister, 2001).

Los dos roles bien definidos en un texto escrito “escritor” y "lector” comienzan a confundirse en la organización hipertextual. Tanto el lector como el autor pueden contribuir a la evolución de un material hipertextual. Ante la propuesta del autor el lector puede elegir relaciones y asignarles un orden de importancia que puede coincidir o no con la intención del autor y en algunos sistemas puede crear sus propias vinculaciones. Así, el lector modifica el texto activamente y puede personalizarlo. De esta manera, el lector pasa de ser un consumidor a un colaborador activo en la construcción y reconstrucción del texto.

"El hipertexto no tiene centro (...) [lo que] significa que quienquiera que use el hipertexto convierte a sus propios intereses en el principio organizador (o eje) de la investigación que está llevando a cabo. El hipertexto se percibe como un sistema que se descentra y vuelve a centrarse infinitamente.” (Burbules y Callister, 2001). Presenta la gran ventaja de poder establecer múltiples asociaciones entre los nodos, pero el hecho de que las piezas componentes del texto no forman parte de una línea argumentativa, introduce el riesgo de la fragmentación y descontextualización de los nodos.

En la elaboración de textos tradicionales los autores deben acotar los temas a incluir en sus obras debido a restricciones de espacio y tiempo. El hipertexto posibilita flexibilizar estas limitaciones, permitiendo incorporar fuentes, textos y nuevas asociaciones, expandiendo a través de las conexiones entre computadoras, la frontera del espacio, y permitiendo una extensión en el tiempo, por medio de la posibilidad de que cada lector pueda establecer nuevas asociaciones significativas. 
En la creación de textos hipertextuales el autor, además de ocuparse del contenido a transmitir, debe considerar el diseño del material. Su obra no presenta un orden rígido en la secuencia de lectura, sino que deben estar previstas las posibilidades de navegación a través de múltiples puntos de entrada y salida.

Estas nuevas formas de comunicación con estructuras y lógicas propias se ven posibilitadas por las nuevas tecnologías, cuya integración en la planificación de cursos de e-learning requiere de un análisis global de los procesos involucrados. Moore (1990), propone en la educación a distancia mediada por tecnología el estudio de dos dimensiones: comunicación transaccional y autonomía del estudiante.

Comunicación transaccional es el espacio generado por la separación entre el alumno y el profesor, la cual puede llevar a una potencial pérdida de comprensión que afecta al proceso de enseñanza y aprendizaje, generando roles especiales para el profesor y el alumno. La distancia transaccional puede ser analizada en relación a dos aspectos: diálogo y estructura. El diálogo es producido entre el profesor y el alumno a través de los medios de comunicación. La estructura es una dimensión asociada al diseño de los cursos, y representa la capacidad de cada programa de educación a distancia para atender necesidades particulares.

La segunda dimensión, autonomía de los alumnos, está relacionada con el grado de distancia transaccional que cada alumno tiene. Por ejemplo, si el programa es altamente estructurado, posee una detallada organización de contenidos y actividades con frecuentes espacios de diálogo ordenados en el tiempo, los alumnos requieren menos autonomía. Por otra parte, si es poco estructurado en su organización y provee pocas oportunidades de diálogo, los alumnos necesitarán un mayor nivel de autonomía para participar y mantenerse en el programa. Esta misma idea se puede aplicar de manera inversa, es decir, si el programa es poco estructurado y provee pocas oportunidades de diálogo, los alumnos necesitarán un mayor nivel de autonomía.

Prieto Castillo (1999) sostiene que se favorece el aprendizaje cuando un material es elaborado jugando al máximo las posibilidades comunicacionales del lenguaje en que está armado el mensaje y del medio a través del cual se lo ofrece. Apropiarse de los medios significa en primer lugar adoptar los recursos de la comunicación en favor de la educación. Al referirse a la relación entre mediación pedagógica y las tecnologías señala que se parte de la necesidad de un modelo interactivo, rico en relaciones humanas y en 
contactos con productos y procesos tecnológicos, a fin de lograr por una parte la capacidad de observación y comprensión del fenómeno y del objeto tecnológico, y por otra la habilidad de generar objetos para atender a necesidades.

En la mediación pedagógica se consolida la figura del tutor como facilitador de los aprendizajes a través del acompañamiento, la información y el asesoramiento, así como en la elaboración de estrategias que se adecuen a las necesidades particulares de los estudiantes. El ejercicio del rol del tutor se centra en la facilitación del aprendizaje, por esto su figura no puede construirse como experto transmisor de contenidos, sino más bien como animador y facilitador del aprendizaje autónomo que realizan los estudiantes. Se distinguen funciones académicas: ayudar a interpretar los objetivos y contenidos del curso o materia, aclarar los prerrequisitos necesarios para hacer esos estudios, acompañar la planificación y el desarrollo del proceso de estudio y aprendizaje, prevenir posibles obstáculos, realizar tareas de evaluación; funciones de orientación: brindar orientación continua, oportuna e integral, establecer la agenda (objetivos, horarios, reglas de procedimiento, normas), facilitar los grupos de aprendizaje y favorecer las interacciones entre profesor- alumnos y entre pares; función institucionales: mantener comunicación permanente con profesores, alumnos, instancias administrativas y de gestión de la institución (Duggleby, 2001).

La modalidad a distancia favorece la flexibilidad en torno de la propuesta de enseñanza promoviendo las interacciones entre docentes y alumnos, posibilitadas por el creciente desarrollo de las Tics. Sin embargo, el valor de la propuesta aún cuando adopte los últimos desarrollos de la tecnología, sigue estando, como en cualquier proyecto educativo, en la calidad de los contenidos y en su propuesta para la enseñanza (Litwin, 2000). “Los problemas hoy no son tecnológicos, sino que se derivan de saber qué hacer y cómo hacerlo, y por qué queremos hacerlo” (Cabero, 2006).

\subsubsection{Plataformas de e-learning: características}

En los comienzos la educación a distancia se caracterizó por el predominio del material impreso distribuído a través del correo postal, promoviendo un modelo educativo caracterizado por el estudio en soledad y la evaluación a través de tests objetivos. La evolución de la tecnología posibilitó que otros medios como la radio y la 
televisión se sumaran a la propuesta educativa. Los materiales impresos se estructuraron en "módulos de aprendizaje” caracterizados por actividades autoevaluativas, permitiendo al estudiante comprobar sus progresos y realizar actividades de recuperación (Lugo y Schulman, 1999). Las posibilidades de intercambio y comunicación entre profesor - alumno y alumno - alumno se vieron favorecidas con la incorporación de Internet, que permitió el desarrollo de ambientes propicios para promover procesos de enseñanza y aprendizaje colaborativos (Vidal Puga, 2004).

Si bien en la definición de un proyecto e-learning se destaca la importancia de las variables asociadas a la propuesta didáctica la forma de presentar los contenidos, el papel del profesor y los alumnos, las estrategias didácticas, los modelos de evaluación, las herramientas de comunicación, etc. (Cabero, 2006), también es importante reflexionar sobre la dimensión tecnológica tanto en su rol mediador de los procesos de enseñanza y aprendizaje, como en su consideración como recurso y soporte de los procesos de gestión y administración del proyecto.

Los Sistemas de Administración de Aprendizaje o LMS (Learning Management System), también conocidos como Plataforma de Aprendizaje o Plataforma Tecnológica, son softwares basados en un servidor web que facilitan la creación de entornos de enseñanza y aprendizaje, integrando materiales didácticos y herramientas de comunicación, colaboración y gestión educativa (García Peñalvo, 2005). Se caracterizan por presentar herramientas de gestión y distribución de contenidos (permiten almacenar, organizar, recuperar, distribuir y estructurar contenidos educativos), herramientas de administración de usuarios (facilitan el registro de los usuarios del sistema), herramientas de comunicación (permiten la comunicación sincrónica y asincrónica entre profesor - alumno y alumnos entre sí), herramientas de evaluación y seguimiento (apoya la construcción de evaluaciones mediante la utilización de diferentes tipos de preguntas: abierta, verdadero o falso, selección múltiple) (Ortiz, 2007).

\subsubsection{Plataforma SAVER (Software de Asistencia Virtual para Educación}

\section{Remota)}


La UNICEN cuenta con una plataforma en proceso de desarrollo, Software de Asistencia Virtual para Educación Remota (SAVER), que es un prototipo de software para el soporte integral de actividades de educación a distancia, basado en la tecnología Web. Este prototipo provee las principales funciones de un sistema LMS. Las actividades de Educación a Distancia promovidas desde la Facultad de Ciencias Exactas de la Universidad Nacional del Centro de la Provincia de Buenos Aires se realizan a través de la plataforma mencionada. En el marco de estas normas institucionales se inscribe el presente curso.

\subsection{Descripción general de la plataforma y herramientas}

Para iniciar una sesión en la plataforma el alumno debe registrarse y luego seleccionar de la lista de cursos habilitados a cuál prefiere ingresar (Figura 3.1)

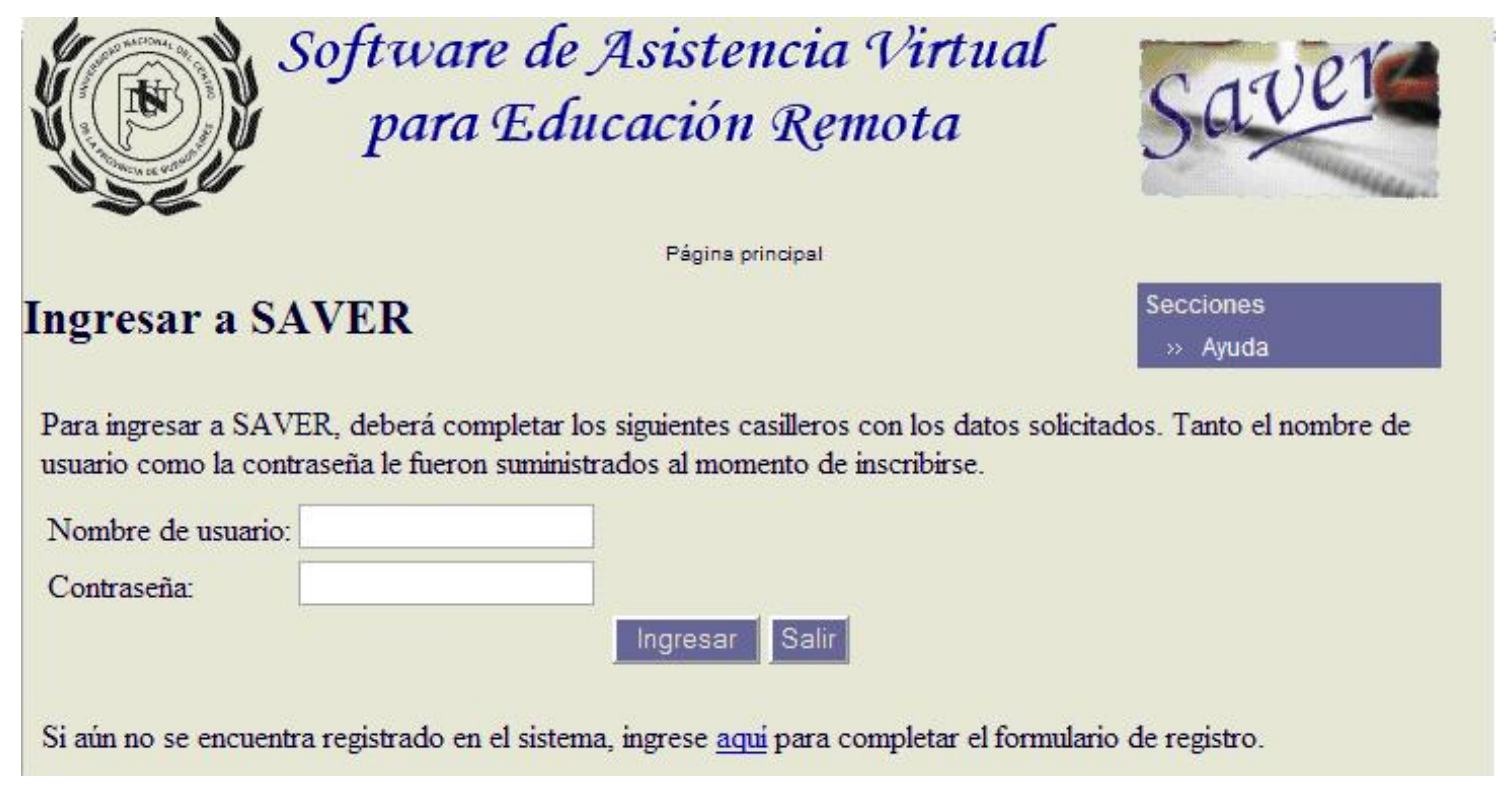

Figura 3.1: Pantalla de inicio de sesión del SAVER.

En la primera pantalla del curso se presentan dos paneles principales: “Comunicación y Desarrollo Académico”, ubicado a la izquierda de la pantalla y el correspondiente a las herramientas de comunicación situado en la parte superior. Se exhibe a la derecha de la pantalla un panel contextual que actualiza la información de acuerdo a la opción elegida en la división de la izquierda (Figura 3.2). 


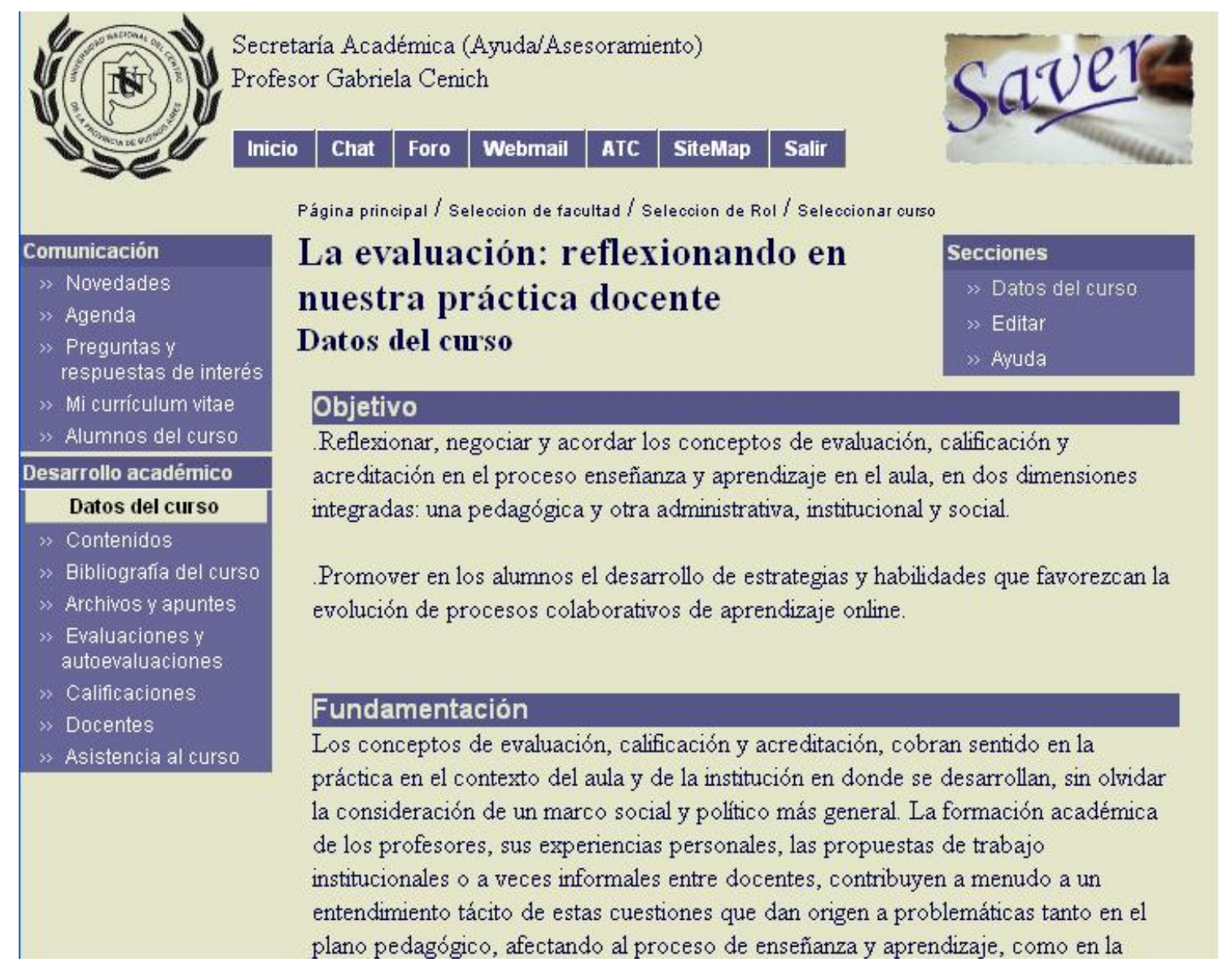

Figura 3.2: Primera pantalla del curso.

El área "Comunicación" permite al profesor publicar nuevos eventos del curso en la opción "Novedades", con la posibilidad de enlazarlo a la "Agenda", espacio en el que se pueden publicar por día recordatorios referidos a exámenes, entrega de trabajos o algún evento relevante del curso.

“Preguntas y respuestas de interés", permite a los alumnos publicar una pregunta referida al curso en general o a la realización de una actividad en particular. El docente tiene opción a conservarla en este espacio si considerara que la pregunta es de interés para todos los participantes del curso.

Esta sección ofrece al docente además la posibilidad de publicar su Currículum Vitae, en "Mi Currículum Vitae", y de disponer en un espacio común, "Alumnos del curso", la lista de integrantes del curso permitiendo contactarlos por mail y consultar sus currículm vitae. 
El área “Desarrollo académico” facilita los espacios para publicar los datos generales del curso y sus contenidos específicos.

La opción “Datos del curso” permite al docente comunicar los objetivos y ofrecer la fundamentación del curso.

Las unidades o temas del curso se pueden publicar y editar en el apartado “Contenidos”, acompañándolos de su correspondiente explicación.

Se prevé un espacio para informar la bibliografía tanto obligatoria como sugerida, así como también un área “Archivos y apuntes” destinada a publicar el material electrónico facilitado por el docente. El menú contextual de la derecha de la pantalla habilita bajo esta opción el "Espacio compartido de trabajo", que tiene por finalidad ofrecer un espacio común para publicar archivos entre miembros de un grupo de trabajo.

Se pueden diseñar evaluaciones y autoevaluaciones de los tipos respuesta abierta, verdadero o falso y selección, permitiendo asignar una calificación a las mismas.

La herramienta “Asistencia” permite conocer los ingresos de los alumnos a la plataforma, detallando horario de entrada y de salida.

Se destacan como herramientas de comunicación: Chat, Foro y Webmail.

\subsection{La dinámica del curso online según la Teoría de la Actividad}

En el aprendizaje mediado por computadora se pueden distinguir dos tipos de interactividad: cognitiva o individual (interacción con el contenido) y social o interpersonal (Moallem, 2003). Estos dos tipos de interactividades son considerados por la visión social del constructivismo, enfatizando el rol vital de la dimensión humana de la interactividad en el aprendizaje. En esta teoría, el aprendizaje es considerado un constructo social mediado por el lenguaje y el discurso social (Vygotsky, 1930/ 1978). Es decir, se sostiene que el conocimiento es elaborado individual y socialmente por los alumnos basándose en las interpretaciones de sus experiencias en el mundo. Puesto que el conocimiento no es transferible, la enseñanza debería consistir en experiencias que faciliten la elaboración de conocimiento (Jonassen, 2000). Los alumnos aprenden el contenido del ámbito de estudio para resolver el problema, en lugar de solucionarlo como si fuera una aplicación del aprendizaje. 
En otras palabras, se considera que el conocimiento está inmerso y vinculado a la situación en la cual ocurre el aprendizaje (Applefield y col., 2001) como proceso activo, determinado por interacciones complejas entre el conocimiento existente en los alumnos, el contexto social y el problema a resolver (Tam, 2000).

La aplicación de tecnología a la enseñanza y el aprendizaje dentro de un marco de constructivismo social está siendo ampliamente aceptado en todos los campos de la educación (Kanuka y Anderson, 1998). Este interés se relaciona con la capacidad de las nuevas tecnologías de ofrecer entornos interactivos propicios para la implementación de estrategias de enseñanza constructivistas. Se requiere entonces, no sólo de buenos problemas que motiven y den sentido a la tarea a desarrollar en colaboración, sino que es necesario además un diseño didáctico cuidadoso que considere de una manera holística todos los elementos que intervienen en la propuesta didáctica. En este sentido, la TA se presenta como un referente adecuado para representar las actividades de grupos de personas en donde la tecnología juega un papel mediador (Barros y Verdejo, 2000).

En los primeros trabajos de la escuela histórico-cultural representada por Vygotsky, la unidad de análisis fue la acción orientada al objeto mediada por las herramientas culturales y los signos (Figura 3.3).

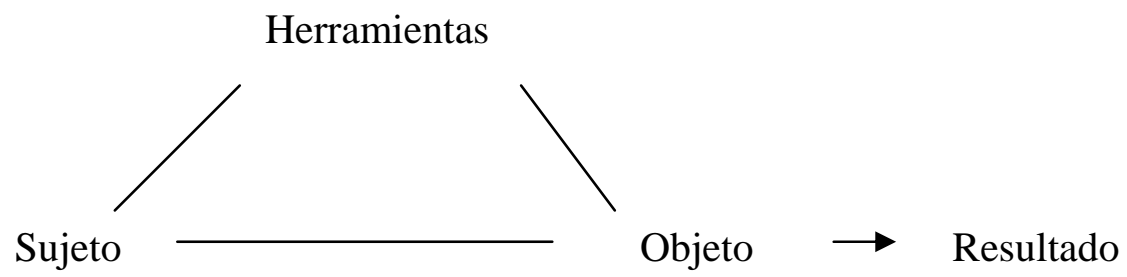

Figura 3.3: La relación mediada individual (Nardi, 1996)

Engeström apoyándose en diferentes conceptos tomados de la TA, propone una representación de la mediación que denomina “triángulo mediacional expandido", el cual incluye la noción inicial de mediación como acción individual proveniente de los primeros psicólogos histórico-culturales, pero además incorpora otros componentes (Nardi, 1996). Según Lewis (1998) “Un individuo (sujeto) se apoya en herramientas para lograr un objetivo (objeto) y puede aceptar reglas para trabajar en una comunidad que contribuye al objetivo mediante una división del trabajo. A partir de esta actividad, 
se produce un resultado.” Kutti (citado en Lewis, 1998), representa la estructura de una actividad en el siguiente diagrama:

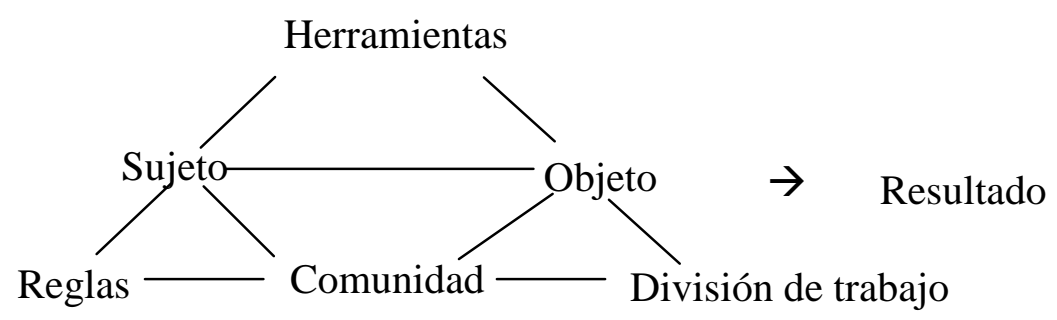

Figura 3.4: Estructura básica de una actividad (Nardi, 1996)

En un sistema de actividad se considera a los alumnos como miembros de una comunidad de práctica que utilizan herramientas para alcanzar objetivos compartidos (Spector y Wang, 2002). El objeto generalmente se transforma en el curso de una actividad y expresa las intenciones que motivan la misma (Wang, 2002). Cuando el objetivo de este sistema dinámico se orienta a favorecer los aprendizajes tanto individuales como de la comunidad, el sistema de actividad conforma un sistema de aprendizaje (Spector y Wang, 2002). Los tres componentes principales de un sistema de actividad - sujeto, objeto y comunidad - no actúan uno sobre otro directamente, sus interacciones se hallan mediadas por otros factores. Los instrumentos intervienen en la relación entre sujeto y objeto, las reglas arbitran las interacciones entre sujeto y comunidad, los roles participan en las relaciones entre comunidad y objeto (Wang, 2002). El diseño de una actividad de enseñanza y aprendizaje como sistema de actividad (Barros, Vélez y Verdejo, 2004), permite considerar no sólo los componentes sino también sus interrelaciones, promoviendo una visión integradora que favorece el desarrollo y evolución del sistema.

Para lograr el objetivo de la actividad, el sujeto utiliza determinados sistemas de acciones y operaciones que se corresponden con el motivo, la meta y las condiciones de la misma, destacándose tres niveles jerárquicos (Figura 3.5) (Jonassen y RohrerMurphy, 1999). La actividad es la realización de acciones conscientes, las que a su vez se componen de cadenas de operaciones que son acciones cuando se realizan por primera vez porque necesitan del esfuerzo consciente para llevarlas a cabo (Jonassen y Rohrer-Murphy, 1999). 


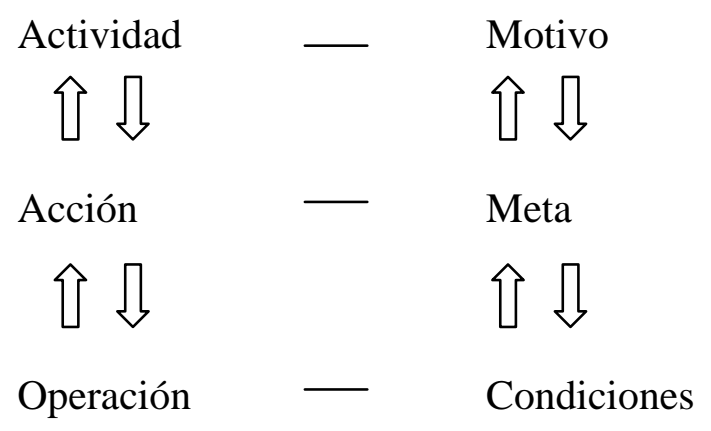

Figura 3.5: Naturaleza jerárquica de actividades, acciones y operaciones.

La actividad es asociada con el motivo o propósito, sobre el nivel de las acciones orientadas al objetivo o meta. Las actividades son llevadas a cabo por una colección de acciones, dirigidas hacia un objetivo específico y por lo general a corto plazo. Bajo ciertas condiciones, las acciones conscientes pueden ser dirigidas hacia un nivel más bajo de automatización (Hasan, 2003). Lewis (2001), interpreta estos niveles refiriéndose a la "actividad” como "qué hacer”, el correspondiente a la "acción” como el de “cómo hacerlo", y por último, relaciona el operativo con "hacerlo”. Resalta además la importancia de este análisis haciendo notar que al atravesar las distintas fases: “qué”, “cómo” y "hacerlo", el grado de incertidumbre varía de ser muy alto en el nivel de la “actividad”, disminuyendo en la etapa de “cómo”, y reduciéndose a su valor más bajo al "hacerlo" (Figura 3.6). Este análisis es especialmente importante para ser tenido en cuenta por los tutores ya que de acuerdo a la etapa que esté transitando el grupo, podrán reflexionar sobre la mejor manera de ayudarlo a alcanzar el objetivo propuesto.

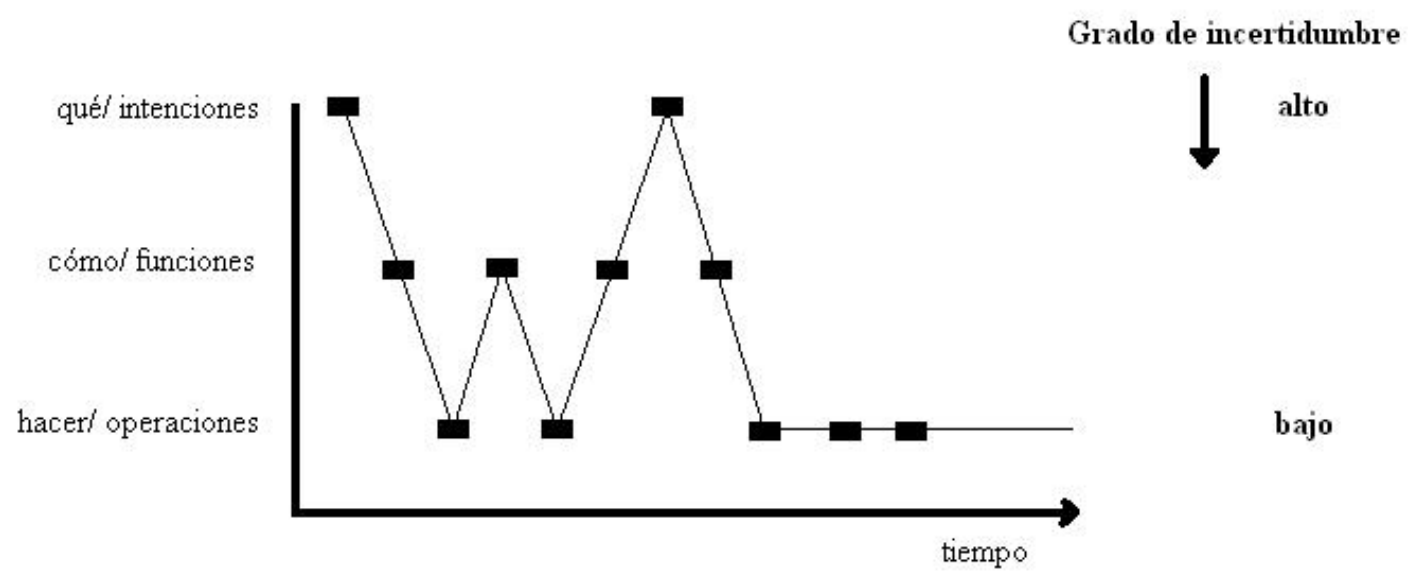

Figura 3.6: Niveles en la actividad humana y grado de incertidumbre (Lewis, 2001) 
La TA considera las actividades dinámicas, las operaciones nuevas se forman a partir de acciones previas en la medida que aumentan las habilidades de los participantes y se incorporan diferentes acciones como respuesta a situaciones actuales. En una actividad el objeto mismo es a veces cuestionado, y puede ser adaptado como consecuencia de cambios producidos en la misma actividad o en otras relacionadas. Estos cambios afectan al equilibrio del sistema manifestándose como problemas o rupturas, causados por contradicciones entre los distintos componentes del sistema. La TA utiliza el término contradicción para indicar una perturbación entre elementos, ya sean éstos componentes de una actividad se refieran a actividades diferentes o a fases en el desarrollo de una misma actividad (Nardi, 1996).

Las contradicciones son consideradas como fuerzas de cambio y desarrollo (Hasu y Engeström, 2000), surgen en un determinado punto en el tiempo demandando de los participantes encontrar estrategias para poder avanzar hacia el logro del objetivo.

Pensar en el diseño de situaciones de enseñanza y aprendizaje colaborativas conlleva a considerar una gran cantidad de variables y sus posibles interacciones, que imposibilitan su estudio en forma aislada (Novak y Gowin, 1988). Se hace necesario entonces un enfoque integrador que permita realizar una simplificación de la situación real a través de la identificación de variables e interrelaciones. Desde esta perspectiva y en consonancia con el marco teórico expuesto, se propone utilizar la TA como una heurística para el diseño y análisis en propuestas de aprendizaje colaborativo, que permita evaluar la dinámica y los resultados del sistema de actividad planteado. Se propone considerarla como una guía en la construcción de un modelo para ayudar a visualizar y a entender el curso de formación colaborativo como un sistema, utilizándola para especificar la estructura y comportamiento del sistema de actividad, sirviendo a la vez como registro para documentar las decisiones tomadas (Booch y col., 2000). 
CAPÍTULO IV

METODOLOGÍA PARA EL ESTUDIO DEL

E-CURSO 


\subsection{Introducción}

Se propone utilizar la TA, como metodología cualitativa para la estructuración y análisis de los datos, en combinación con métodos descriptivos estudio de caso (Russell y Schneiderheinze, 2005). La TA considera que la unidad de estudio primaria es el sistema de actividad colectivo orientado al objeto, integrando los distintos componentes que intervienen como un todo unificado (Hasu y Engeström, 2000). Además, en coherencia con un estudio de tipo etnográfico, permite analizar el sistema desde las perspectivas y puntos de vista de los distintos actores, valorando no sólo las acciones grupales sino también las acciones individuales, de manera que se reflejen "lo más fielmente posible las percepciones, acciones y normas de juicio de esa unidad social" (Rodríguez Gómez y col., 1999).

El diseño del curso colaborativo online se elabora aplicando y adaptando el modelo para diseñar entornos de aprendizaje constructivista (EAC) de David Jonassen (2000). De acuerdo a este modelo se concibe un problema, una pregunta o un proyecto como centro del entorno, que los alumnos intentan resolver. Los problemas dirigen el aprendizaje, en el sentido que para solucionarlo el alumno construirá nuevos conocimientos o establecerá nuevas relaciones entre los que ya posee a partir del contenido del entorno.

El modelo incluye en el entorno de aprendizaje:

-Los ejemplos relacionados: tienen como objetivo ayudar a los alumnos a comprender las cuestiones implícitas en la representación del problema

-Las fuentes de información: los alumnos necesitan información para comprender e interpretar el problema que les posibilite elaborar hipótesis de potenciales soluciones

-Herramientas cognitivas: son instrumentos informáticos cuyo propósito es facilitar tipos específicos de procedimientos cognitivos. "Se trata de dispositivos intelectuales utilizados para visualizar (representar), organizar, automatizar o suplantar las técnicas de pensamiento" (Jonassen, 2000).

-Herramientas de conversación y colaboración: para fomentar la colaboración en un grupo de alumnos el entorno debería promover los debates sobre los problemas y 
proyectos en los que están trabajando y facilitar las herramientas informáticas para llevar adelante dichos procesos.

-Apoyo social/ contextual: en la ejecución de los EAC es importante que el diseño y la realización se adapten a los factores contextuales, en cuanto a aspectos físicos, organizativos y culturales del entorno.

\subsection{Metodología a utilizar e instrumentos}

La propuesta fue implementada con profesores y preceptores de la Escuela Nacional "Ernesto Sábato" dependiente de la UNICEN. Esta institución de nivel polimodal se encuentra vinculada académicamente a la Universidad, ya que muchos de los docentes se desempeñan en ambas instituciones. Particularmente, trabajé como Profesora de Primer Año de la escuela en la materia Tecnologías de la Información y la Comunicación en el año 2004, lo que me permitió profundizar en el conocimiento de la propuesta educativa. Considerando que el personal de la Institución asume el compromiso de la formación continua, se decidió realizar la experiencia con aquellas personas que decidieran voluntariamente realizar el curso, conformando una muestra inicial de 22 participantes de un total de 71 (41 docentes de Tronco Común, 24 docentes de Modalidad y 6 preceptores). Para promover el desarrollo de procesos colaborativos entre los participantes del curso, los alumnos trabajaron en grupos de hasta cuatro personas. Se consideró la formación de equipos pequeños porque promueven el desarrollo de habilidades sociales en los estudiantes para trabajar en grupo, facilitan la tarea del tutor de monitorear las contribuciones individuales y el progreso grupal, y ofrecen oportunidades para interacciones de calidad y mejorar el compromiso con el grupo (Johnson y Johnson, 1999; Moallem, 2003; Graham and Misanchuk, 2004). En la selección de los miembros de cada grupo se consideró que pertenecieran a áreas de conocimiento diferentes para enriquecer el trabajo grupal desde distintas perspectivas docentes y promover interacciones entre los integrantes de la institución escolar (Johnson y Johnson, 1999; Graham and Misanchuk, 2004).

Se utilizó la TA como una heurística para la evaluación de los diferentes sistemas de actividad que integran el curso de formación y sus relaciones, considerando que la 
evolución de cada sistema influye en el desarrollo del siguiente y todos contribuyen al logro del resultado final (ver Capítulo V).

Los datos fueron obtenidos durante el desarrollo de las actividades del curso a través de diferentes fuentes: el registro de los mensajes de foro, documentos digitales, registros de ingreso a la plataforma SAVER, mensajes de correo electrónico particular y de la plataforma, mensajes publicados en el espacio "preguntas frecuentes" de la plataforma.

La actividad colaborativa se desarrolló a través de la herramienta foro, obteniéndose el registro de todos los mensajes publicados por los miembros del grupo.

En un mensaje el alumno podría referirse a distintos tópicos y a diferentes integrantes del grupo, su división en unidades de significado (Henri, citado en Gunawardena y col., 1997) conllevaría a una potencial pérdida de información en lo que se refiere a la consideración integradora del mensaje como un todo, y no la mera suma de las unidades que la componen (Gunawardena y col. 1997). Por esta razón, se consideró como unidad de análisis adecuada a la problemática el mensaje, que debido a sus características pudo ser incluido en una o más categorías (Kanuka y Anderson, 1998).

Los alumnos fueron identificados en este trabajo como Ai, donde i es un número único asignado a cada participante. De esta manera se preservó la identidad de los participantes del curso.

Se trató de reconocer la presencia de procesos colaborativos a partir de la identificación de los indicadores participación, interacción y síntesis, que se describen a continuación:

Para establecer la participación de los alumnos en cada actividad se contabilizó los mensajes publicados por cada alumno.

Las interacciones entre los miembros del grupo fueron descriptas a través de un diagrama de flujo, utilizando la categorización propuesta en "Funcionamiento de grupo: Categorías e indicadores" (Cenich y Santos, 2006) y utilizando el instrumento de Gunawardena y col. (1997) "Modelo de análisis de la interacción para examinar la construcción social del conocimiento en conferencias por computadora"1.

\footnotetext{
${ }^{1}$ Interaction analysis model for examining social construction of knowledge in computer conferencing
} 
A efectos de favorecer la visualización e interpretación de las interacciones entre los participantes de cada grupo, se mostró la información procesada en un diagrama de flujo. En dichos diagramas los alumnos fueron identificados mediante elipses (Ai), la dirección de los mensajes (emisor-destinatario) con flechas, el orden de publicación del mensaje (i) y el tipo de mensaje de acuerdo a lo planteado en la actividad. Los mensajes dirigidos al grupo sin una identificación explícita del destinatario se graficaron como una flecha de menores dimensiones que no alcanza a ningún nodo destino, con el fin de obtener un diagrama más claro. En ocasiones un solo mensaje puede corresponder a más de un tipo de los indicados anteriormente y estar dirigido a más de un miembro del grupo, en tal caso se trazó más de una flecha con el mismo número de mensaje.

En un trabajo previo se han estudiado las interacciones entre los alumnos de un curso online de la carrera del Profesorado en Informática de la UNICEN. En el mismo se definió la dimensión funcionamiento de grupo como el conjunto de estrategias y habilidades que contribuyen al proceso de colaboración y se elaboró un sistema de categorización e indicadores (Cenich y Santos, 2006). A partir de considerar las ideas de Johnson y Johnson (1999) en referencia a procesos colaborativos en la dirección gestión de grupo y las categorizaciones propuestas Rourke y col. (1999) en el plano de la integración social, se realizó un proceso iterativo crecientemente complejo en el análisis de los datos originando la formulación de las nuevas categorías gestión de grupo e integración social las que se presentan, definen y ejemplifican en la Tabla 4.1.

\begin{tabular}{|c|c|c|c|}
\hline Categoría & Indicadores & Definición & Ejemplo \\
\hline \multirow{3}{*}{ Gestión de grupo } & Consultar al grupo & $\begin{array}{l}\text { se pregunta o pide parecer al } \\
\text { grupo para generar feedback } \\
\text { sobre alguna cuestión } \\
\text { relacionada al contenido o al } \\
\text { funcionamiento del grupo. }\end{array}$ & $\begin{array}{l}\text {..."Sería forma de } \\
\text { entrega de material, } \\
\text { actividades, evaluación? } \\
\text { Espero comentarios" }\end{array}$ \\
\hline & $\begin{array}{l}\text { Compartir } \\
\text { interpretaciones }\end{array}$ & $\begin{array}{l}\text { Se explica de modo personal el } \\
\text { sentido de algo }\end{array}$ & $\begin{array}{l}\text {..."Comprendo que } \\
\text { debemos acordar los } \\
\text { puntos del diseño } \\
\text { didáctico"... }\end{array}$ \\
\hline & Argumentar & $\begin{array}{l}\text { Emplear razonamientos para } \\
\text { convencer sobre lo que se afirma } \\
\text { o se niega. }\end{array}$ & $\begin{array}{l}\text {..."ya que el tema de } \\
\text { hipervínculos no es tan } \\
\text { extenso y complejo...", } \\
\text {..."si bien es cierto } \\
\text { que..." }\end{array}$ \\
\hline
\end{tabular}




\begin{tabular}{|c|c|c|c|}
\hline Categoría & Indicadores & Definición & Ejemplo \\
\hline \multirow{8}{*}{ Gestión de grupo } & Secuenciar & $\begin{array}{l}\text { Establecer una serie o sucesión } \\
\text { de tareas }\end{array}$ & $\begin{array}{l}\text {..."Yo propongo que una } \\
\text { vez que nos pongamos } \\
\text { de acuerdo..., ...y cuáles } \\
\text { serían las posibles } \\
\text { actividades..., podría } \\
\text { salir una posible idea..." }\end{array}$ \\
\hline & Acordar & Aceptar la propuesta de alguien & $\begin{array}{l}\text {..."comparto la idea de } \\
\text { tener una charla por } \\
\text { medio del chat..." }\end{array}$ \\
\hline & Presentar alternativas & Ofrecer opciones para elegir & $\begin{array}{l}\text {...'les parece juntarnos } \\
\text { hoy viernes para chatear } \\
\text { a las } 17 \text { hs, sino llegan a } \\
\text { poder la dejamos para } \\
\text { mañana a las } 10 . . . \\
\text { cualquier cosa que no } \\
\text { puedan..." }\end{array}$ \\
\hline & $\begin{array}{l}\text { Presentar síntesis de lo } \\
\text { acordado }\end{array}$ & $\begin{array}{l}\text { Componer en un todo los } \\
\text { aspectos acordados }\end{array}$ & $\begin{array}{l}\text { "Según hemos ido } \\
\text { aportando, creo que ya } \\
\text { estamos de acuerdo en } \\
\text { algunos puntos, que } \\
\text { son:..." }\end{array}$ \\
\hline & $\begin{array}{l}\text { Evaluar el avance del } \\
\text { trabajo }\end{array}$ & $\begin{array}{l}\text { Estimar los aspectos resueltos } \\
\text { del trabajo }\end{array}$ & $\begin{array}{l}\text { "Ya hemos ido entre } \\
\text { todos aportando para la } \\
\text { elaboración de la } \\
\text { propuesta final, creo que } \\
\text { ya estarían todos los } \\
\text { puntos..." }\end{array}$ \\
\hline & Tomar decisión & Determinar acción a seguir & $\begin{array}{l}\text { "Bueno fijemos un } \\
\text { horario..." }\end{array}$ \\
\hline & Pedir aclaración & Requerir más información & $\begin{array}{l}\text { “...no entendí bien lo } \\
\text { que decías en el último } \\
\text { párrafo de este mail..." }\end{array}$ \\
\hline & $\begin{array}{l}\text { Formular propuesta de } \\
\text { trabajo }\end{array}$ & $\begin{array}{l}\text { Expresar en forma y contenidos } \\
\text { ideas para resolver el trabajo }\end{array}$ & $\begin{array}{l}\text { "Propuesta de Trabajo } \\
\text { Objetivos:..." }\end{array}$ \\
\hline \multirow{4}{*}{ Integración social } & Motivar & Transmitir entusiasmo & $\begin{array}{l}\text {..."se podría decir que ya } \\
\text { estamos pensando como } \\
\text { profes...jejeje...no les } \\
\text { parece??? O es una idea } \\
\text { mía...". }\end{array}$ \\
\hline & Involucrar al grupo & $\begin{array}{l}\text { Responzabilizar al grupo por lo } \\
\text { actuado }\end{array}$ & $\begin{array}{l}\text { "saben que nos faltó } \\
\text { acordar algo importante, } \\
\text { que es..." }\end{array}$ \\
\hline & $\begin{array}{l}\text { Contestar a un } \\
\text { compañero }\end{array}$ & $\begin{array}{l}\text { Referirse explícitamente a un } \\
\text { miembro del grupo, para } \\
\text { contestar sobre una cuestión }\end{array}$ & $\begin{array}{l}\text { "Ma José, disculpá tal } \\
\text { vez..." }\end{array}$ \\
\hline & $\begin{array}{l}\text { Manifestar } \\
\text { compromiso con la } \\
\text { tarea grupal }\end{array}$ & $\begin{array}{l}\text { Percibir la obligación de } \\
\text { participar activamente en el } \\
\text { grupo de trabajo }\end{array}$ & $\begin{array}{l}\text { "chicos ante todo, les } \\
\text { pido disculpas que no he } \\
\text { podido participar con } \\
\text { aportes..." }\end{array}$ \\
\hline
\end{tabular}

Tabla 4.1: Funcionamiento de grupo: Categorías e indicadores. 
Para el análisis de la interacción relacionada con los procesos de construcción social de conocimiento y elaboración de síntesis se utilizó el modelo de Gunawardena y col (1997) "Modelo de análisis de la interacción para examinar la construcción social del conocimiento en conferencias por computadora", que considera la construcción activa del conocimiento a través de cinco fases (Tabla 4.2). Aunque alguna instancia de construcción social de conocimiento podría no avanzar linealmente a través de las cinco fases, ellas son en la visión de Kanuka y Anderson (1998), consistentes con la mayoría de la literatura relacionada a la creación de conocimiento constructivista.

\begin{tabular}{|c|l|}
\hline Etapas & \multicolumn{1}{|c|}{ Descripción } \\
\hline Fase I & $\begin{array}{l}\text { Compartiendo/ comparando información } \\
\text { Incluye: sentencias de observación u opinión; sentencias de acuerdo; corroboración de } \\
\text { ejemplos; clarificación; definición, descripción o identificación de problemas. }\end{array}$ \\
\hline Fase II & $\begin{array}{l}\text { Descubrimiento y exploración de disonancias o inconsistencias entre ideas, conceptos o } \\
\text { sentencias. } \\
\text { Incluye: identificación y establecimiento de áreas de desacuerdo; clarificación del origen y } \\
\text { extensión del desacuerdo. }\end{array}$ \\
\hline Fase III & $\begin{array}{l}\text { Negociación de significados/ Co-construcción de conocimiento. } \\
\text { Incluye: negociación o clarificación del significado de términos; identificación de áreas de } \\
\text { acuerdo o de superposición acerca de conceptos conflictivos, propuestas de compromiso o } \\
\text { de co-construcción. }\end{array}$ \\
\hline Fase IV & $\begin{array}{l}\text { Evaluación y modificación de síntesis propuesta o co-construcción. } \\
\text { Incluye: la evaluación respecto a esquemas cognitivos existentes, experiencias personales, } \\
\text { experimentación de datos formales, o información contradictoria de la literatura. }\end{array}$ \\
\hline Fase V & $\begin{array}{l}\text { Sentencias de acuerdo/ aplicación de los nuevos significados construidos. } \\
\text { Incluye: síntesis de acuerdos y sentencias metacognitivas que ilustran la construcción de } \\
\text { nuevo conocimiento y su aplicación. }\end{array}$ \\
\hline
\end{tabular}

Tabla 4.2: Las cinco fases en la construcción activa del conocimiento.

Se estudió el indicador síntesis en el trabajo colaborativo final realizado por el grupo de los docentes participantes a través de la identificación de acuerdos consensuados durante el desarrollo del curso.

A los fines de aumentar la confiabilidad de las inferencias extraídas a nivel grupal se decidió implementar un instrumento para una instancia de reflexiones individuales. Para ello se optó por la técnica de la entrevista semiestructurada, que se realizó al menos a un docente de las áreas involucradas (ver Anexo I).

En el capítulo siguiente se describe el diseño del curso de formación colaborativo online "La Evaluación: reflexionando en nuestra práctica docente" definido como un sistema de actividad. 


\section{DISEÑO DEL E-CURSO}

“LA EVALUACIÓN: REFLEXIONANDO EN NUESTRA PRÁCTICA DOCENTE” 


\subsection{Descripción del diseño del e-curso}

Las principales aplicaciones de la TA se han realizado en el campo de la innovación tecnológica. Se la ha utilizado como marco de referencia en el estudio de procesos de implementación de nueva tecnología en grupos de trabajo específicos, centrando la atención en los procesos que se desarrollan cuando un producto pasa de las manos de los diseñadores a las del usuario (Hasu y Engeström, 2000).

A partir de la consideración de la TA como herramienta de análisis y diseño, se propone en este trabajo su aplicación en el área de la formación online desde la etapa de diseño, la cual se extiende a lo largo de la implementación y seguimiento del desarrollo del curso de formación propuesto. Se proyecta el curso de formación colaborativo online "La Evaluación: reflexionando en nuestra práctica docente" como un SA, definiendo su propósito general y el contexto en el cual se desarrollará el sistema. El curso de formación se propone como respuesta a una problemática planteada, por lo cual es importante establecer de manera explícita el propósito que motiva la actividad, el cual dará origen a la definición del objeto del sistema a diseñar. Si bien en el planteo del diseño del sistema general se definen componentes que guardan relación con el medio en el cual se encuentra inserto, se hace necesario establecer las características generales del contexto en el cual se define y evoluciona el sistema, que se interrelaciona con un medio cuyos cambios podrían afectar su desarrollo.

El curso en su conjunto se define como un SA, denominado Sistema de Actividad Cero (SA 0). Se propone la elaboración de un diagrama como herramienta gráfica para comprensión global del SA 0 y la identificación de sus componentes (Ver Figura 5.1). En el diagrama se representa el sistema de actividad global con el triángulo mayor y se especifican los componentes principales: objeto, resultado, sujeto, comunidad, división de trabajo, herramientas y reglas. En el interior del triángulo mayor se pueden observar triángulos más pequeños que simbolizan las actividades componentes, las que constituyen en sí mismas sistemas de actividad conteniendo algunas actividades componentes representadas por triángulos más pequeños en su interior. El diagrama utilizado en el diseño de este e-curso se presenta a continuación: 


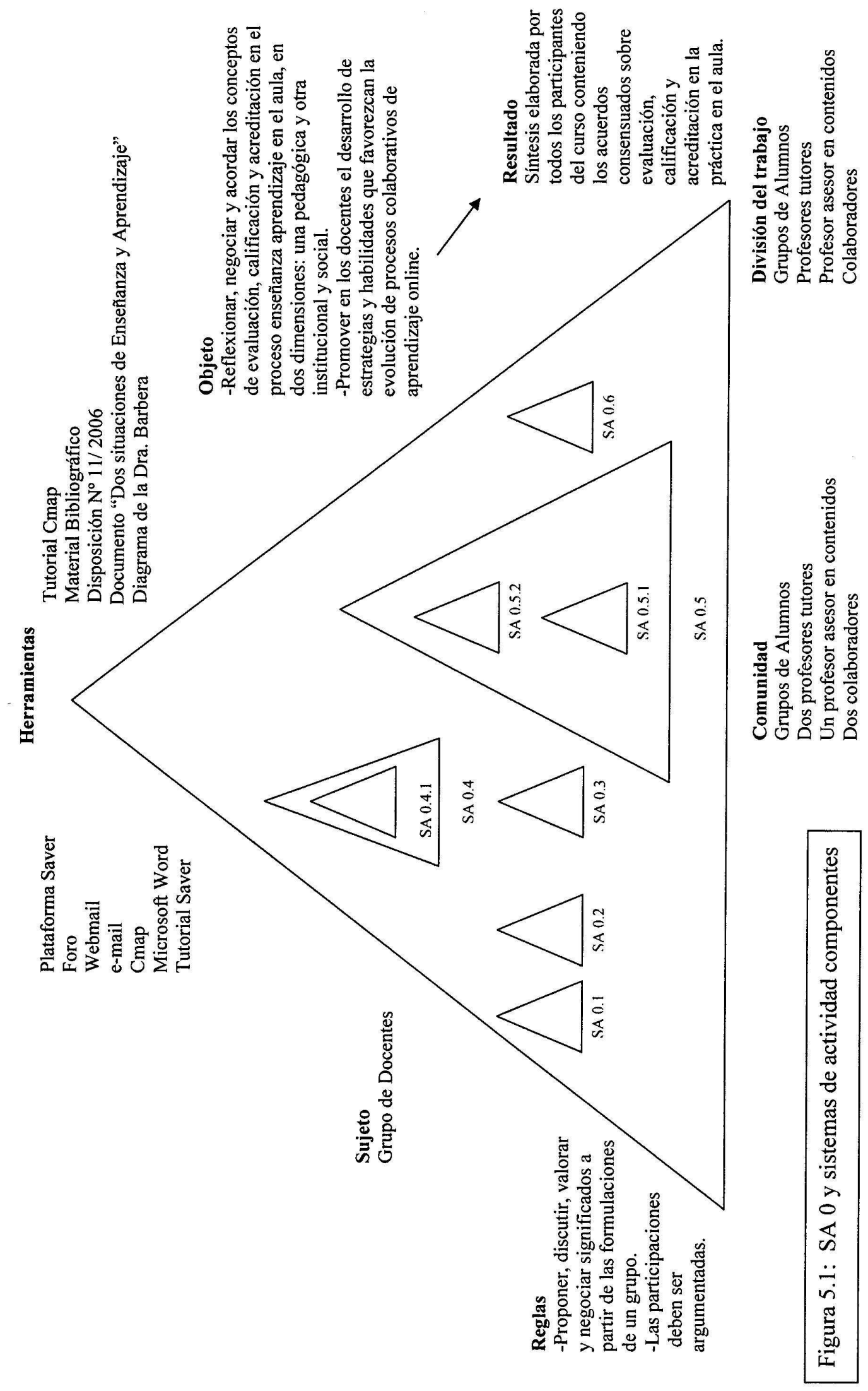


Para la identificación de cada sistema se utiliza la siguiente nomenclatura: el sistema global se designa como Sistema de Actividad Cero (SA 0), sus actividades componentes se las nombra como $0 . i$, donde $\mathrm{i}$ es un número que identifica a una actividad. Esta convención en la nomenclatura se utiliza para cada nivel de actividades componentes, por ejemplo en la Figura 5.1, el SA 0.4.1 identifica a la actividad componente 1 del sistema de actividad 4 que a su vez forma parte del SA 0.

Los triángulos interiores se disponen de acuerdo a la secuencia de los plazos proyectados para su desarrollo, considerando una línea horizontal temporal imaginaria con el instante cero del curso en el extremo izquierdo. De esta manera se reconoce de izquierda a derecha la secuencia propuesta para el avance de las actividades. Se puede observar además en la Figura 5.1, que el desarrollo simultáneo de actividades se representa ubicando los triángulos en el mismo espacio temporal.

De esta manera se describe un primer diseño del curso de formación, el cual a través del seguimiento del desarrollo del sistema se irá modificando de acuerdo a la dinámica de los subsistemas involucrados. Se concibe al diseño como un proceso activo que se desarrolla en forma previa a la realización del curso y que se extiende durante todo el período de práctica.

\subsubsection{Propósito del SA 0}

Las autoridades de la escuela han diagnosticado en el cuerpo de profesores ciertas discrepancias en los criterios de evaluación y discordancias entre lo que se manifiesta y la práctica. Además, han detectado dificultades para concertar reuniones de trabajo debido a la imposibilidad de que los profesores puedan acordar un horario común. Esto obstaculiza la formación de una comunidad de trabajo efectiva, que promueva acciones conjuntas de los profesores como agentes sustantivos de la institución para mejorar las prácticas educativas.

Como una posible solución al problema planteado se presenta a las autoridades de la escuela un curso de formación para los docentes, el cual se diseña como un sistema de actividad que pretende alcanzar un doble propósito, por un lado, favorecer la negociación y la construcción de acuerdos sobre las prácticas evaluativas en la institución y por otro, promover la formación de equipos de trabajo dentro de la escuela. 
Se propone para ello, innovar en la modalidad de trabajo sumando la potencialidad de las Tecnologías de la Información y Comunicación, planteando una metodología que promueva trabajo colaborativo entre profesores en un espacio "virtual", contribuyendo de esta manera a superar las dificultades para coincidir espacio-temporalmente entre los grupos de docentes.

En un principio el curso se pensó para ser desarrollado del veinticinco de septiembre al once de diciembre de 2006, con una carga horaria estimada de cuarenta horas reloj.

\subsubsection{Contexto del SA 0}

El colegio de nivel polimodal "Ernesto Sábato" de la Universidad Nacional del Centro de la Provincia de Buenos Aires, fue creado por ordenanza del Consejo Superior en octubre de 2003 y reconocido por el Ministerio de Educación, Ciencia y Tecnología de la Nación en el año 2004, a partir del cual comienza su funcionamiento.

La pertinencia de un proyecto de escuela de nivel polimodal dependiente de la universidad pública y regional se funda en las siguientes necesidades que, a su vez, constituyen los fines generales ${ }^{1}$ :

- Promover el desarrollo de competencias orientadas a la generación de prácticas sociales activas e inclusivas en el marco de la diversidad, que:

○ faciliten la construcción social desde una perspectiva creativa y participativa;

- abonen la autonomía cultural necesaria para el desarrollo de los pueblos en el contexto de las actuales demandas y necesidades.

- Favorecer el acceso equitativo a los bienes materiales y simbólicos que los avances científico-tecnológicos promueven, atendiendo al potencial sentido dignificante que los mismos proponen, revalorizando los aportes de las ciencias, artes y tecnologías en general desde una perspectiva humana, al servicio colectivo e individual.

\footnotetext{
${ }^{1}$ Documento Fundacional de las Escuelas de Nivel Polimodal de la UNCPBA, aprobado por Ordenanza del Consejo Superior N $N^{\circ} 3006 / 03$.
} 
- Contribuir a la redefinición constante de los valores sociales desde una perspectiva centrada en la solidaridad, el respeto y la responsabilidad como criterios imprescindibles para construir una sociedad más inclusiva, cuyas decisiones son producto de la clara conciencia de los miembros en un debate igualitario, dadas las capacidades de habla y de acción y de las actitudes (en tanto valores y predisposiciones), siendo éstas finalidades indelegables de la educación.

- Incluir para contener en el marco de la histórica función de incluir para integrar, orientando y capacitando para la participación ciudadana, el mundo del trabajo, y la continuidad de estudios superiores.

La designación de profesores se realiza a través de concurso de oposición. Se requiere de los profesores el conocimiento exhaustivo de la propuesta, alto compromiso institucional y estrecha colaboración entre los pares, no sólo para la coordinación de actividades sino también para el tratamiento de los problemas personales y sociales de los estudiantes. Se considera además dentro de la propuesta de la institución la necesidad de la formación continua de los docentes.

\subsubsection{Descripción de los elementos del SA 0 según el modelo de Engeström (1987)}

Se plantea un Sistema de Actividad 0 que corresponde a una visión global de la solución propuesta, seleccionada del conjunto de posibles respuestas al problema. En base a las necesidades diagnosticadas se propone reflexionar sobre la problemática de la evaluación en el ámbito del aula y la institución, con el sentido de favorecer la coherencia y la consistencia de los conceptos involucrados y su práctica. Además, se procura promover nuevas formas de interacción entre los docentes para trabajar coordinada y colaborativamente, tanto a nivel disciplinar como institucional, considerando que el trabajo en ambientes virtuales podría favorecer el desarrollo de capacidades específicas para poder trabajar colaborativamente tanto en forma presencial como online.

Se describen a continuación los elementos considerados en el diseño del SA 0 a partir del modelo de Engeström (1987): 


\section{Objeto:}

De acuerdo a los aspectos antes mencionados los objetivos establecidos son:

- Reflexionar, negociar y acordar los conceptos de evaluación, calificación y acreditación en el proceso enseñanza y aprendizaje en el aula, en dos dimensiones: pedagógica e institucional y social;

- Promover en los docentes el desarrollo de estrategias y habilidades que favorezcan la evolución de procesos colaborativos de aprendizaje online.

Resultado: se espera la obtención de una síntesis elaborada por el grupo conteniendo los acuerdos consensuados sobre evaluación, calificación y acreditación en la práctica en el aula.

Sujeto: cada grupo de cuatro docentes (Capítulo IV) de la Escuela Nacional "Ernesto Sábato" dependiente de la UNICEN que realizan el curso de formación.

\section{Comunidad:}

Grupos de alumnos: las personas inscriptas en el curso serán divididas en equipos de trabajo de hasta cuatro alumnos ( Capítulo IV)

Dos profesores tutores: Dra. Graciela Santos y Prof. Gabriela Cenich

Un profesor asesor en contenidos: Dra. Sonia Araujo

Dos colaboradores: Prof. Mg. Silvia Gallarreta y Lic. Mg. Tomás Landivar (Vicedirectora y Director del colegio de Nivel Polimodal "Ernesto Sábato" dependiente de la UNICEN)

\section{División del trabajo:}

Grupo de alumnos: contribuir en la elaboración de acuerdos consensuados sobre evaluación, calificación y acreditación en la práctica en el aula y colaborar en la creación de una síntesis institucional en referencia a lo acordado.

Profesores Tutores: acompañar, guiar y animar el proceso de aprendizaje individual y grupal, observando y evaluando el desarrollo general del curso para mediar en consecuencia. Se prevé intervenir cuando haya un pedido expreso del grupo ante alguna dificultad que no puedan resolver, o ante la observación de una situación conflictiva que los alumnos no sean capaces de solucionar, o de dificultades de interpretación de los elementos teóricos comunes al grupo. La intervención de los profesores en estos casos 
será reorientar la dirección del proceso a través de devoluciones oportunas y pertinentes, cuidando de conservar las características propias del trabajo colaborativo mencionadas anteriormente.

Un profesor asesor en contenidos: asesorar a los profesores tutores en el contenido específico del curso: la evaluación educativa

Dos colaboradores: orientar a los profesores tutores sobre la problemática de la evaluación en la Escuela y las necesidades observadas antes y durante el desarrollo del curso.

\section{Herramientas:}

En un SA (Figura 3.4, Capítulo III) las relaciones entre los distintos componentes se hallan mediadas: las herramientas median la relación entre el sujeto y el objeto de la actividad, las reglas entre sujeto y comunidad, y la división de tareas entre la comunidad y el objeto. Conforman un complejo sistema integrado de relaciones mediatizadas bidireccionales entre los distintos componentes del sistema, por lo que la selección de determinadas herramientas puede influir en el desarrollo de la actividad promoviendo un rediseño de la misma (Gay y Hembrooke, 2004). Teniendo en cuenta lo anterior y considerando además las interrelaciones entre los diferentes sistemas, se intenta seleccionar y elaborar herramientas que favorezcan la evolución del SA hacia los objetivos propuestos.

El desarrollo de las actividades del curso se centraliza en la plataforma SAVER, para favorecer la interacción entre los diferentes individuos del SA y dar soporte a las actividades en colaboración. Se distinguen las herramientas de comunicación webmail y foro, utilizando además, los correos electrónicos particulares de los miembros de la comunidad.

En el diseño del curso se seleccionan y elaboran materiales escritos y multimediales, algunos de ellos con la intención de favorecer los procesos de aprendizaje de los alumnos del curso y otros para promover el proceso de familiarización con el entorno de trabajo.

A continuación se describen las herramientas utilizadas en el desarrollo del curso:

-Plataforma SAVER: Software de Asistencia Virtual para Educación Remota (SAVER), prototipo de software para el soporte integral de actividades de educación a 
distancia basado en la tecnología Web.

-Foro: aplicación de la plataforma SAVER que da soporte a debates o discusiones asincrónicas entre los miembros de un curso de la plataforma.

-Webmail: aplicación de correo electrónico de la plataforma SAVER.

-e-mail: servicio de correo electrónico.

-Cmap: software para elaborar mapas conceptuales, creado por el Institute for Human and Machine Cognition, The University of West Florida http://cmap.coginst.uwf.edu/ El software CmapTools está disponible gratuitamente para el uso educativo y sin fines de lucro en http://cmap.ihmc.us

-Microsoft Word: programa para la edición de textos.

-Tutorial sobre el uso de la plataforma SAVER: guía hipertextual realizada en Power Point con información de acceso y utilización de todas las herramientas de la plataforma que se utilizarán en el curso.

-Tutorial sobre Cmap: guía realizada en html con información sobre las características y utilización del software Cmap. (Castro Pérez, 2006. Tutorial sobre Cmap. Disponible en www.ramoncastro.es)

-Material Bibliográfico:

Álvarez Méndez J. M. (1995). Valor social y académico de la evaluación. En: Volver a pensar la educación: Congreso Internacional de Didáctica / coord. Por Pablo Manzano Bernárdez, Vol 2, 1995, ISBN 84-7112-404-1, pags. 173-193.

Álvarez Méndez J. M. (2000). Didáctica, currículo y evaluación. Ensayos sobre cuestiones didácticas. Buenos Aires / Madrid: Miño y Dávila Editores.

Álvarez Méndez J. M. (2001). Evaluar para conocer, examinar para excluir. Madrid: Ediciones Morata.

Camilloni A., "Sistemas de calificación y regímenes de promoción” En Camilloni, A, Celman, S., Litwin, E. y Palou, C. (Eds.) La evaluación de los aprendizajes en el debate didáctico contemporáneo. Buenos Aires: Paidós, pág. 133-176.

Celman S. (1998) "Es posible mejorar la evaluación y transformarla en herramienta de conocimiento?". En Camilloni, A, Celman, S., Litwin, E. y Palou, 
C. (Eds.) La evaluación de los aprendizajes en el debate didáctico contemporáneo. Buenos Aires: Paidós, pág. 35-66

Díaz Barriga A. (1989). Didáctica y Curriculum. México: Ediciones Nuevomar.

Santos Guerra M. (1995). La evaluación: un proceso de diálogo, comprensión y mejora. Málaga: Ediciones Aljibe.

-Disposición N $\mathrm{N}^{\mathrm{o}}$ 11/2006: Regimen de evaluación, acreditación y promoción de las escuelas de nivel polimodal de la Universidad Nacional del Centro

-Documento "Dos situaciones de Enseñanza y Aprendizaje": Texto extraído y adaptado del artículo "Constructivism in Theory and Practice: Toward a Better Understanding", James. M. Applefield, Richard Huber y Mahnaz Moallem. The High School Journal, 84 (2) Dec 2000/Jan 2001.

-Diagrama de la Dra. Elena Barbera: presentación Power Point sobre evaluación elaborada con audio extraído de la videoconferencia de la Dra. Barbera del Congreso IV Seminario Internacional, II Encuentro Nacional de Educación a Distancia organizado por Red Universitaria de Educación a Distancia de Argentina, Mayo 2006, Córdoba.

\section{Reglas:}

El desarrollo de las actividades del sujeto en la comunidad se halla mediado por las reglas que pueden ser implícitas o explícitas. Las primeras generalmente forman parte de la cultura de trabajo de la institución o son construídas a medida que los integrantes de la actividad trabajan juntos. Las segundas son determinadas por la institución o construídas para un proyecto en particular (Nardi, 1996). En el presente trabajo las reglas diseñadas para cada actividad se hacen explícitas a través de su comunicación a los alumnos por medio del enunciado de la actividad (Capítulo VI). Las siguientes reglas se definen para el SA 0:

-Proponer, discutir, valorar y negociar significados a partir de las formulaciones de un grupo.

-Las participaciones deben ser justificadas.

\subsubsection{Descripción de la estructura interna del SA 0}


A partir del planteo del sistema de actividad del curso (SA 0), que brinda una visión general del mismo, se analizan y diseñan las actividades componentes que contribuirán a alcanzar el objeto definido (que expresa las intenciones que motivan la actividad) (Wang, 2002).

La Figura 5.1 representa la definición del SA 0 como un todo, refiriéndonos al diseño del curso colaborativo online. Es necesario además, identificar y definir cuáles son las actividades componentes y sus interrelaciones en este sistema general, que permitirán avanzar hacia el logro del resultado final. Se deben tener en cuenta al detallar las actividades componentes las herramientas que serán asociadas a cada una de entre todas las herramientas definidas en la actividad general. Se debe considerar además, que una actividad puede responder a varios objetivos los cuales pueden dar origen a nuevas actividades. En la relación entre dos actividades el resultado de la primera puede que constituya una herramienta de mediación para la segunda, estableciendo una dependencia entre ambas (Barros y col, 2004).

En particular en el diseño del curso colaborativo online, cada actividad componente se constituye en input de la siguiente, tanto en plano conceptual como en el desarrollo de estrategias y habilidades colaborativas. En virtud de la dinámica del proceso, si alguno de los objetivos planteados no fueran alcanzados, influye en la definición del siguiente sistema de actividad.

\subsubsection{Descripción de los elementos de las actividades componentes del SA 0 según el modelo de Engeström (1987)}

En este apartado se describen los SA que integran el SA 0, detallando cada uno de sus componentes.

\section{Sistema de Actividad 0.1 (Encuentro presencial)}

Esta actividad consiste en un primer encuentro presencial con los alumnos en el laboratorio de informática, donde se posibilita el acceso a Internet. El propósito es brindar información general sobre el curso en cuanto a sus objetivos, metodología de 
trabajo y herramientas que se utilizarán en el desarrollo, así como explicar las necesidades que motivan el curso y compartir la propuesta de solución a estas dificultades. Se explican las características y dinámica propias del trabajo colaborativo (Ingram y Hathorn, 2004) que contribuirían a favorecer la reflexión, la negociación y los acuerdos sobre los conceptos involucrados por parte de los docentes considerados como una comunidad de aprendizaje en línea (Tu y Corry, 2001).

\section{Objeto:}

-Compartir con los participantes la problemática que dió origen al curso, la solución propuesta, y los aspectos y dinámica propios del aprendizaje colaborativo

-Presentar, explicar y experimentar el uso de las herramientas que mediarán el desarrollo de las distintas actividades durante el curso

-Construir y acordar reglas explícitas de trabajo, en particular en el ambiente online

\section{Resultado:}

-Definición de los objetivos del curso

-Primeras experiencias en la utilización de las herramientas mediadoras del curso

Sujeto: profesores tutores a cargo del desarrollo del curso.

Comunidad: está formada por los alumnos y dos profesores tutores.

División del trabajo: se distinguen los roles de alumno y profesor tutor. La tarea del alumno consiste en interpretar y contribuir a la interpretación por parte de sus compañeros de la problemática a resolver a través de aportes y cuestionamientos sobre áreas dudosas o en las que se detecten inconsistencias, experimentar e interpretar el uso de las herramientas en el contexto propuesto.

Las tareas principales del tutor son explicar y consensuar con los participantes los objetivos del curso. Promover el uso y apropiación por parte de los alumnos de las herramientas que mediarán en el proceso de enseñanza y aprendizaje.

Herramientas: Plataforma SAVER, Tutorial sobre el uso de la plataforma SAVER y Cmap.

\section{Reglas:}

-Proponer, discutir y negociar significados a partir de las formulaciones del profesor o de un par. 


\section{Sistema de Actividad 0.2 (Presentación social)}

La interacción alumno-profesor y alumno-alumno es considerada uno de los aspectos centrales en el desarrollo de procesos colaborativos online (Ingram y Hathorn, 2004). Se debe tener en cuenta que esta interacción difiere de la que se produce en una clase presencial como consecuencia de varios factores que inciden en el desarrollo de los procesos de colaboración en línea. La comunicación a través de medios asincrónicos se realiza en un contexto de tiempo y espacio diferente. La sensación de distancia se puede relacionar no tanto a la distancia geográfica real sino a la imposibilidad de sobreponer la condición de asincronismo. La producción y la comprensión de los mensajes ocurren en tiempos diferentes e independientes uno de otro (Sorensen, 2004). La naturaleza de la participación basada en texto difiere de la cara a cara fundamentalmente en la ausencia de comunicación no verbal (Dirkx y Smith, 2004), lo cual afecta las formas de interactuar entre los participantes. La proyección social y afectiva de los miembros en la comunidad de aprendizaje requiere habilidades que contribuyan a promover su integración social (Rourke y col., 1999), considerada como eje fundamental de la dimensión funcionamiento de grupo (Cenich y Santos, 2006). Para avanzar en este sentido se plantea la siguiente actividad que consiste en la publicación de un mensaje de presentación personal de cada uno de los participantes, la misma tiene además, la intención de promover el desarrollo de habilidades que permitan a los participantes desenvolverse en el uso de las herramientas que ofrece la plataforma, tanto en sus dimensiones tecnológicas como en aquellas que contribuyen al desarrollo de procesos colaborativos.

\section{Objeto:}

-Promover el desarrollo de estrategias de integración social.

-Promover la familiarización de los miembros con el entorno virtual.

-Favorecer la utilización del Foro de discusión como herramienta para compartir e intercambiar información.

\section{Resultado:}

Documento de foro conteniendo el detalle de los mensajes de presentación de todos los miembros del grupo. 
Sujeto: alumno

La comunidad: está formada por los alumnos y dos profesores tutores.

División del trabajo: alumno y profesor tutor. El alumno contribuirá con su presentación personal al foro. El profesor tutor animará a presentarse a los participantes dentro del lapso previsto.

Herramientas: Plataforma SAVER, Foro

\section{Reglas:}

-La presentación personal debe incluir por lo menos el nombre, las materias y años en donde desarrolla su actividad en la Institución.

\section{Sistema de Actividad 0.3 (Compartir anécdotas)}

Este sistema de actividad se sustenta en dos conceptos clave de raíz constructivista, uno que considera que "la construcción de nuevos conocimientos comienza con la observación de acontecimientos o de objetos a través de los conceptos que ya poseemos" (Novak y Gowin, 1988) y otro que sostiene que la experiencia humana se construye en un proceso que implica pensamiento, actuación y afectividad, siendo a través del aprendizaje que se enriquece este proceso y se posibilitan cambios en el significado de la experiencia. En este sentido, y con el objetivo de que los participantes reflexionen sobre sus experiencias en evaluación, se propone una actividad para compartir y comentar anécdotas personales sobre evaluación con los integrantes del grupo, referidas tanto a experiencias en el rol de alumno como en el de profesor, y comentar las experiencias publicadas por otros participantes.

\section{Objeto:}

-Reflexionar sobre los conceptos de evaluación, calificación y acreditación en el proceso enseñanza y aprendizaje en relación a sus experiencias personales.

-Promover la familiarización de los miembros con el entorno virtual.

-Favorecer la utilización del Foro de discusión como herramienta para compartir e intercambiar información y posturas personales en referencia a un tema.

\section{Resultado:}


Documento conteniendo el detalle de anécdotas personales sobre cómo fueron evaluados como alumnos y anécdotas de copias de evaluación de sus alumnos.

Sujeto: grupo de alumnos

Comunidad: está formada por los alumnos del grupo y dos profesores tutores.

División del trabajo: alumno y profesor tutor. El alumno deberá contribuir al foro con relatos de experiencias personales y comentarios sobre los aportes de los otros miembros del grupo.

El profesor tutor observará y animará el desarrollo de la actividad, pudiendo intervenir para enriquecer los comentarios efectuados sobre las experiencias personales.

Herramientas: Plataforma SAVER, Foro

\section{Reglas:}

-Trabajar en el espacio de foro correspondiente al grupo de área

-Publicar al menos un mensaje con el relato de una anécdota

-Publicar al menos un mensaje comentando la anécdota publicada por otro miembro del grupo.

-Realizar las intervenciones en el lapso de tiempo prefijado

Los sistemas de actividad 0.2 (Presentación social) y 0.3 (Compartir anécdotas) se diseñan para su desarrollo en forma simultánea en un período previsto de diez días (con la intención de incluir el fin de semana), considerando que los participantes, docentes en ejercicio, podrían contribuir a las actividades preferentemente durante los fines de semana.

La actividad 0.2 se diseña como un primer paso hacia la integración social de los miembros del curso a través de mensajes de presentación personales, considerando además, el concepto de aprendizaje significativo de la teoría de Ausubel, según la cual el individuo establecería relaciones entre los nuevos conocimientos y los conceptos y proposiciones relevantes que ya conoce (Novak y Gowin, 1988), se plantea la actividad 0.3 para que a través de las anécdotas personales los alumnos puedan expresar los conceptos y proposiciones que poseen en relación al tema evaluación. Estas actividades se plantean con la intención de que integren un valioso input de la siguiente actividad, y 
a la vez se constituyan en fuente de información que permita a los tutores generar los feedbacks necesarios.

\section{Sistema de Actividad 0.4 (Compartir y discutir mapas conceptuales)}

Este sistema de actividad se diseña con la intención de favorecer que los miembros de cada grupo puedan alcanzar significados compartidos. Para ello, se propone a cada alumno la realización de una actividad componente, que consiste en la elaboración de un mapa conceptual con el objetivo de promover la reflexión y la expresión de sus conocimientos sobre el tema evaluación (SA 0.4.1).

Se propone como estrategia para favorecer el desarrollo de procesos de integración social y negociación de significados la realización de un foro de debate donde a partir de los mapas conceptuales individuales los alumnos cuestionen, discutan, negocien y acuerden significados de conceptos relacionados con el tema evaluación.

\section{Objeto:}

-En base a los conocimientos previos, reflexionar sobre los conceptos de evaluación, calificación y acreditación en el proceso de enseñanza y aprendizaje.

-Fomentar el uso de los mapas conceptuales como una herramienta de representación del conocimiento.

-Promover el uso de la herramienta Cmap para la construcción de mapas conceptuales.

-Promover el desarrollo de estrategias de gestión de grupo e integración social.

-Favorecer el uso del foro como herramienta para la discusión, negociación y consenso sobre conceptos entre varias personas.

\section{Resultado:}

Documento del foro con la discusión sobre los mapas conceptuales elaborados por los miembros del grupo.

Sujeto: grupo de alumnos

Comunidad: está formada por los alumnos del área y dos profesores tutores.

División del trabajo: alumno y profesor tutor. La tarea del alumno consiste en 
contribuir a la reflexión grupal sobre el tema evaluación a través del cuestionamiento, discusión y negociación de significados.

El tutor controlará y animará el proceso de debate.

Herramientas: Plataforma SAVER, Cmap, Tutorial sobre el uso de Cmap, Mapas conceptuales elaborados por los alumnos.

\section{Reglas:}

-Proponer, discutir, valorar y negociar significados a partir de las formulaciones de un par.

-Realizar por lo menos dos intervenciones en el lapso de tiempo prefijado

Esta actividad tiene una actividad componente que deben realizar los participantes en forma individual que se describe a continuación:

\section{Sistema de Actividad 0.4.1 (Elaborar Mapa Conceptual individual)}

La elaboración de mapas conceptuales permite poner de manifiesto conceptos y proposiciones. En el proceso de construcción de un mapa conceptual la persona puede desarrollar nuevas relaciones entre conceptos y redefinir relaciones anteriores reestructurando el conocimiento sobre cierto tema, generando de esta manera nuevos significados o haciendo conscientes significados a través del proceso de elaboración del mapa (Novak y Gowin, 1988).

Esta actividad tiene como intención que los alumnos reflexionen sobre sus conocimientos sobre evaluación. Para ello, se les propone construir un mapa conceptual individual sugiriéndoles como guía algunos conceptos que podrán tener en cuenta en la elaboración.

En este SA se considera sólo la triada sujeto, herramientas y objeto, y sus posibles interrelaciones, poniendo énfasis en la relación mediada individual entre sujeto y objeto, (ver Capítulo III, Pág. 42).

\section{Objeto:}

-En base a los conocimientos previos, reflexionar sobre los conceptos de evaluación, calificación y acreditación en el proceso EA. 
-Favorecer el uso de los mapas conceptuales como una herramienta de representación del conocimiento.

-Promover el uso de la herramienta Cmap para la construcción de mapas conceptuales.

\section{Resultado:}

Publicación del Mapa Conceptual elaborado por cada miembro del grupo.

Sujeto: alumno

Herramientas: Plataforma SAVER, Cmap y Tutorial sobre el uso de Cmap

\section{Sistema de Actividad 0.5 (Reflexionar, negociar y acordar conceptos de evaluación)}

El constructivismo considera al aprendizaje como un proceso activo, determinado por complejas interacciones entre el conocimiento existente en los alumnos, el contexto social y el problema a resolver (Tam, 2000). En este sentido, esta actividad plantea una fuerte interrelación entre el dominio conceptual y la aplicación del mismo a una situación problemática, intentando favorecer el desarrollo de procesos dinámicos de interacción tanto individuales como colaborativos a través del diseño integrado de sus dos actividades componentes. Se propone leer los materiales bibliográficos interviniendo en un foro para compartir y negociar significados sobre el tema propuesto, a la vez que los miembros del grupo deben resolver en forma individual una situación problemática que requiere de la aplicación de los conocimientos en proceso de construcción por parte del grupo, considerando al conocimiento como público y compartido (Novak y Gowin, 1988). Desde esta perspectiva y considerando que el SA se construye a través de la visión e interpretación del sujeto, se define como sujeto del SA al alumno (Engeström y col., 1999).

\section{Objeto:}

-Reflexionar, negociar y acordar los conceptos de evaluación, calificación y acreditación en el proceso enseñanza y aprendizaje en el aula.

-Promover el desarrollo de estrategias de Gestión de grupo e Integración social.

-Favorecer el uso del Foro como herramienta para la discusión, negociación y consenso 
de conceptos entre varias personas.

-Promover la interactividad entre el alumno y el material del curso.

\section{Resultado:}

Documento del Foro Discusión.

Resolución de la actividad individual

Sujeto: alumno

Comunidad: está formada por los alumnos del área y dos profesores tutores.

División del trabajo: alumno y profesor tutor. El alumno tiene como tarea resolver la actividad individual a través de la lectura de los materiales bibliográficos, resignificando conceptos a través de la participación e interacción en el foro y de la aplicación a la solución al problema planteado. El tutor monitorea el cumplimiento de las normas establecidas y reorienta las acciones individuales promoviendo mayor número de intervenciones productivas y de mejor calidad.

Herramientas: Plataforma SAVER, Word, Bibliografía, Disposición Nº11/2006 y

Documento "Dos situaciones de enseñanza y aprendizaje"

\section{Reglas:}

-Proponer, discutir, valorar y negociar significados a partir de las formulaciones de un par

-Las participaciones deben ser argumentadas.

-Realizar la actividad en el plazo previsto

\section{Sistema de Actividad 0.5.1 (Promover la reflexión sobre el concepto de evaluación)}

Los aprendizajes son mediatizados por actividades diseñadas para mejorar la comprensión de los estudiantes y la significación del conocimiento a través de la interacción con el material en contextos reconfigurados para diferentes propósitos y la interacción entre pares para compartir conocimientos (Jonassen y Rohrer-Murphy, 1999); favoreciendo la reflexión y el compromiso activo de los alumnos (Moallem, 2003). Para avanzar en este sentido, se propone a los miembros del grupo leer los 
materiales del curso, para analizar la problemática planteada en la actividad siguiente y promover el intercambio de ideas a través del espacio foro. Esta actividad se constituye en un input necesario para el desarrollo de la actividad 0.5.2 (resolver una situación problemática), favoreciendo la reflexión individual a través de la interacción social.

\section{Objeto:}

-Reflexionar, negociar y acordar los conceptos de evaluación, calificación y acreditación en el proceso enseñanza y aprendizaje en el aula.

-Promover el desarrollo de estrategias de gestión de grupo e integración social.

-Favorecer el uso del foro como herramienta para la discusión, negociación y consenso de conceptos entre varias personas.

-Promover la interactividad entre el alumno y el material del curso.

\section{Resultado:}

Documento foro discusión.

Sujeto: alumno

Comunidad: está formada por los alumnos del área y dos profesores tutores.

División del trabajo: alumno y profesor tutor. La tarea del alumno consiste en leer los materiales reflexivamente para contribuir al debate planteado.

El tutor guía en la lectura de los materiales, monitorea el desarrollo de la actividad tanto grupal como individual, responde a inquietudes, dudas y cuestionamientos de los alumnos, y anima a los estudiantes a participar respetando las reglas definidas.

Herramientas: Plataforma SAVER, Word, Bibliografía, Disposición Nº11/2006

\section{Reglas:}

-Proponer, discutir, valorar y negociar significados a partir de las formulaciones de un par

-Las participaciones deben ser argumentadas

-Realizar la actividad en el plazo previsto 


\section{Sistema de Actividad 0.5.2 (Resolver una situación problemática)}

Este sistema de actividad plantea la resolución de una situación problemática en forma individual. Su desarrollo es simultáneo al de la actividad 0.5.1 con el fin de favorecer la interacción con los materiales proporcionados como herramientas y entre pares, promoviendo la resignificación de conceptos a través de la aplicación de los conocimientos a una situación problemática.

\section{Objeto:}

-Reflexionar sobre los conceptos de evaluación, calificación y acreditación en el proceso EA en el aula, teniendo en cuenta lo debatido en el foro y el material leído.

\section{Resultado:}

Documento conteniendo la solución a la problemática planteada

Sujeto: alumno

Herramientas: Plataforma SAVER, Word, Bibliografía, Disposición Nº11/2006,

Documento con situación planteada a resolver (ver Anexo II)

\section{Sistema de Actividad 0.6 (Acordar pautas de evaluación)}

La propuesta de solución al problema planteado formula favorecer el desarrollo de estrategias y habilidades que contribuyan a la generación de procesos colaborativos. Así en el diseño de las actividades componentes se consideró promover la participación equitativa, la interacción genuina entre los miembros del grupo y la síntesis del trabajo realizado por los miembros (Ingram y Hathorn, 2004). Se plantea en esta actividad la necesidad de definir una síntesis de lo trabajado por los participantes a través de la expresión de lineamientos que favorecerían poder mejorar las prácticas de evaluación en el área a la que pertenecen a la luz de las dimensiones pedagógica y administrativa, institucional y social.

\section{Objeto:}

Reflexionar, negociar y acordar los conceptos de evaluación, calificación y acreditación en el proceso EA en el aula, en dos dimensiones: una pedagógica y otra administrativa, 
institucional y social.

\section{Resultado:}

Propuesta consensuada para mejorar las prácticas de evaluación teniendo en cuenta dos dimensiones: una pedagógica y otra administrativa, institucional y social.

Sujeto: alumno

Comunidad: está formada por los alumnos del área y dos profesores tutores.

División del trabajo: alumno y profesor tutor

Herramientas: Plataforma SAVER, Word, Bibliografía, Disposición №11/2006,

Diagrama de la Dra. Elena Barbera

\section{Reglas:}

-Proponer, discutir, valorar y negociar significados a partir de las formulaciones de un área.

-Las participaciones deben ser argumentadas.

\subsubsection{Evaluación integral del Sistema de Actividad}

La evaluación se considera como un proceso continuo en el diseño del sistema de actividad, que plantea la necesidad de rever y reajustar el diseño parcial a medida que se avanza, generando feedback entre las diferentes fases, favoreciendo la reflexión y la toma de decisiones en el proceso de diseño.

Desde una visión holística del sistema, algunas actividades componentes no pueden ser definidas de antemano en una forma completa, debido a que el diseño se realiza sobre un caso real, respondiendo a las características más generales de los problemas mal estructurados y haciendo necesaria una evaluación que contemple la evolución del sistema en forma iterativa (Nash y col., 2004).

En el siguiente capítulo se describe el desarrollo del curso a partir del diseño inicial y las modificaciones realizadas surgidas del análisis de los resultados parciales obtenidos. 
CAPÍTULO VI

\section{IMPLEMENTACIÓN Y SEGUIMIENTO DEL E-CURSO}


En este capítulo se utiliza la teoría de la actividad como una heurística que facilita el diseño y evaluación del desarrollo de la experiencia, favoreciendo procesos de tipo top down ${ }^{1}$ y bottom up ${ }^{2}$ que permiten la evaluación de las actividades en desarrollo, generando feedback sobre el sistema en general.

El análisis de la evolución del e-curso se centra sobre los elementos participación, interacción y síntesis definidos como esenciales para el desarrollo de procesos colaborativos (Ingram y Hathorn, 2004). No se estudia en este trabajo el desarrollo del contenido conceptual del curso en referencia al tema "evaluación".

De acuerdo a lo detallado en la metodología (Capítulo IV) se analiza la participación en un SA considerando la cantidad de mensajes que publica cada participante. El estudio de las interacciones desarrolladas en cada grupo de trabajo se describe mediante diagramas con el objeto de tener una primera visión global de las mismas. Luego se avanza en el análisis de las interacciones relacionadas al funcionamiento de grupo (Cenich y Santos, 2006), y se identifica la presencia de procesos para compartir y negociar significados (Gunawardena y col, 1997). Posteriormente se realiza un análisis holístico del desarrollo de cada actividad teniendo en cuenta su estructura, las relaciones entre los componentes del sistema, las vinculaciones del SA en estudio con el contexto y con los restantes sistemas de actividad que conforman el e-curso.

Se presenta a continuación un cuadro (Tabla 6.0) con información sobre la implementación y seguimiento del e-curso.

La primera fila indica cada SA y sus actividades componentes.

En la siguiente fila se presenta sujeto comprometido en el desarrollo de cada actividad: grupo se refiere al total de docentes participantes del curso, subgrupos cada uno de los equipos formados a partir de la división del total de personas participantes en unidades de hasta 4 alumnos. Los subgrupos fueron identificados con el nombre de un color violeta, rosa, gris, naranja y lila, individual cuando se considera a cada participante del curso como sujeto de la actividad.

\footnotetext{
${ }^{1}$ El modelo Top-down se diseña teniendo en cuenta las características de todos los módulos y sus relaciones para integrarlos en un sistema coherente (Ghezzi, Jazayeri y Mandrioli, 1991).

${ }^{2}$ En el diseño Bottom-up las partes individuales se diseñan con detalle ignorando las particularidades de otros módulos (Ghezzi, Jazayeri y Mandrioli, 1991).
} 
En la próxima fila se detallan los factores de colaboración participación, interacción y síntesis, considerando además en la interacción los tres instrumentos mencionados anteriormente $\mathrm{D}$ diagrama de flujo, $\mathrm{F}$ funcionamiento de grupo y $\mathrm{C}$ modelo de análisis de la interacción para examinar la construcción social del conocimiento en conferencias por computadora.

Cada casillero de esta tabla contiene una X o una línea punteada según se haya estudiado el factor de colaboración o no en cada actividad.

Como último componente de este cuadro se presenta el análisis holístico realizado al finalizar cada actividad.

\begin{tabular}{|c|c|c|c|c|c|c|c|c|c|c|c|c|c|c|c|c|c|c|c|}
\hline \multirow{3}{*}{\multicolumn{3}{|c|}{$\begin{array}{c}\text { Sistema de } \\
\text { Actividad }\end{array}$}} & \multicolumn{17}{|l|}{0} \\
\hline & & & & 0.1 & 0.2 & & & 0.3 & & & & & 0.4 & & & & 0.5 & & \\
\hline & & & & & & & & & & & & & & & & 0.4 .1 & & 0.5 .1 & 0.5 .2 \\
\hline \multirow{2}{*}{\multicolumn{2}{|c|}{ Sujeto }} & \multirow{2}{*}{\multicolumn{2}{|c|}{ Grupo }} & \multirow[t]{2}{*}{ Grupo } & \multirow[t]{2}{*}{ Grupo } & \multicolumn{5}{|c|}{ Subgrupos } & \multicolumn{5}{|c|}{ Subgrupos } & \multirow[t]{2}{*}{ Individual } & \multirow[t]{2}{*}{ Grupo } & \multirow[t]{2}{*}{ Grupo } & \multirow[t]{2}{*}{ Individual } \\
\hline & & & & & & v & 月 & $G_{G}$ & \begin{tabular}{|l|}
$\mathrm{N}$ \\
\end{tabular} & & v & & \begin{tabular}{|l|} 
G \\
\end{tabular} & $\mathrm{H}$ & I & & & & \\
\hline \multirow{5}{*}{$\begin{array}{l}\text { Fac- } \\
\text { tores } \\
\text { de } \\
\text { colabo- } \\
\text { ración }\end{array}$} & \multicolumn{2}{|l|}{$P$} & $x$ & - & $x$ & $x$ & $\mathrm{x}$ & $\mathbf{x}$ & $\mathbf{x}$ & $x$ & $x$ & $x$ & $x$ & $x$ & $x$ & $x$ & - & $x$ & $\mathbf{x}$ \\
\hline & \multirow{4}{*}{$\mathbf{I}$} & $D$ & $x$ & - & - & $x$ & \begin{tabular}{|l|}
$x$ \\
\end{tabular} & $x$ & $x$ & $x$ & $x$ & $x$ & $x$ & $x$ & $x$ & - & - & $x$ & - \\
\hline & & $F$ & $x$ & - & $x$ & $\mathrm{x}$ & $x$ & $\mathbf{x}$ & $x$ & $x$ & $x$ & $x$ & $x$ & $x$ & $x$ & - & - & $x$ & - \\
\hline & & c & $x$ & - & - & . & - & - & - & - & $x$ & $x$ & $x$ & $x$ & $x$ & - & - & $x$ & - \\
\hline & & & $x$ & - & -- & . & - & - & - & . & - & |- & . & - & - & -- & - & - & - \\
\hline \multicolumn{3}{|c|}{$\begin{array}{l}\text { Análisis } \\
\text { holístico }\end{array}$} & $\mathbf{x}$ & - & $x$ & \multicolumn{5}{|c|}{$x$} & \multicolumn{5}{|c|}{$x$} & $x$ & $x$ & -- & -- \\
\hline
\end{tabular}

Tabla 6.0: Implementación y seguimiento del e-curso

A continuación se detalla el estudio de cada uno de los sistemas de actividad y subsistemas, de acuerdo a la secuencia temporal establecida en el diseño inicial (Capítulo V, Pág. 55), finalizando con la evaluación del SA 0 que representa el sistema global.

\subsection{Sistema de Actividad 0.1 (Encuentro presencial)}

El curso comenzó con un encuentro presencial, con la intención de explicar la problemática del curso y la metodología de trabajo.

Una presentación Power Point expuso a los participantes las necesidades diagnosticadas por las autoridades de la escuela. Las mismas presentaban dos ejes principales, uno de ellos referido a acordar criterios de evaluación entre los profesores que puedan trasladarse de forma coherente a la práctica institucional, y el otro, en 
relación a la formación de una comunidad de trabajo efectiva, que promueva acciones conjuntas de los profesores como agentes sustantivos de la institución para mejorar las prácticas educativas.

Se presentó la propuesta de solución elaborada fundamentada en el aprendizaje basado en problemas y el aprendizaje colaborativo. Se realizó una explicación acerca de los motivos por los cuales se adoptó este marco conceptual en particular y cuál sería la metodología de trabajo, se dió a conocer las pautas tanto individuales como grupales que permitirían el desarrollo del curso en el contexto definido. En referencia al concepto de colaboración, descripto en el marco teórico, se presentaron sus componentes principales -participación, interacción y síntesis- y las interrelaciones que los vinculan. Destacando que la colaboración requiere de una participación más o menos igualitaria entre sus participantes posibilitando interacciones en las cuales los miembros del grupo se respondan activamente unos con otros, explicitando ideas y generando devoluciones y promoviendo la síntesis de las ideas de todos los miembros del grupo presente en el producto final (Ingram y Hathorn, 2004).

Se presentaron los objetivos principales del curso explicando la importancia y la contribución de cada uno a la solución de la problemática planteada:

- Reflexionar, negociar y acordar los conceptos de evaluación, calificación y acreditación en el proceso enseñanza y aprendizaje en el aula, en dos dimensiones integradas: pedagógica y administrativa, institucional y social.

- Promover en los docentes el desarrollo de estrategias y habilidades que favorezcan la evolución de procesos colaborativos de aprendizaje online.

El primer propósito surgió como respuesta a la necesidad de compartir significados entre los miembros de la comunidad educativa favoreciendo el desarrollo de prácticas evaluativas consistentes a nivel institucional.

Se reflexionó en particular sobre el segundo objetivo, destacando los aspectos positivos del trabajo colaborativo online que trascienden el contexto de este curso en particular en cuanto a aquellas capacidades y estrategias que les permitirán desenvolverse en otros entornos virtuales de colaboración, e incluso les permitirían proyectar espacios compartidos de trabajo online en el futuro, reforzando por ejemplo, la estructura institucional que agrupa a los profesores en departamentos por áreas.

Se explicitó la metodología de trabajo, detallando los aspectos correspondientes a 
la asistencia, la conformación de los grupos, la realización de actividades individuales y grupales y la evaluación del curso.

Se comentó la necesidad de explicitar los conocimientos personales de manera que puedan ser socializados en el grupo de trabajo. Se explicó entonces, que se utilizarían en el desarrollo del curso, los mapas conceptuales (los docentes manifestaron conocer la metodología) como herramientas que permiten representar explícitamente las concepciones que una persona tiene sobre determinado campo de conocimiento. Se explicaron las ventajas de la utilización del software Cmap en la construcción y modificación de mapas conceptuales, destacando su interfaz de usuario y funcionalidad, diseñadas para que resultaran fáciles de utilizar por usuarios novatos (Cañas y col., 2005). Se expusieron a modo de ejemplo, a través del mapa conceptual sobre colaboración elaborado en el marco del diseño de este curso, los procedimientos para construir un mapa conceptual utilizando la aplicación Cmap. Se indicó además, que el software para su instalación junto con un documento conteniendo información sobre mapas conceptuales ${ }^{3}$, estaría disponible en el CD que se entregaría a cada participante.

Se comentó acerca de las características más importantes de la educación a distancia, aclarando los alcances de las dimensiones tiempo y espacio en esta modalidad y para este curso en particular. Se destacó la importancia del rol activo que debe asumir el alumno, en un entorno en el que se promueven la generación de diferentes interacciones: alumno-profesor, alumno-alumno, alumno-herramientas, alumnocontenido.

A continuación se realizó un recorrido explicativo por la plataforma SAVER, se les indicó la dirección de acceso a la plataforma, y distribuídas las claves de acceso, cada participante ingresó con su perfil al curso online. Se explicó la distribución de las distintas herramientas en pantalla, ingresando a aquellas que se utilizarían durante el curso y recomendando la consulta de los espacios de comunicación que permitirían conocer las novedades y actividades a desarrollar.

Se presentó un tutorial sobre la plataforma elaborado en Power Point con la intención de proveer a los participantes una guía con la información de acceso y utilización de todas las herramientas de la plataforma que necesitarían conocer para desenvolverse en el desarrollo del curso. Se explicaron las siguientes operaciones:

\footnotetext{
${ }^{3}$ Miranda, A., Santos, G. (2003). Mapa conceptual como recurso didáctico. Apunte de cátedra perteneciente a la materia Informática Educativa de la Licenciatura en Educación Matemática, UNICEN
} 
Revisar las novedades en "Tablón de anuncios", Leer enunciado de una actividad, Publicar y descargar un archivo, Utilizar el webmail, Trabajar en el espacio foro, Utilizar el espacio preguntas frecuentes, detallando las herramientas involucradas, para qué y cómo utilizarlas. Se trabajó en especial con la herramienta Foro, explicando en líneas generales sus características como herramienta asincrónica a través de la cual se puede crear un espacio para debatir, negociar, acordar y sintetizar ideas sobre algún tema. Se destacó a nivel del uso las características particulares en esta plataforma, y a nivel conceptual acerca de la importancia de colocar en forma adecuada el comentario dentro de la cadena de mensajes, respondiendo a un participante en particular o a la problemática general del foro, teniendo en cuenta además, la importancia de intentar sintetizar en el asunto (Título en SAVER) del mensaje el contenido del comentario.

Los tutores enviaron por mail a todos los participantes del curso un mensaje resumiendo el encuentro presencial, explicando en forma detallada lo referente a la utilización de las herramientas y la forma de trabajo en el curso:

Les damos la Bienvenida al curso "La Evaluación: reflexionando en nuestra práctica docente”, que comenzó el día de ayer con una primera clase presencial. Algunos de los temas que les indicamos fueron detallados en esa oportunidad, pero como algunos de Ustedes estuvieron ausentes, reiteramos algunas informaciones sobre el curso.

-- Se entregó un CD a cada alumno con material para utilizar en el curso. Hay un archivo en el CD que resume el contenido del mismo.

--Los presentes llenaron una encuesta.

El CD y la encuesta quedaron a cargo de la ayudante de laboratorio de informática del colegio, por favor comuníquense con ella para retirarlos y entregar la encuesta.

Utilizaremos para el desarrollo del curso la plataforma SAVER (Software de Asistencia Virtual para Educación Remota). La dirección de acceso es www.e-unicen.edu.ar/saver Al ingresar les pedirá usuario y nombre de clave, los que se encuentran en el archivo adjunto "Claves.doc". Al ingresar a la plataforma podrán a través del menú de la derecha cambiar su clave.

En el CD hay un archivo "Guía para el alumno.ppt" que les servirá de ayuda para trabajar en la plataforma.

La primera Actividad (que se encuentra en la plataforma en "desarrollo", opción del menú de la izquierda) consiste en una presentación personal que deberán realizar en el Foro "Presentaciones".

El resto de las actividades deberán realizarlas en los espacios correspondientes a cada grupo de trabajo (identificado con un color). La descripción de los grupos se adjunta en el archivo "Grupos.doc".

Recuerden mirar el "Tablón de anuncios" para informarse sobre las actividades y sus fechas.

Ante cualquier inconveniente o duda pueden comunicarse por mail, o a través del espacio "preguntas frecuentes" de la plataforma.

Saludos cordiales 


\subsection{Sistema de Actividad 0.2 (Presentación social)}

En el área de contenidos de la plataforma se publicó el enunciado de la actividad, se indicó la herramienta a utilizar y se sugirieron además algunos puntos para comentar en el mensaje de presentación. El Tablón de Novedades se actualizó con la información del lapso de tiempo asignado a la tarea: desde el 25/09/06 hasta el 01/10/06.

\section{Actividad 1:}

25/09/06

-Deberá realizar una presentación personal en el espacio Foro "Presentaciones".

Puede incluir en el mensaje su nombre, el cargo o materias y años en los que se desempeña como docente, además de cualquier otro dato o comentario que considere apropiado.

\subsubsection{Análisis de los factores que caracterizan el desarrollo de procesos colaborativos (Ingram y Hathorn, 2004)}

Como se mencionó en el Capítulo IV , los alumnos serán identificados como Ai (i representa un número) con el fin de no dar a conocer su nombre y poder realizar el seguimiento de las actuaciones individuales.

\subsubsection{Participación}

En el transcurso de esta actividad seis docentes informaron que por no contar con el tiempo necesario para la realización del curso decidieron no comenzarlo, quedando un total de dieciséis docentes participantes.

En la Figura 6.1 se muestra la distribución discreta de las presentaciones a lo largo del período establecido para esta actividad. En el eje horizontal se indica el intervalo de tiempo de duración del SA dividido en lapsos de cinco días y en el eje vertical los alumnos, donde por ejemplo, el 10 representa al alumno A10. 


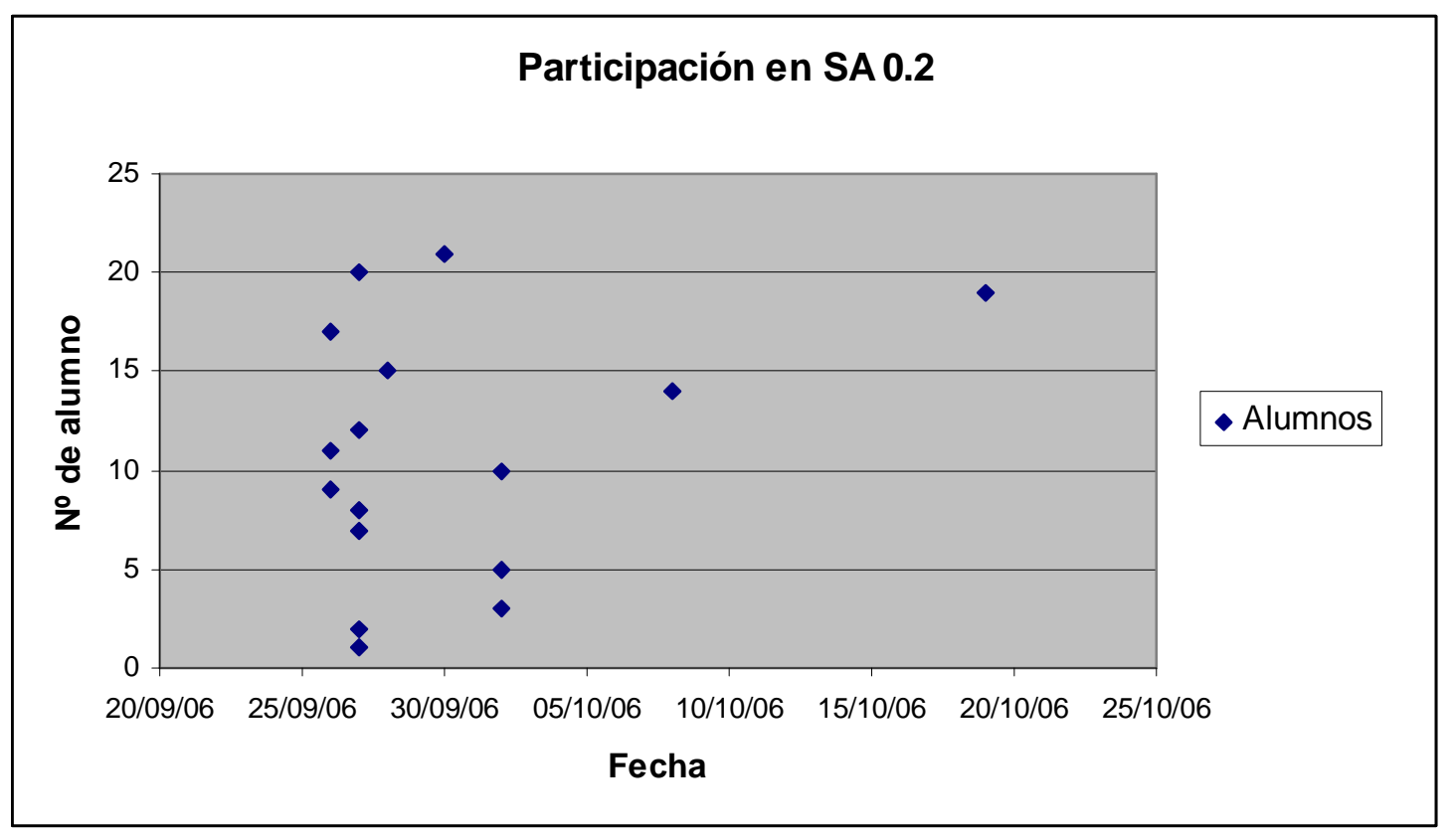

Figura 6.1: La participación de los alumnos en el SA 0.2 (Presentación social)

Todos los participantes contribuyeron a la actividad, dos de ellos intervinieron fuera de la fecha establecida (Figura 6.1). Se observa que los mensajes publicados en el foro fueron consultados en sesenta y nueve oportunidades, manifestándose un gran interés por conocer las presentaciones de los otros integrantes. En el foro se exhibe la cantidad de visitas que se registran, pero no se puede identificar quién realiza cada acceso. La plataforma SAVER cuenta con una herramienta asistencia que detalla la siguiente información: alumno, fecha, hora de ingreso y salida de la plataforma, pero no ofrece posibilidad de realizar un seguimiento detallado de las operaciones que realiza cada alumno.

La mayoría de los mensajes se limitaron a incluir los contenidos que se sugerían en la actividad. Sin embargo, se destaca en algunos no sólo el interés por la temática del curso sino también cierta expectativa sobre el trabajo colaborativo online como se puede apreciar en los siguientes textos extraídos del foro:

... "Mi interés en este curso es doble: por un lado, por la temática en sí (siempre sentí que la evaluación era lo que peor hacía/hacíamos!) y, por otro, compartir una experiencia de esta naturaleza con gente que también se preocupa por el tema." A2

..." Espero, además de trabajar en el tema de evaluación, generar nuevos vínculos para el trabajo en equipo en la escuela." A7

...” ¡Que buena la idea de encontrarnos cooperativamente!” A10 
..."Me parece muy interesante no sólo el tema sobre el que vamos a trabajar sino también la experiencia que tendremos y espero que nos sirva para mejorar nuestra práctica y para generar un espacio de trabajo conjunto." Al4

\subsubsection{Interacción}

Si bien en esta etapa se propuso la participación a través de un único mensaje, por lo cual las características propias de la actividad limitaban la interacción entre los miembros, se observa cierta interacción surgida a través de la lectura de los mensajes anteriores antes de publicar el propio. Se presentan a continuación ejemplos que evidencian la lectura de los mensajes anteriores y su consideración para realizar una nueva publicación (Tabla 6.1):

\section{Categoría Gestión de Grupo}

No se registran en la categoría gestión de grupo los indicadores consultar al grupo, compartir interpretaciones, argumentar, secuenciar, acordar, presentar alternativas, presentar síntesis de lo acordado, evaluar el avance del trabajo, tomar decisión, pedir aclaración, formular propuesta de trabajo.

\begin{tabular}{|c|c|}
\hline \multicolumn{2}{|r|}{ Categoría Integración Social } \\
\hline Indicadores & Ejemplos \\
\hline Motivar & $\begin{array}{l}\text { ”Mi nombre es A11, tengo } 28 \text { años, y soy estudiante de la carrera de Ingenieria } \\
\text { en Sistemas; ya terminada las cursadas.” A11 } \\
\text { ”Me llamo A9. Tengo } 29 \text { años.” A9 } \\
\text { “Soy A17. Tengo } 34 \text { años, estoy casada...” A17 } \\
\text { “Soy A8, profesora de Física de los alumnos de segundo año del Colegio. } \\
\text { Ni por casualidad pienso contarles cuántos años tengo!!!!...” A8 } \\
\text {..."Soy docente del Poli desde el año pasado y estoy con el grupo de } 2^{\circ} \text { año. } \\
\text { Ah!!! Tengo } 32 \text { años. Todavía los puedo decir!!!" A20 }\end{array}$ \\
\hline & los \\
\hline
\end{tabular}

Tabla 6.1: Funcionamiento de grupo. Ejemplos del SA 0.2

\subsubsection{Análisis holístico del SA 0.2 (Presentación social)}

El SA 0.2 (Presentación social) se encuentra relacionado estrechamente al SA 0.1 (Encuentro presencial), ya que en el encuentro presencial se compartieron las características globales del curso y sus componentes. Esta vinculación se manifiesta a través de los comentarios referidos tanto a la temática como a la metodología de trabajo 
que conforman el objeto del sistema de actividad general.

Se distingue la participación de dieciséis alumnos en la actividad respetando la mayoría de los participantes el plazo previsto, y la presencia de interacciones relacionadas a la dimensión integración social.

Desde este enfoque holístico, se destaca la importancia del desarrollo de la presente actividad que se convierte en input de la siguiente. Todas se encuentran relacionadas con el objetivo del SA 0. Por ello, cuando se acercaba el plazo previsto para esta actividad y no se habían presentado todos los docentes (alumnos del curso), los tutores se comunicaron por mail, con el fin de recordarles la importancia de su participación para avanzar en el objetivo general del curso relacionado con las capacidades y estrategias a desarrollar para el trabajo colaborativo:

Esta semana comienzan las actividades 2 y 3. Debido a la metodología de trabajo se requiere de la participación activa de todos los miembros del grupo. Les pido por favor me informen por mail si han tenido algún inconveniente para participar o han decidido no realizar el curso.

En un mail anterior se enviaron explicaciones generales acerca del desarrollo del curso, si no lo han recibido y no pueden incorporarse a las actividades que estamos desarrollando por favor comuníquense con nosotras.

Si al recibir este mail ya se han sumado a las actividades, no lo tengan en cuenta.

No duden en comunicarse...

Saludos cordiales

A este mail responden cinco docentes manifestando su intención de seguir con el curso. Dos de ellos no realizan la actividad y abandonan más tarde el curso. Un docente contesta expresando no poder realizar el curso y tres más comunican a través de la secretaría del colegio no poder comenzarlo. Todos ellos coinciden en que el motivo es la falta de tiempo para desarrollar las actividades. El curso cuenta entonces con dieciséis participantes.

\subsection{Sistema de Actividad 0.3 (Compartir anécdotas)}

Las actividades 2 y 3 correspondientes a los sistemas de actividad 0.3 (Compartir anécdotas) y 0.4 .1 (Elaborar Mapa Conceptual individual), se desarrollaron simultáneamente, en un plazo previsto desde el 02/10/06 al 12/10/06. 
A partir de estas actividades los participantes se agruparon en equipos asignándoles para su identificación un color. La formación de los grupos se realizó con el total inicial de 22 participantes, distribuidos en seis grupos: lila, rosa, gris, marrón, naranja y violeta, contando cuatro grupos con cuatro integrantes y dos con tres participantes. Los grupos vieron afectado su desempeño porque esta distribución original contemplaba a aquellas personas que al comienzo de este período anunciaron no realizar el curso. Una vez confirmado el número de participantes que deseaban proseguir se reagruparon los alumnos, se eliminó el grupo Marrón quedando el curso dividido en cuatro grupos de tres participantes y uno de cuatro integrantes.

Cada SA pensado para cada grupo se puede considerar como una instancia del sistema original. Para el SA 0.3 se observa entonces cinco instancias correspondientes a cada grupo.

En el área contenidos de la plataforma se publicó la Actividad 2 y se actualizó el Tablón de Novedades:

\section{Actividad 2:}

\section{2/10/06 al 12/10/06}

-Se han abierto foros de discusión para cada grupo de trabajo para llevar adelante la Actividad 2 ( Rosa-Act2, Naranja-Act2,...).

-Esta actividad consiste en contar anécdotas personales sobre cómo han sido evaluados durante su etapa de alumnos (en cualquiera de los niveles transitados) y/o anécdotas sobre episodios de copias en evaluaciones, tanto de aquellos años de estudiantes como copias detectadas en nuestra tarea como docentes.

Deberán publicar por lo menos una anécdota y realizar al menos un comentario sobre relatos publicados por los compañeros de grupo.

\subsubsection{Análisis de los factores que caracterizan el desarrollo de procesos colaborativos (Ingram y Hathorn, 2004)}

En el inicio del presente capítulo se mencionó que los procesos colaborativos de este curso se estudian a través de los factores participación, interacción y síntesis. Dado que el SA 0.3 (Compartir anécdotas) consiste en el desarrollo de una actividad que promueve la comunicación entre pares, se utilizan los instrumentos de análisis de 
interacción descriptos en el Capítulo IV: diagrama de flujo e indicadores de gestión de grupo e integración social.

Tomando como unidad de análisis los grupos de trabajo, se describe y analiza en primer lugar, la participación en todos los grupos. A continuación se analizan los resultados de la variable interacción obtenidos mediante los instrumentos de análisis.

Cada SA finaliza con un análisis holístico, a manera de síntesis. Además, se identifican las contradicciones entre los componentes del SA (Capítulo III, Pág. 44) y se infieren las posibles causas con el objeto de proponer estrategias para modificar dichos comportamientos.

\subsubsection{Participación}

El SA contemplaba como reglas la publicación de al menos dos mensajes, uno relatando una anécdota y otro comentando lo publicado por un compañero.

En la Figura 6.2 se puede observar la participación de cada alumno en la actividad en referencia a su grupo de trabajo.

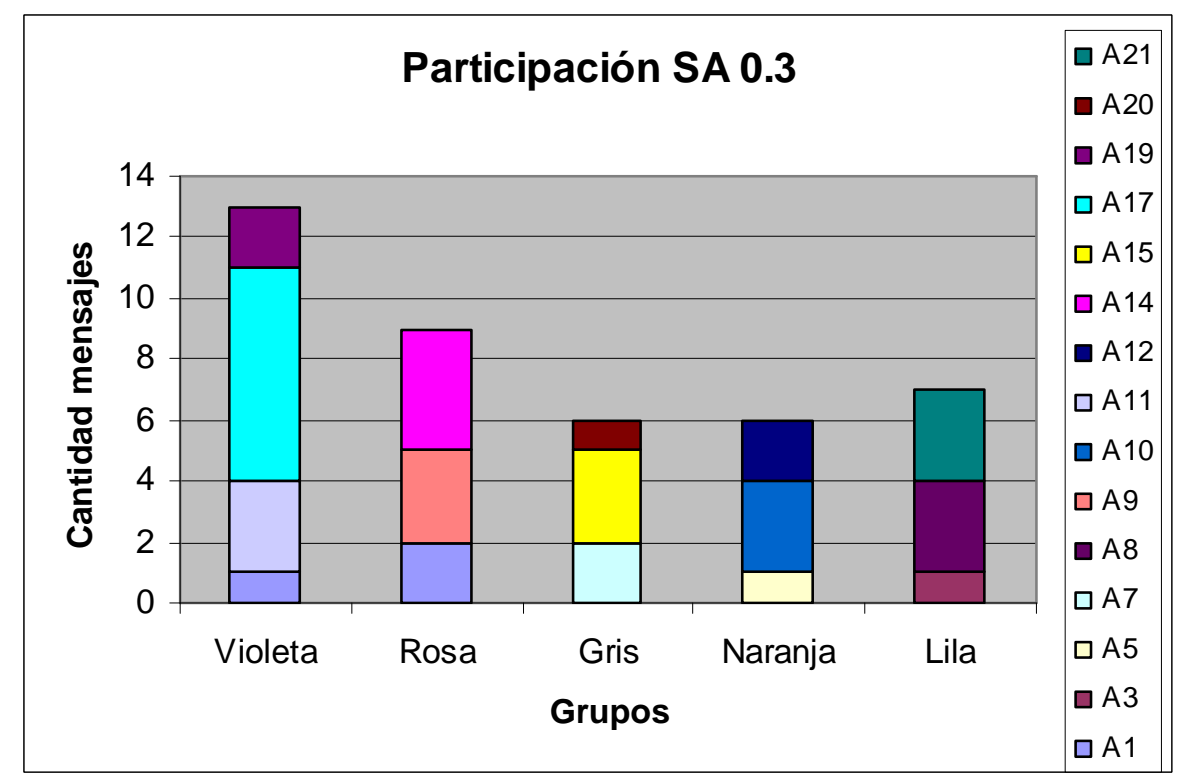

Figura 6.2: La participación de los alumnos por grupo en SA 0.3

El grupo violeta es el único que cuenta con cuatro participantes. A2 publicó un mensaje correspondiente a la anécdota y no realizó comentarios. Se destaca la 
participación de A17 con siete contribuciones, distribuidas en cuatro anécdotas y tres comentarios. Se realizaron un total de trece aportes, de los cuales dos fueron realizados por A19 fuera de término.

En el grupo rosa todos los alumnos cumplieron con la cantidad y tipo mínimo sugerido. Sólo el alumno A1 publicó sus mensajes fuera del plazo previsto. Se contabilizan en total nueve mensajes publicados.

El grupo gris registra cinco mensajes publicados. Se observa una participación adicional de A15 que contribuyó al foro de otro grupo, no respetando la regla que se refiere al ámbito de trabajo del grupo. Aunque en el momento en que se desarrolló el curso la plataforma no contaba con herramientas para trabajo en grupo específicas para restringir el ingreso de los alumnos a un grupo, se indicó en el enunciado de la actividad la apertura de un foro para cada equipo.

El grupo naranja desarrolló la actividad en los plazos previstos. Si bien se registra una sola contribución de A5, la misma incluyó una anécdota y un comentario. Los restantes integrantes publicaron tres y dos mensajes respectivamente, totalizando el grupo un total de seis mensajes.

A3 participó en el grupo lila sólo con un mensaje correspondiente al relato de una anécdota. Los otros dos participantes se desempeñaron respetando las reglas, A8 publicó un mensaje con una anécdota y dos con comentarios, y A21 contribuyó al foro del grupo con el relato de dos anécdotas y un comentario que sumó un total de siete mensajes publicados. Otra de las reglas que afecta tanto a la participación como a la interacción es la que propone participar en los lapsos de tiempo estipulados. En relación a esta regla sólo un participante publicó un comentario fuera de término.

\subsubsection{Interacción}

El análisis de la interacción se realiza mediante la aplicación de los instrumentos diagrama de flujo y las categorías de funcionamiento de grupo a cada equipo de trabajo. Como se mencionó en el Capítulo IV, se utiliza el diagrama de flujo para contribuir a la interpretación de las interacciones a partir de la visualización del proceso de manera gráfica, y se intenta a través de los indicadores de las categorías de funcionamiento de 
grupo identificar aquellas estrategias y habilidades de los participantes que contribuyen a la dinámica del proceso de colaboración.

\section{$\underline{\text { Grupo Violeta }}$}

\section{Diagrama de flujo de interacciones}

Este grupo se distingue por la participación del alumno A15 perteneciente al grupo gris, que interfiere en las interacciones al recibir un comentario por parte de A19 (Fig. 6.3).

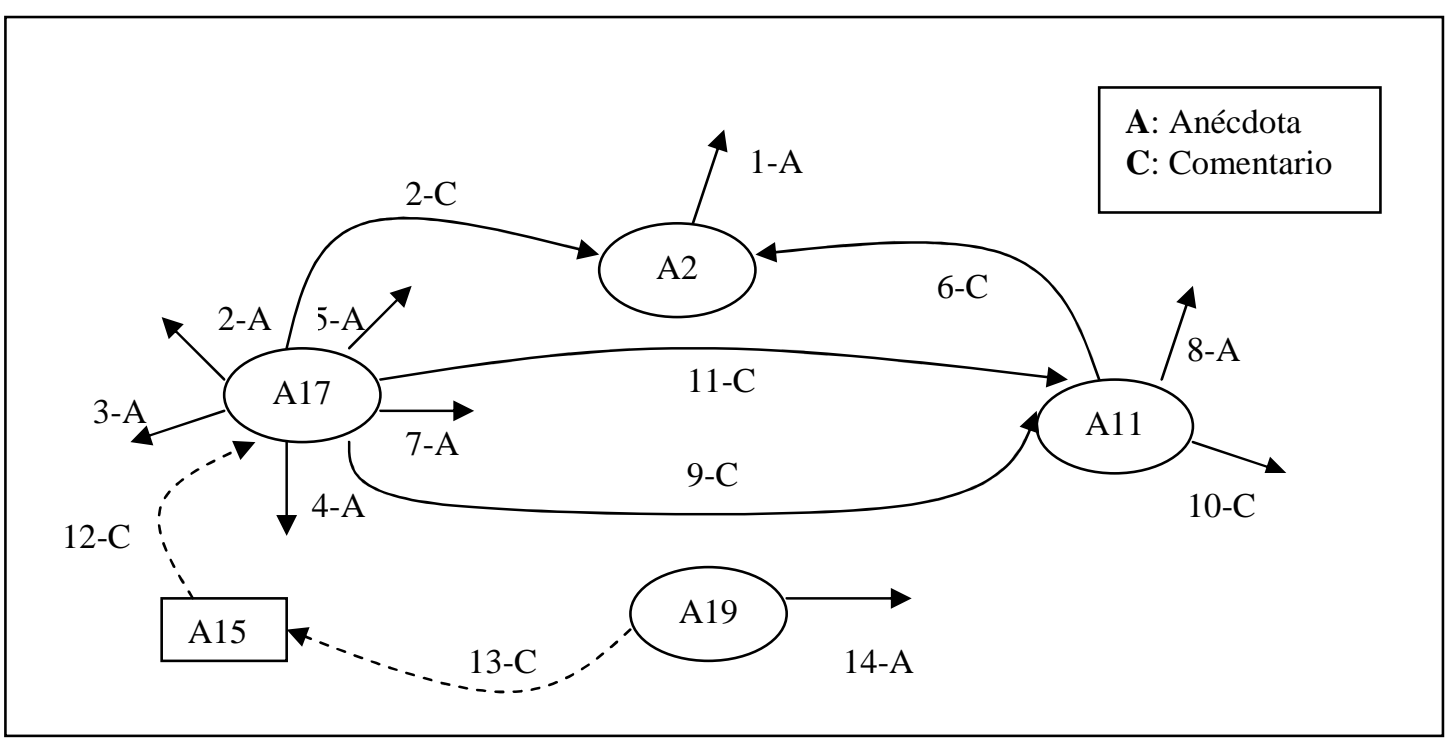

Figura 6.3: Diagrama de flujo de las interacciones entre los participantes del foro Violeta-Act2, indicando orden, dirección y tipo de mensaje.

\section{Funcionamiento de Grupo: Categorías e Indicadores}

\begin{tabular}{|c|c|}
\hline \multicolumn{2}{|r|}{ Categoría Gestión de Grupo } \\
\hline Indicadores & Ejemplos \\
\hline $\begin{array}{c}\text { Compartir } \\
\text { interpretaciones }\end{array}$ & $\begin{array}{l}\text {..."He tratado de valerme siempre de estas experiencias de las que rescato, en } \\
\text { este caso, que no sirve hacer preguntas cuyas respuestas sean sólo una } \\
\text { palabra... porque creo que no refleja mucho de lo que el alumno estudió"... A17 } \\
\text {..."Pero creo que la copia sirve para saber qué es lo que no se está } \\
\text { entendiendo"... A17 } \\
\text {..."El machete te ayuda a estudiar porque tenés que extraer la idea principal y } \\
\text { los conceptos de manera que entren en un diminuto papel que generalmente no } \\
\text { utilizas porque te lo acordás de cuando lo armaste"... Al5 }\end{array}$ \\
\hline
\end{tabular}




\begin{tabular}{|c|c|}
\hline & Categoría Gestión de Grupo \\
\hline Indicadores & Ejemplos \\
\hline Acordar & $\begin{array}{l}\text {..."Es cierto lo que decís A11, sobre aprenderse el machete de los nervios que } \\
\text { provoca usarlo!"... A17 } \\
\text {..."Coincido, ya que para armar un "ayudamemoria" es necesario aplicar } \\
\text { criterios de comprensión de estructuras y síntesis"... A19 }\end{array}$ \\
\hline \multicolumn{2}{|c|}{$\begin{array}{l}\text { No se registran en la categoría gestión de grupo los indicadores consultar al grupo, argumentar, } \\
\text { secuenciar, presentar alternativas, presentar síntesis de lo acordado, evaluar el avance del trabajo, tomar } \\
\text { decisión, pedir aclaración, formular propuesta de trabajo. }\end{array}$} \\
\hline \multicolumn{2}{|r|}{ Categoría Integración Social } \\
\hline Indicadores & Ejemplos \\
\hline Motivar & $\begin{array}{l}\text {...”Me encantó la anécdota!!”... A17 } \\
\text {...”Es muy gracioso copiarse en música!!!"”... A11 }\end{array}$ \\
\hline $\mathrm{o} \mathrm{se}$ & los indicadores involucra \\
\hline
\end{tabular}

Tabla 6.2: Funcionamiento de grupo. Ejemplos del SA 0.3 - Grupo Violeta.

\section{$\underline{\text { Grupo Rosa }}$}

\section{Diagrama de flujo de interacciones}

En la Figura 6.4 se pueden visualizar las dos interacciones (flechas 8-C y 4-C) generadas en el grupo rosa al desarrollar la actividad.

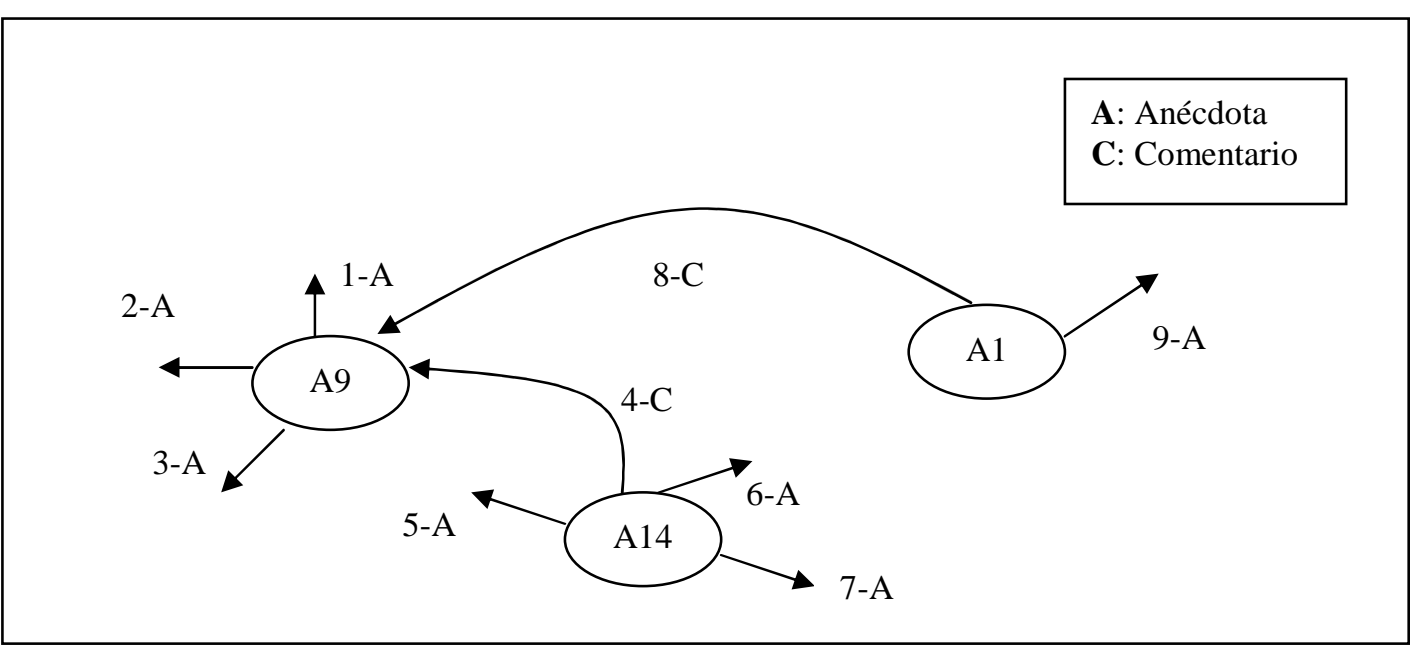

Figura 6.4: Diagrama de flujo de las interacciones entre los participantes del foro Rosa-Act2, indicando orden, dirección y tipo de mensaje.

Para un análisis contextualizado se debe tener en cuenta las fechas en que se han realizado las participaciones. El alumno A9 publicó sus contribuciones del 3 al 9 de 
octubre, y luego no volvió a participar. El alumno A14 intervino solamente el día 12 (fecha de cierre de la actividad). El alumno A1 participó un día posterior al período previsto para el desarrollo de la actividad. En una de las reglas para esta actividad se indica la participación dentro del lapso de tiempo prefijado, habiéndose resaltado en la clase inicial presencial la importancia de una participación más o menos equitativa entre los integrantes del grupo para favorecer procesos de interacción.

El hecho que la plataforma no cuente con herramientas específicas para el trabajo colaborativo permitió a los participantes poder ver e incluso intervenir en el foro de otro grupo, a pesar que una de las reglas del SA contemplaba trabajar sólo en el grupo asignado.

El alumno A9 se refiere a contribuciones de otros grupos:

..."En general era considerada como A17 y A2 decían, una "buena" alumna, de las que dictaba o permitía que las demás se copien..." A9

..."Después, no me di cuenta en otras ocasiones de situaciones parecidas, aunque reconozco que las debe haber y no las registro como decía A20 y alguien más..." A9

Funcionamiento de Grupo: Categorías e Indicadores

\begin{tabular}{|c|c|}
\hline \multicolumn{2}{|r|}{ Categoría Gestión de Grupo } \\
\hline Indicadores & Ejemplos \\
\hline Consultar al grupo & $\begin{array}{l}\text {..."Bueno, espero que aparezca algún compañero de grupo que me diga algo"... } \\
\text { A9 }\end{array}$ \\
\hline $\begin{array}{l}\text { Compartir } \\
\text { interpretaciones }\end{array}$ & $\begin{array}{l}\text {..” He sido evaluada de muchas maneras diferentes. Entre las que más me han } \\
\text { gustado están los exámenes orales de la facultad, no los de preparar un tema, } \\
\text { sino los que hay que pensar y responder o elaborar en el momento. Creo que } \\
\text { son con los que más sufí pero los que mejor me dejaron después...” A9 } \\
\text {..”En mi experiencia también rescato las evaluaciones orales y en particular } \\
\text { aquéllas en las que tenemos que justificar lo que hemos realizado o elaborar un } \\
\text { juicio sobre alguna cuestión. Les confieso que cuando comencé el profesorado } \\
\text { me costó muchísimo el cambio de modalidad. Estaba acostumbrada en } \\
\text { Ingeniería a exámenes en general escritos, en los que había que resolver } \\
\text { ejercicios, a veces muy complejos y no sabíamos hasta varios días después cuál } \\
\text { había sido el resultado”... Al4 } \\
\text {... Entiendo que muchas veces, aunque cada vez menos, queda eclipsada en la } \\
\text { práctica didáctica por la importancia que se le da, habitualmente, a los } \\
\text { contenidos conceptuales. Paradójicamente parece que en tu curso de postgrado } \\
\text { se intenta algo en este sentido pero por tu percepción parece que no alcanza...” } \\
\text { Al }\end{array}$ \\
\hline
\end{tabular}




\begin{tabular}{|c|c|}
\hline \multicolumn{2}{|r|}{ Categoría Gestión de Grupo } \\
\hline Indicadores & Ejemplos \\
\hline Acordar & ..."Coincido con vos A9 en lo que decís sobre el tipo de evaluaciones...” A14 \\
\hline \multicolumn{2}{|c|}{$\begin{array}{l}\text { No se registran en la categoría gestión de grupo los indicadores argumentar, secuenciar, presentar } \\
\text { alternativas, presentar síntesis de lo acordado, evaluar el avance del trabajo, tomar decisión, pedir } \\
\text { aclaración, formular propuesta de trabajo. }\end{array}$} \\
\hline \multicolumn{2}{|r|}{ Categoría Integración Social } \\
\hline Indicadores & Ejemplos \\
\hline $\begin{array}{l}\text { Contestar a un } \\
\text { compañero }\end{array}$ & $\begin{array}{l}\text { "A9: } \\
\text { Primero me disculpo por la demora de este comentario..." A1 } \\
\text {..."Bueno, espero que les haya gustado la anécdota y te prometo A9 que a } \\
\text { partir de ahora voy a participar de manera más fluida en este grupo..." A14 }\end{array}$ \\
\hline est & $\begin{array}{l}\text { ría integración social los indicadores mot } \\
\text { area grupal. }\end{array}$ \\
\hline
\end{tabular}

Tabla 6.3: Funcionamiento de grupo. Ejemplos del SA 0.3 - Grupo Rosa.

\section{Grupo Gris}

\section{Diagrama de flujo de interacciones}

Todos los integrantes del grupo contribuyen con anécdotas al foro, pero sólo se registra un mensaje con un comentario entre los participantes (Fig. 6.5). La interacción se vio afectada por la contribución de A15 de un comentario en otro equipo.

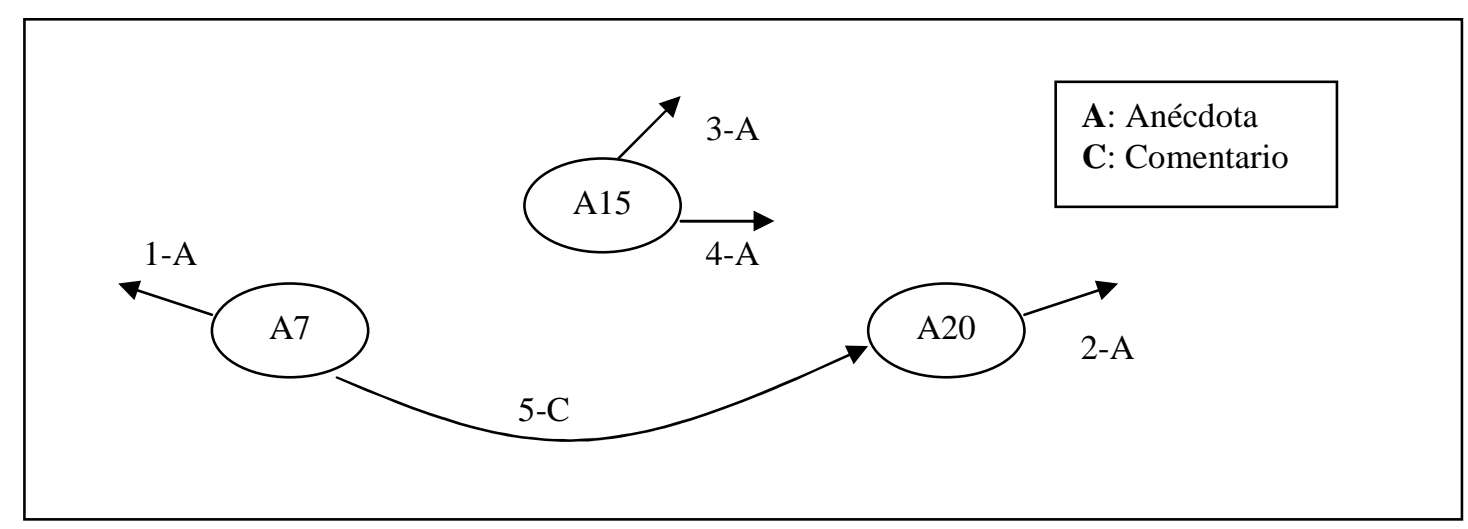

Figura 6.5: Diagrama de flujo de las interacciones entre los participantes del foro Gris-Act2, indicando orden, dirección y tipo de mensaje.

\section{Funcionamiento de Grupo: Categorías e Indicadores}




\begin{tabular}{|c|c|}
\hline \multicolumn{2}{|r|}{ Categoría Gestión de Grupo } \\
\hline Indicadores & Ejemplos \\
\hline $\begin{array}{l}\text { Compartir } \\
\text { interpretaciones }\end{array}$ & $\begin{array}{l}\text {..."Esas buenas experiencias no tienen como indicadores centrales a un buen } \\
\text { profesor o el mayor o menor gusto por una materia, o la forma en la que el } \\
\text { profesor encaraba el exámen, no. } \\
\text { Por supuesto que esas cuestiones juegan un papel importante, pero me parece } \\
\text { que el más relevante (para que yo tenga este buen recuerdo) es lo que me } \\
\text { pasaba como estudiante. Es ese momento en el que uno sabe que tiene que } \\
\text { comprender globalmente, que revisa todo junto, que comienza a ver las } \\
\text { relaciones entre temas, autores, ideas, que antes no veía, justamente porque no } \\
\text { había realizado esta nueva "mirada" que requiere una evaluación"... A7 }\end{array}$ \\
\hline \multicolumn{2}{|r|}{ Categoría Gestión de Grupo } \\
\hline Indicadores & Ejemplos \\
\hline Acordar & $\begin{array}{l}\text {.." quizás como dice A7 hay alguna negación por mi parte o los chicos han } \\
\text { encontrado maneras distintas de copiarse!!!!”... A20 }\end{array}$ \\
\hline \multicolumn{2}{|c|}{$\begin{array}{l}\text { No se registran en la categoría gestión de grupo los indicadores consultar al grupo, argumentar, } \\
\text { secuenciar, presentar alternativas, presentar síntesis de lo acordado, evaluar el avance del trabajo, tomar } \\
\text { decisión, pedir aclaración, formular propuesta de trabajo. }\end{array}$} \\
\hline \multicolumn{2}{|r|}{ Categoría Integración Social } \\
\hline Indicadores & Ejemplos \\
\hline Motivar & $\begin{array}{l}\text {.."hay tanto para debatir sobre este tema..me gusta lo que estamos } \\
\text { haciendo"... A20 }\end{array}$ \\
\hline $\begin{array}{l}\text { Contestar a un } \\
\text { compañero }\end{array}$ & $\begin{array}{l}\text {..."Leía tu experiencia en la facultad, A20, y pensaba que en mi caso la } \\
\text { experiencia de los exámenes finales fue diferente. Hoy me doy cuenta que eran } \\
\text { importantes momentos de aprendizaje”....A7 }\end{array}$ \\
\hline & oría integración social los indicadores involucrar al grupo, m \\
\hline
\end{tabular}

Tabla 6.4: Funcionamiento de grupo. Ejemplos del SA 0.3 - Grupo Gris.

\section{Grupo Naranja}

\section{Diagrama de flujo de interacciones}

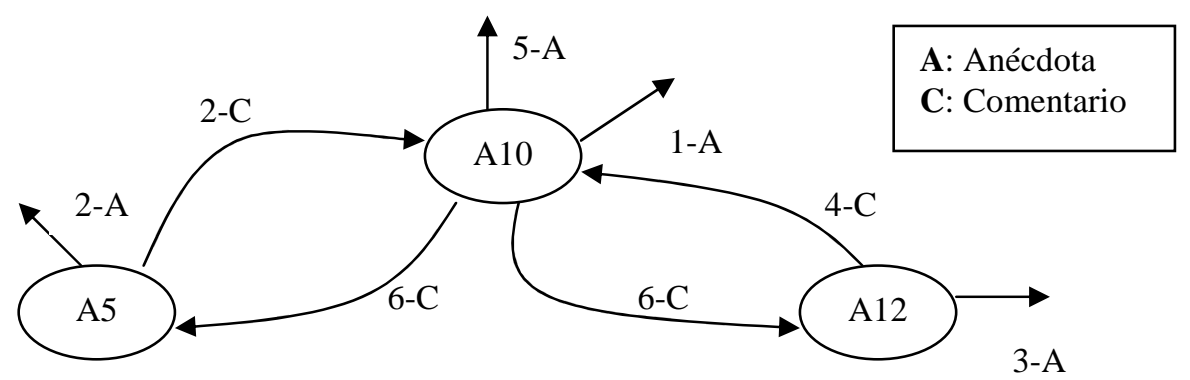

Figura 6.6: Diagrama de flujo de las interacciones entre los participantes del foro Naranja-Act2, indicando orden, dirección y tipo de mensaje. 
Se observa que los participantes intervinieron con comentarios acerca de las contribuciones de los compañeros, respetando la regla definida al respecto (Fig. 6.6).

Se puso de manifiesto la lectura de mensajes pertenecientes a otros grupos, no respetando la regla donde se indica trabajar sólo en el espacio de foro correspondiente al grupo:

...”Después de dos entradas leyendo las producciones de las compañeras yo también tengo que decir como A2"... A10

...”yo no soy del grupo de las buenas alumnas, me sumo al grupo de A3 aunque somos pocos"... A5

\section{Funcionamiento de Grupo: Categorías e Indicadores}

\begin{tabular}{|c|c|}
\hline \multicolumn{2}{|r|}{ Categoría Gestión de Grupo } \\
\hline Indicadores & Ejemplos \\
\hline $\begin{array}{l}\text { Compartir } \\
\text { interpretaciones }\end{array}$ & $\begin{array}{l}\text {... De las copias de mis alumnos, a veces desafíos adolescentes, otras } \\
\text { reaccionando ante presiones por la nota o por el ingreso en la universidad me } \\
\text { quedan enseñanzas: como adulto responsable hacerme cargo, sancionar la } \\
\text { copia y reflexionar con ellos que así no es, pero sin enojos. Además hacerle } \\
\text { entender que la evaluación es una instancia personalizada más de aprendizaje". } \\
\text { A10 } \\
\text {.."Por lo vivido, desde los marcos teóricos y por convicción ya como docente } \\
\text { nunca tomo una evaluación sin aviso(acordamos la fecha), no obligo a que } \\
\text { nadie la realice si considera que no está en condiciones, recomiendo y facilito } \\
\text { que tengan los materiales necesarios para trabajar, trato de crear un clima } \\
\text { cordial y de constituirme en consultor de lo que necesiten (en algunos casos } \\
\text { bajar la ansiedad o ayudarlos a pensar)." Alo }\end{array}$ \\
\hline Acordar & $\begin{array}{l}\text {.." con respecto a las copias de los chicos, coincido con A10 que en esta } \\
\text { escuela vivimos cada cosa"... A5 }\end{array}$ \\
\hline \multicolumn{2}{|c|}{$\begin{array}{l}\text { No se registran en la categoría gestión de grupo los indicadores consultar al grupo, argumentar, } \\
\text { secuenciar, presentar alternativas, presentar síntesis de lo acordado, evaluar el avance del trabajo, tomar } \\
\text { decisión, pedir aclaración, formular propuesta de trabajo. }\end{array}$} \\
\hline \multicolumn{2}{|r|}{ Categoría Integración Social } \\
\hline Indicadores & Ejemplos \\
\hline $\begin{array}{l}\text { Involucrar al } \\
\text { grupo }\end{array}$ & $\begin{array}{l}\text {.." Leyendo nuevamente nuestras intervenciones me parece que compartimos el } \\
\text { recuerdo de experiencias que evidentemente están influenciando nuestra vida } \\
\text { profesional.Y que ante alguna "soplada" o copia de nuestros alumnos no } \\
\text { podemos decir "yo nunca" "no sé de que se trata"... Alo }\end{array}$ \\
\hline $\begin{array}{l}\text { Contestar a un } \\
\text { compañero }\end{array}$ & “A10 si pensabas que había terminado tu etapa de evaluacion”... A12 \\
\hline \multicolumn{2}{|c|}{$\begin{array}{l}\text { No se registran en la categoría integración social los indicadores motivar, manifestar compromiso con la } \\
\text { tarea grupal. }\end{array}$} \\
\hline
\end{tabular}

Tabla 6.5: Funcionamiento de grupo. Ejemplos del SA 0.3 - Grupo Naranja. 


\section{Grupo Lila}

\section{Diagrama de flujo de interacciones}

Se observa que el alumno A3 publicó una anécdota, y si bien recibió comentarios de sus compañeros, no los contestó ni realizó observaciones sobre las otras anécdotas (Fig. 6.7). Consultados sus ingresos a la plataforma, a través de la herramienta Asistencia, se observa que lo hizo en dos oportunidades más después de publicar su anécdota, y éstas fueron anteriores a las intervenciones de los otros miembros.

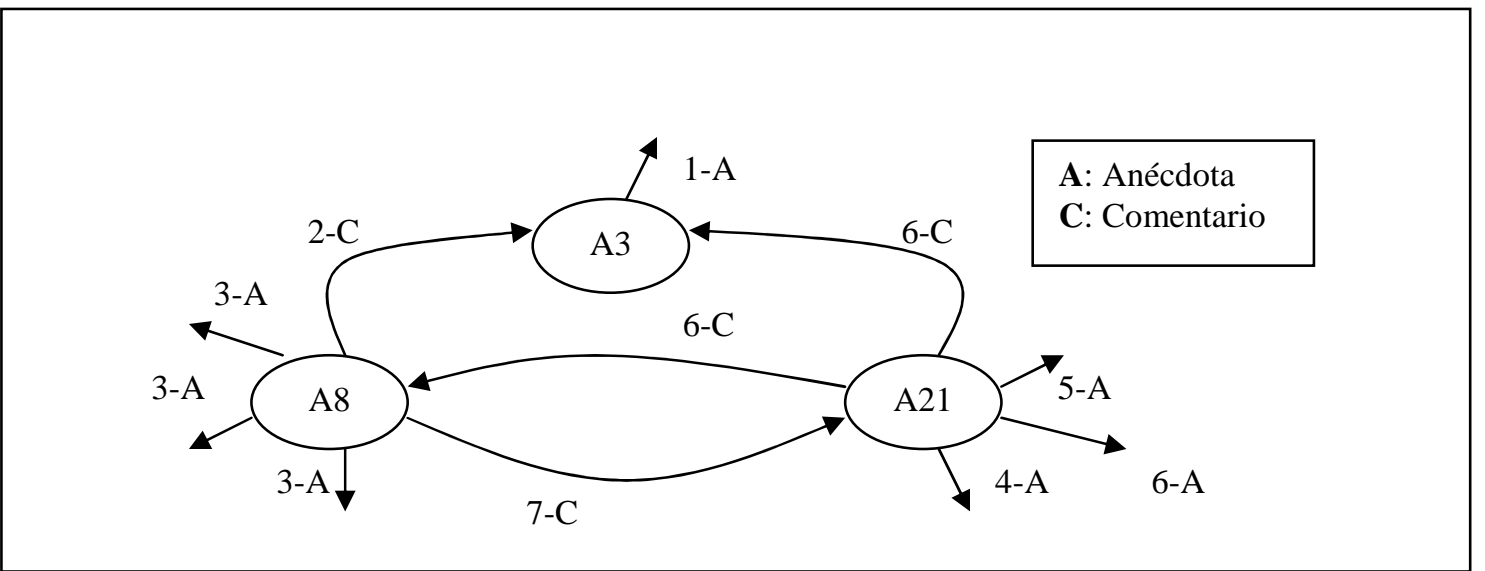

Figura 6.7: Diagrama de flujo de las interacciones entre los participantes del foro Lila-Act2, indicando orden, dirección y tipo de mensaje.

\section{Funcionamiento de Grupo: Categorías e Indicadores}

\begin{tabular}{|c|c|}
\hline \multicolumn{2}{|r|}{ Categoría Gestión de Grupo } \\
\hline Indicadores & Ejemplos \\
\hline $\begin{array}{l}\text { Compartir } \\
\text { interpretaciones }\end{array}$ & $\begin{array}{l}\text { ”... Opino que lo mejor es asumir que se trata de una tarea subjetiva y } \\
\text { repetirnos esto una y otra vez, como para tratar de tomar la debida conciencia } \\
\text { de cada caso. “A8 } \\
\text { “...de la imposibilidad de pensar que la evaluación (aún cuando escrita) pueda } \\
\text { considerarse objetiva. Aún cuando un nombre (que no era tu caso) no nos diga } \\
\text { nada, la letra, la organización que ha seguido, a veces, la presentación, son } \\
\text { todos elementos que conspiran contra la supuesta objetividad...” A8 }\end{array}$ \\
\hline Acordar & “...Como dice A8, es muy difícil no ser subjetivo a la hora de evaluar...” A21 \\
\hline \multicolumn{2}{|c|}{$\begin{array}{l}\text { No se registran en la categoría gestión de grupo los indicadores consultar al grupo, argumentar, } \\
\text { secuenciar, presentar alternativas, presentar síntesis de lo acordado, evaluar el avance del trabajo, tomar } \\
\text { decisión, pedir aclaración, formular propuesta de trabajo. }\end{array}$} \\
\hline \multicolumn{2}{|r|}{ Categoría Integración Social } \\
\hline Indicadores & Ejemplos \\
\hline Motivar & $\begin{array}{l}\text { “Hola A21 bienvenida al grupo!!!!..” ...” Me encantó lo de la lapicera!!! A8 (en } \\
\text { referencia a una anécdota) }\end{array}$ \\
\hline
\end{tabular}




\begin{tabular}{|c|c|}
\hline \multicolumn{2}{|r|}{ Categoría Integración Social } \\
\hline Indicadores & Ejemplos \\
\hline $\begin{array}{l}\text { Involucrar al } \\
\text { grupo }\end{array}$ & $\begin{array}{l}\text { "No me digan que nunca les preguntaron éso!" (refiriéndose al asunto del } \\
\text { mensaje: Cuántas verdaderas y cuántas falsas hay"), A21 }\end{array}$ \\
\hline $\begin{array}{l}\text { Contestar a un } \\
\text { compañero }\end{array}$ & $\begin{array}{l}\text { “...Leo tu anécdota y no puedo más que pensar en lo difícil que resulta ser } \\
\text { medianamente justos como profesores...” A8 } \\
\text { “He dedicado un tiempo a leer las anécdotas y son geniales, creo que la de A3 } \\
\text { es la que más me preocupa a mí como docente. Como dice A8 es muy difícil ser } \\
\text { objetivo...” A21 }\end{array}$ \\
\hline $\begin{array}{c}\text { Manifestar } \\
\text { compromiso con la } \\
\text { tarea grupal }\end{array}$ & $\begin{array}{l}\text { “...no respondí antes porque estuve afuera y si bien consultaba el mail, el } \\
\text { tiempo no me alcanzaba para entrar en este sitio y dar mi opinión...” A8 }\end{array}$ \\
\hline
\end{tabular}

Tabla 6.6: Funcionamiento de grupo. Ejemplos del SA 0.3 - Grupo Lila.

\subsubsection{Análisis holístico del SA 0.3 (Compartir anécdotas)}

Se han estudiado los factores participación e interacción en relación a lo actuado en cada foro de grupo. Se observa la participación de todos los integrantes en cada grupo, destacándose el desempeño del grupo naranja en el cual todos los miembros respetaron la consigna de trabajo. En los grupos lila, rosa y violeta se observa que un integrante no realiza comentarios a sus compañeros, y por último, en el equipo gris sus integrantes publican anécdotas pero sólo uno realiza un comentario.

Uno de los objetos del SA 0 considera la importancia de desarrollar habilidades tales como toma de decisiones, construcción consensuada, tratamiento del conflicto y estrategias de comunicación para poder realizar una experiencia de trabajo colaborativo (Graham y Misanchuk, 2004): promover en los docentes el desarrollo de estrategias y habilidades que favorezcan la evolución de procesos colaborativos de aprendizaje online.

Para favorecer el logro de este objetivo en el SA 0.3 se plantea: favorecer la utilización del Foro de discusión como herramienta para compartir e intercambiar información y posturas personales en referencia a un tema.

De esta manera cobra especial relevancia el estudio de la dimensión funcionamiento de grupo, que permite indagar a través del análisis de los ejes gestión de grupo e integración social aquellas estrategias y habilidades que favorecen procesos de 
colaboración (Cenich y Santos, 2006). En la Tabla 6.7 se puede apreciar el resumen de los indicadores que se hallaron en el estudio de los foros realizados por los grupos. Se observa en la categoría gestión de grupo que en todos los equipos se publicaron mensajes donde los participantes compartían sus interpretaciones y en la mayoría contribuciones donde se expresaban acuerdos. La categoría integración social permite apreciar la interacción generada a partir de la lectura de los mensajes de los compañeros y la intervención en consecuencia a través del indicador contestar a un compañero, que se manifestó en los mensajes de la mayoría de los grupos. Se observa además que se registraron mensajes relacionados a los indicadores motivar e involucrar al grupo, notándose sólo en uno la presencia del indicador manifestar compromiso con la tarea grupal.

En referencia al otro objetivo del SA 0: reflexionar, negociar y acordar los conceptos de evaluación, calificación y acreditación en el proceso enseñanza y aprendizaje en el aula, en dos dimensiones: una pedagógica y otra institucional y social.

Se propone en el SA 0.3: reflexionar sobre los conceptos de evaluación, calificación y acreditación en el proceso enseñanza y aprendizaje en relación a sus experiencias.

Se notó en algunos mensajes el tratamiento de conceptos referidos al tema de evaluación a través de los indicadores Compartir interpretaciones y Acordar, a partir de la reflexión sobre anécdotas propias o de otros compañeros.

Así, el tercer objetivo del sistema correspondiente a esta actividad: promover la familiarización de los miembros con el entorno virtual.

Se desarrolla en forma complementaria a los anteriores, contribuyendo de esta manera al logro de los objetivos del SA curso.

Como resultado de la experiencia se obtuvo de acuerdo a lo planteado:

Un documento de foro conteniendo el detalle de anécdotas personales sobre cómo fueron evaluados como alumnos, anécdotas de copias de evaluación de sus alumnos y los comentarios que realizaron los participantes.

En esta actividad los tutores realizaron una síntesis reflejando los aspectos destacados, acompañados de ejemplos extraídos de los mensajes de los foros. 


\begin{tabular}{|c|c|c|c|c|c|}
\hline \multicolumn{6}{|c|}{ Categoría: Gestión de grupo } \\
\hline \multirow[b]{2}{*}{ Indicadores } & \multicolumn{5}{|c|}{ Ejemplos de los grupos } \\
\hline & Violeta & Rosa & Gris & Naranja & Lila \\
\hline Consultar al grupo & & $\begin{array}{lr}\text {..."Bueno, } \\
\text { espero } \\
\text { aparezca } \\
\text { compañero } \\
\text { grupo"... } \\
\end{array}$ & & & \\
\hline $\begin{array}{l}\text { Compartir } \\
\text { interpretaciones }\end{array}$ & $\begin{array}{l}\text {..."He tratado de } \\
\text { valerme siempre } \\
\text { de estas } \\
\text { experiencias de } \\
\text { las que } \\
\text { rescato"... }\end{array}$ & $\begin{array}{l}\text {..."Entiendo que } \\
\text { muchas veces, } \\
\text { aunque cada vez } \\
\text { menos, queda } \\
\text { eclipsada en la } \\
\text { práctica } \\
\text { didáctica"... }\end{array}$ & $\begin{array}{l}\text {..."pero me } \\
\text { parece que el } \\
\text { más relevante } \\
\text { (para que yo } \\
\text { tenga este buen } \\
\text { recuerdo)"... }\end{array}$ & $\begin{array}{l}\text {.."me quedan } \\
\text { enseñanzas: } \\
\text { como adulto"... }\end{array}$ & $\begin{array}{l}\text { "...Opino que lo } \\
\text { mejor es asumir } \\
\text { que se trata de } \\
\text { una tarea } \\
\text { subjetiva"... }\end{array}$ \\
\hline Acordar & $\begin{array}{l}\text {..."Coincido, ya } \\
\text { que para } \\
\text { armar"... }\end{array}$ & $\begin{array}{l}\text {..."Coincido con } \\
\text { vos A9 en lo que } \\
\text { decís sobre"... }\end{array}$ & $\begin{array}{l}\text {.."quizás como } \\
\text { dice A7 hay } \\
\text { alguna } \\
\text { negación"... }\end{array}$ & $\begin{array}{l}\text {..."con respecto } \\
\text { a las copias de } \\
\text { los chicos, } \\
\text { coincido con } \\
\text { A10"... }\end{array}$ & \\
\hline \multicolumn{6}{|c|}{$\begin{array}{l}\text { No se registran en la categoría gestión de grupo los indicadores argumentar, secuenciar, presentar } \\
\text { alternativas, presentar síntesis de lo acordado, evaluar el avance del trabajo, tomar decisión, pedir } \\
\text { aclaración, formular propuesta de trabajo. }\end{array}$} \\
\hline \multicolumn{6}{|c|}{ Categoría: Integración social } \\
\hline \multirow{2}{*}{ Indicadores } & \multicolumn{5}{|c|}{ Ejemplos de los grupos } \\
\hline & Violeta & Rosa & Gris & Naranja & Lila \\
\hline Motivar & $\begin{array}{l}\text {..."Me encantó } \\
\text { la anécdota!!"... }\end{array}$ & & $\begin{array}{l}. . " m e \text { gusta lo } \\
\text { que estamos } \\
\text { haciendo"... }\end{array}$ & & $\begin{array}{l}\text { "Hola A21 } \\
\text { bienvenida al } \\
\text { grupo!!!..." }\end{array}$ \\
\hline Involucrar al grupo & & & & $\begin{array}{l}\text {...'Leyendo } \\
\text { nuevamente } \\
\text { nuestras } \\
\text { intervenciones } \\
\text { me parece que } \\
\text { compartimos"... }\end{array}$ & $\begin{array}{l}\text {..."No me digan } \\
\text { que nunca les } \\
\text { preguntaron } \\
\text { eso!"... }\end{array}$ \\
\hline $\begin{array}{l}\text { Contestar a un } \\
\text { compañero }\end{array}$ & & $\begin{array}{l}\text { "A9: } \\
\text { Primero me } \\
\text { disculpo por la } \\
\text { demora"... }\end{array}$ & $\begin{array}{l}\text {...'Leía tu } \\
\text { experiencia en la } \\
\text { facultad, A20, y } \\
\text { pensaba"... }\end{array}$ & $\begin{array}{l}\text { "A10 si } \\
\text { pensabas que } \\
\text { había terminado } \\
\text { tu etapa de } \\
\text { evaluacion"... }\end{array}$ & $\begin{array}{l}\text {...'Leo tu } \\
\text { anécdota y no } \\
\text { puedo más que } \\
\text { pensar"... }\end{array}$ \\
\hline $\begin{array}{l}\text { Manifestar } \\
\text { compromiso con la } \\
\text { tarea grupal }\end{array}$ & & & & & $\begin{array}{l}\text { "...no respondí } \\
\text { antes porque } \\
\text { estuve afuera" }\end{array}$ \\
\hline
\end{tabular}

Tabla 6.7: Funcionamiento de grupo. Ejemplos de SA 0.3

La evolución del SA se vio afectado por la presencia de contradicciones entre los componentes sujeto-reglas y sujeto-herramientas. Las reglas del sistema proponían:

-Trabajar en el espacio de foro correspondiente al grupo de área.

-Publicar al menos un mensaje con el relato de una anécdota.

-Publicar al menos un mensaje comentando la anécdota publicada por otro miembro del grupo. 
-Realizar las intervenciones en el lapso de tiempo prefijado.

Las normas fueron definidas con la intención de contribuir al desarrollo de procesos colaborativos que permitieran a los participantes avanzar hacia el logro del objetivo. Se observa a partir del análisis de la participación en los diferentes grupos que el no cumplimiento de alguna de las normas influyó tanto en la participación como en la interacción de los integrantes del equipo. Por ejemplo no participar en término, no publicar una contribución o hacerlo en el foro destinado a otro equipo, limita a los demás participantes para poder reflexionar a partir de la propuesta de un compañero y contestar o emitir comentarios sobre lo publicado.

Las dificultades que se les presentaron a los alumnos con el uso de las herramientas influyeron además en el cumplimiento de los plazos previstos, afectando las reglas del sistema. Surgió la necesidad de explicitar en el rol del tutor la asistencia que debe realizar al alumno tanto en la observación y cumplimiento de las reglas como en los problemas originados por el uso de las herramientas. Esta modificación se realiza en todos los sistemas de actividad definidos. A continuación se detalla un ejemplo relacionado a las contradicciones identificadas y cómo se intentó solucionarlas a través de la asistencia del tutor:

..."Tengo problemas para entrar a la plataforma. Estuve una semana sin computadora y no pude hacer las actividades. Ayer lo intenté y no pude y hoy pasa lo mismo. Cómo puedo hacer?"... A21 (mail enviado el mismo día que finalizaba la actividad)

En este caso, el tutor verificó el no funcionamiento de la plataforma, contactó a los responsables y en el mismo día se solucionó el problema, informando al alumno.

A los alumnos que no habían participado en fecha en la actividad se les envió el siguiente mail tanto a sus cuentas personales, como por webmail de la plataforma:

..."No han participado en la actividad 2 (Foro de anécdotas), si han tenido inconvenientes, por favor comuníquense con nosotras, dejaremos abierta hasta el lunes 16.

Los esperamos en los foros...” Tutores

Se modifica de esta manera el plazo previsto para la actividad, y se anima a comunicar cualquier inconveniente presentado. Uno de los alumnos contestó:

..."Efectivamente he tenido problemas con la plataforma, recién hoy terminé de "subir" las dos actividades solicitadas.

Pero mi mapa conceptual no puede ser abierto y no entiendo la causa.

Cualquier cosa me avisas, si puedo hacer algo. Gracias”... Al 


\subsection{Sistema de Actividad 0.4.1 (Elaborar Mapa Conceptual individual)}

Al mismo tiempo que se desarrolló el SA 0.3 (Compartir anécdotas) se realizó la actividad 3 (SA 0.4.1), con la intención de reflexionar sobre algunos conceptos relacionados con la evaluación en la medida que avanzaban los foros propuestos para llevar adelante el SA 0.3.

La presente actividad se propone obtener un resultado individual, asignando como sujeto al alumno. Para la publicación de la producción individual se utilizó el espacio en la plataforma asignado a cada grupo. El producto obtenido por cada alumno es insumo para el SA 0.4.

Actividad 3:

02/10/06 al 12/10/06

-Confeccionar un Mapa Conceptual (utilizando el software Cmap) que refleje sus ideas sobre evaluación.

A continuación se detalla una lista tentativa de conceptos (se pueden agregar u omitir conceptos):

recursos, proceso enseñanza aprendizaje, calificación, objetivos, conocimiento, error, tiempo, observación, diálogo, acreditación.

-Publicar el mapa conceptual como archivo de imagen en la carpeta correspondiente a su grupo de trabajo (Archivos y apuntes / Espacio compartido de trabajo).

Nota: para nombrar los archivos de los alumnos utilizaremos

"ActnApellido" por ejemplo Act3Cenich

\subsubsection{Análisis de los factores que caracterizan el desarrollo de procesos colaborativos (Ingram y Hathorn, 2004)}

\subsubsection{Participación}

Como se mencionó anteriormente, el SA 0.4.1 se corresponde con una actividad que los alumnos deben resolver de manera individual para luego compartir y discutir con sus pares de equipo. Esta estructura de actividad individual no pierde la noción de 
grupo: cada alumno hace una actividad individual como integrante de un grupo.

Los resultados se muestran en la Fig. 6.8, donde se puede apreciar los integrantes de cada grupo que contribuyeron con la publicación de su mapa conceptual discriminados por equipo.

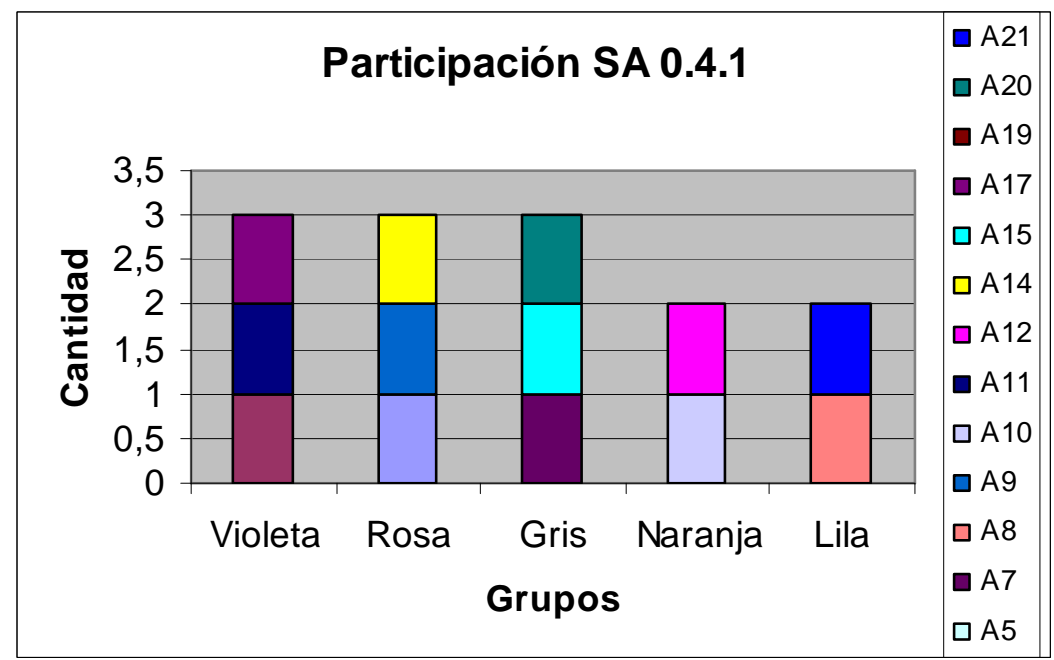

Figura 6.8: Participación en SA 0.4.1 por Grupo.

Se observa que de un total de 16 alumnos contribuyeron a la actividad 13 estudiantes. En los grupos violeta y gris participaron la totalidad de sus miembros.

Una vez finalizada la actividad, los tutores enviaron mails a los alumnos que no habían participado para indagar acerca de posibles inconvenientes y alentarlos a participar.

El equipo rosa no publicó su mapa conceptual el alumno A19, quien responde a los mails enviados por los tutores cinco días después de la fecha de finalización de la actividad, consultando acerca del software Cmap. Se reiteró la información dada al comienzo del curso acerca de los recursos con que cuenta el CD que se entregó al inicio, y se lo invitó a comunicarse con los tutores ante cualquier inconveniente alentándolo a participar. El alumno envió un mail ocho días más tarde agradeciendo el mensaje de los tutores y aludió que su retraso se debió a que no tenía conexión a Internet en su domicilio.

En el grupo naranja el alumno A5 manifestó haber estado muy ocupado con la preparación de un concurso de oposición docente, por lo que no realizó a tiempo su publicación. Expone su interés por completar la actividad y poder continuar con el 
curso.

En el grupo lila no participó el alumno A3, el cual no respondió a los mails enviados por los tutores y no manifestó por otro medio su intención de proseguir el curso.

\subsubsection{Análisis holístico del SA 0.4.1 (Elaborar Mapa Conceptual individual)}

La mayoría de los alumnos que participaron lograron realizar el mapa utilizando las posibilidades que ofrece el software, y de esta manera pudieron resaltar conceptos, ya sea a través del cambio en la tipografía o utilizando colores de fondo, establecer sentidos en la lectura del mapa a través del dibujo de flechas y reordenar los componentes a medida que el mapa era construido (Figura 6.9).

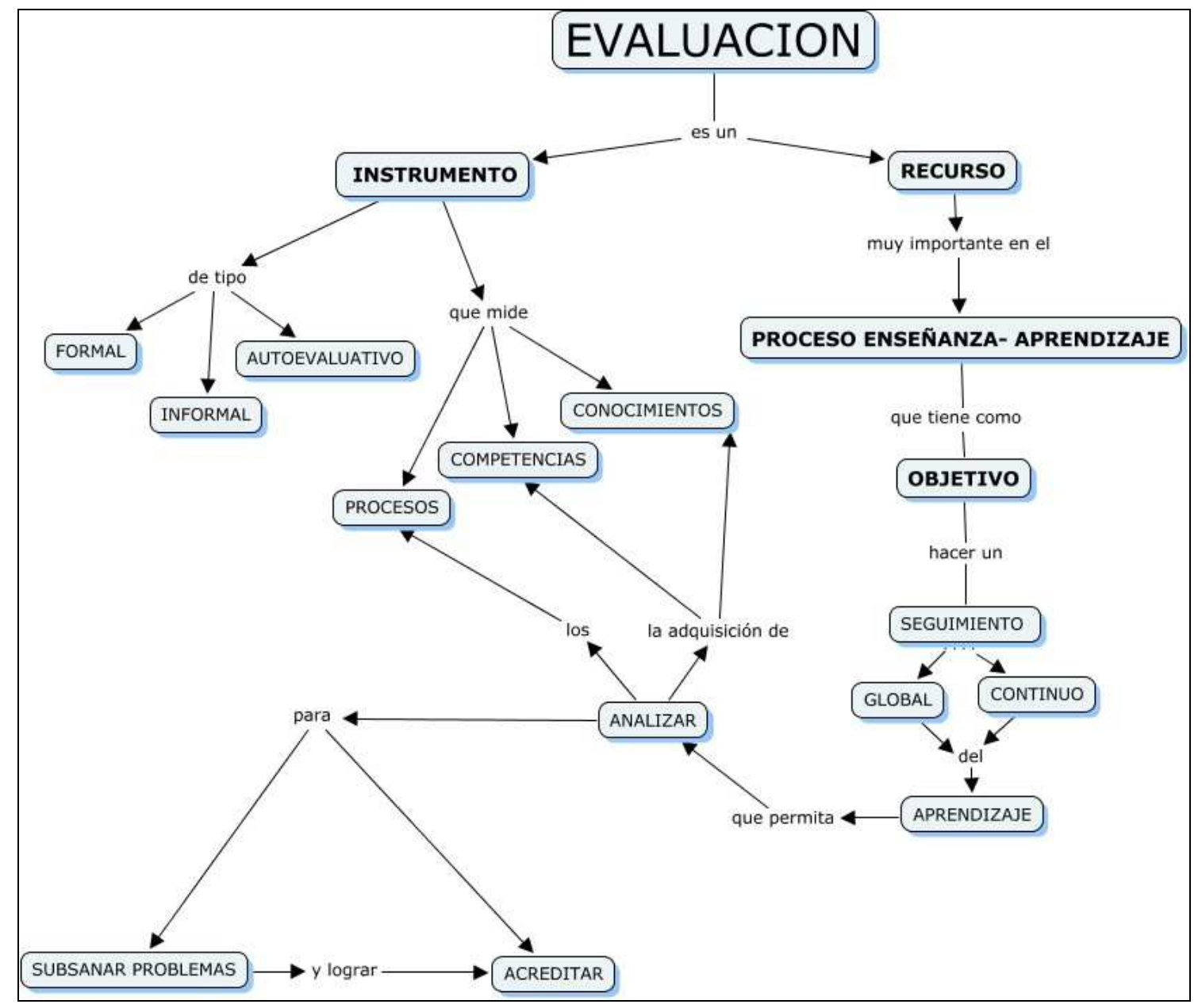

Figura 6.9: Mapa conceptual sobre evaluación - A21 
En cuanto al contenido de los mapas se observan dos posturas diferentes, una donde se tiene en cuenta la evaluación a nivel institucional y otra centrada en el aula. Si bien en la clase presencial se presentó el programa Cmap, se explicó su funcionamiento y los alumnos elaboraron un mapa de ejemplo manipulando las distintas opciones que ofrece la aplicación, se detectó en este SA una contradicción sujeto-herramientas que se puso de manifiesto en algunos inconvenientes respecto del uso del software Cmap.

Para dar respuesta a los problemas presentados se rediseña el SA original, pensado como una actividad individual, agregando los siguientes elementos para promover interacciones que posibiliten superar las dificultades en el uso de la herramienta:

Comunidad: todos los participantes del curso y dos tutores

División de trabajo: alumno y tutor. El alumno desarrollará en forma individual la tarea propuesta. El tutor asistirá al alumno durante la actividad, tanto en el plano conceptual como en los aspectos relacionados con el uso de las herramientas propuestas y promoviendo la evolución del sistema dentro de las normas previstas. El tutor efectuará modificaciones al sistema cuando lo considere necesario a la luz de los objetivos propuestos.

Reglas: - Publicar el mapa conceptual en formato imagen.

- Publicar el mapa conceptual en el plazo previsto.

De esta manera, se incorpora la figura del tutor al sistema haciendo explícitas sus relaciones con los otros miembros de la comunidad, con el objeto de brindar la asistencia necesaria a aquellos alumnos que tuvieron inconvenientes en el desarrollo de la actividad a causa del uso de la herramienta Cmap. Se suma además a la comunidad a todos los participantes, considerando que a través del espacio de la plataforma "preguntas y respuestas de interés" se puede socializar la problemática entre todos los miembros del curso.

A continuación se presentan ejemplos de los inconvenientes surgidos y de las acciones llevadas a cabo por los tutores:

El alumno A20 no puede publicar su mapa por inconvenientes con su conexión particular a Internet, 
... "Te quería comentar que tengo problemas con la conexión de Internet en mi casa, que es donde tengo descargado el programa para construir mapas conceptuales.

Voy a intentar a la tarde nuevamente o descargar en otra máquina el programa”...

Los alumnos A1 y A21 presentan dificultades para guardar como imagen el mapa construído y publicarlo en sus respectivos grupos. El tutor contesta y pueden llevar a cabo el procedimiento.

El alumno A17 no logra instalar el software Cmap en su máquina, por lo cual el tutor le hace llegar un nuevo CD,

..."hoy jueves al mediodía te dejo un CD en el Colegio. Si persiste el inconveniente, por favor avisame, te llamo por teléfono y buscamos la solución.

No dejes de comunicarte”...

El tutor volvió a insistir con otro mail ofreciendo ayuda. A los días recibe la siguiente contestación que da cuenta que el problema no se pudo superar y a pesar de contar con un laboratorio de informática en la escuela donde se podría haber utilizado el Cmap, el alumno decide desistir del intento y utilizar como herramienta alternativa el Word,

..." De todos modos (tampoco pude con el CD que me dejaste por eso supongo que es mi máquina vieja) he decidido hacerlo en Word y colgarlo si es que se puede, así no doy más vueltas. Gracias de todos modos!’...A17

Los mapas fueron almacenados en formato de imagen en los grupos correspondientes; de esta manera el resultado de esta actividad constituye el input del SA 0.4 del cual forma parte, reflejando así el avance con respecto a los objetivos de la actividad y consistentes con los objetivos del sistema general:

-En base a los conocimientos previos, reflexionar sobre los conceptos de evaluación, calificación y acreditación en el proceso enseñanza y aprendizaje.

-Favorecer el uso de los mapas conceptuales como una herramienta de representación del conocimiento.

-Promover el uso de la herramienta Cmap para la construcción de mapas conceptuales.

\subsection{Sistema de Actividad 0.4 (Compartir y discutir mapas conceptuales)}


En esta actividad los alumnos utilizaron los mapas conceptuales (publicados en la actividad anterior) que reflejan la postura personal de los participantes en referencia al tema de formación. A través de las interacciones de los participantes de cada grupo se propuso avanzar en tres direcciones principales: en base a los conocimientos previos, reflexionar sobre los conceptos de evaluación, calificación y acreditación en el proceso enseñanza y aprendizaje; promover el uso de los mapas conceptuales como una herramienta de representación del conocimiento y la utilización de la herramienta Cmap para este propósito, y favorecer el desarrollo de estrategias de gestión de grupo e integración social, así como aquellas habilidades relacionadas con la negociación de conceptos, a través del uso de la herramienta foro. Se presentó a los alumnos la siguiente actividad:

Actividad 4:

18/10/06 al 27/10/06

-Leer los Mapas Conceptuales publicados por los compañeros del grupo.

-En el grupo buscar dos consistencias e inconsistencias entre los mapas presentados. Publicarlas en el foro del grupo explicitando el motivo y los mapas de referencia.

-Publicar mensajes (al menos dos) contestando a un compañero que permita una mejor interpretación de los conceptos y proposiciones cuestionadas (inconsistencias) o referidas (consistencias).

\subsubsection{Análisis de los factores que caracterizan el desarrollo de procesos colaborativos (Ingram y Hathorn, 2004)}

\subsubsection{Participación}

En la Fig. 6.10 se expone la cantidad de mensajes publicados por cada alumno distribuidos por grupo de trabajo. 


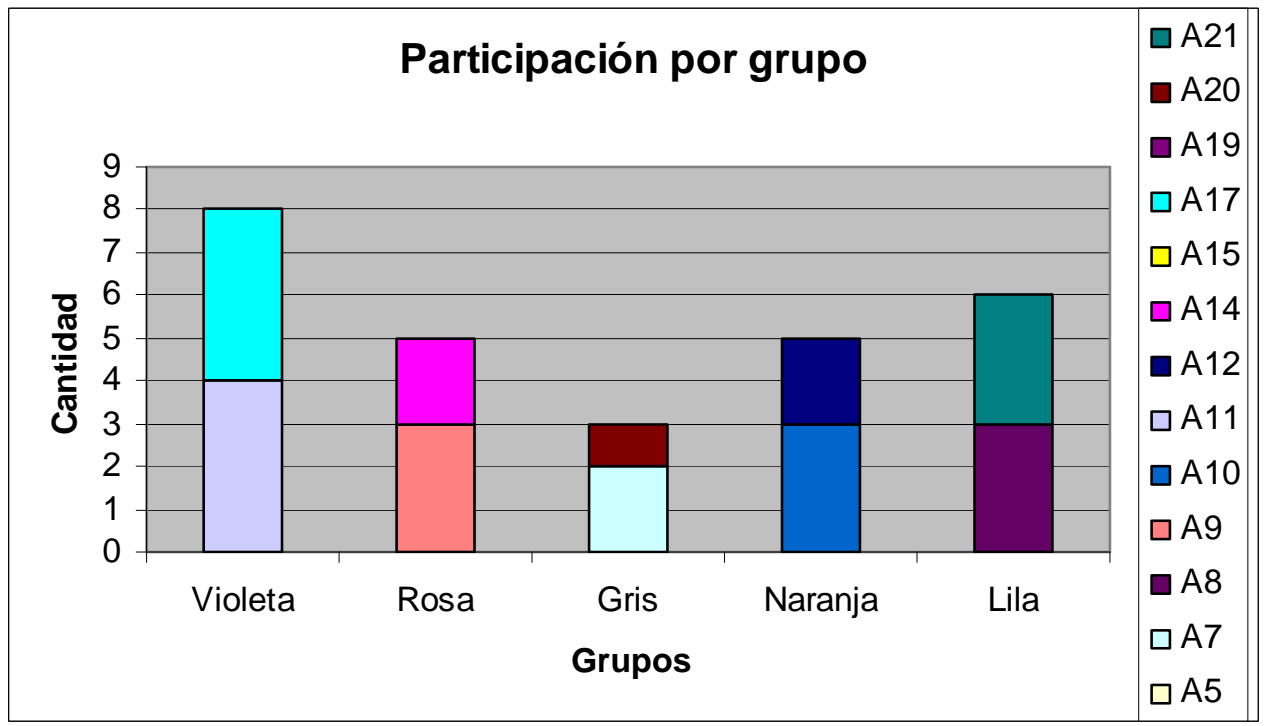

Figura 6.10: Participación en SA 0.4 por Grupo.

Se distingue la intervención de 10 alumnos del total de 13 que contribuyeron con la publicación de sus mapas conceptuales a la actividad anterior. Se observa en todos los grupos la participación de 2 integrantes, lo que permitió a todos los equipos llevar a cabo la actividad.

En el grupo violeta se registró la mayor cantidad de intervenciones por participante. Se publicaron 6 mensajes en fechas posteriores al lapso estipulado para el desarrollo de la actividad.

En el grupo rosa la participación fue la esperada, ya que se requería por lo menos la publicación de dos mensajes por integrante. La actividad fue desarrollada en gran parte fuera de los términos establecidos, observando que sólo uno de los mensajes fue publicado en el lapso previsto.

El grupo gris registró la menor participación en relación con los otros grupos y con lo mencionado en la consigna de esta actividad. Todas las contribuciones fueron publicadas fuera de término.

En el grupo naranja se respetó la cantidad mínima de mensajes que se debían publicar, observándose 2 mensajes fuera del plazo establecido.

En el grupo lila se distingue una participación homogénea de los dos participantes que siguen desarrollando el curso, observándose la publicación de 3 contribuciones fuera de término. 


\subsubsection{Interacción}

\section{$\underline{\text { Grupo Violeta }}$}

\section{Diagrama de flujo de interacciones}

Se observa cómo la identificación de inconsistencias por parte de uno compañeros genera la respuesta por parte del otro integrante dando lugar a discutir, valorar y negociar significados (Fig. 6.11).

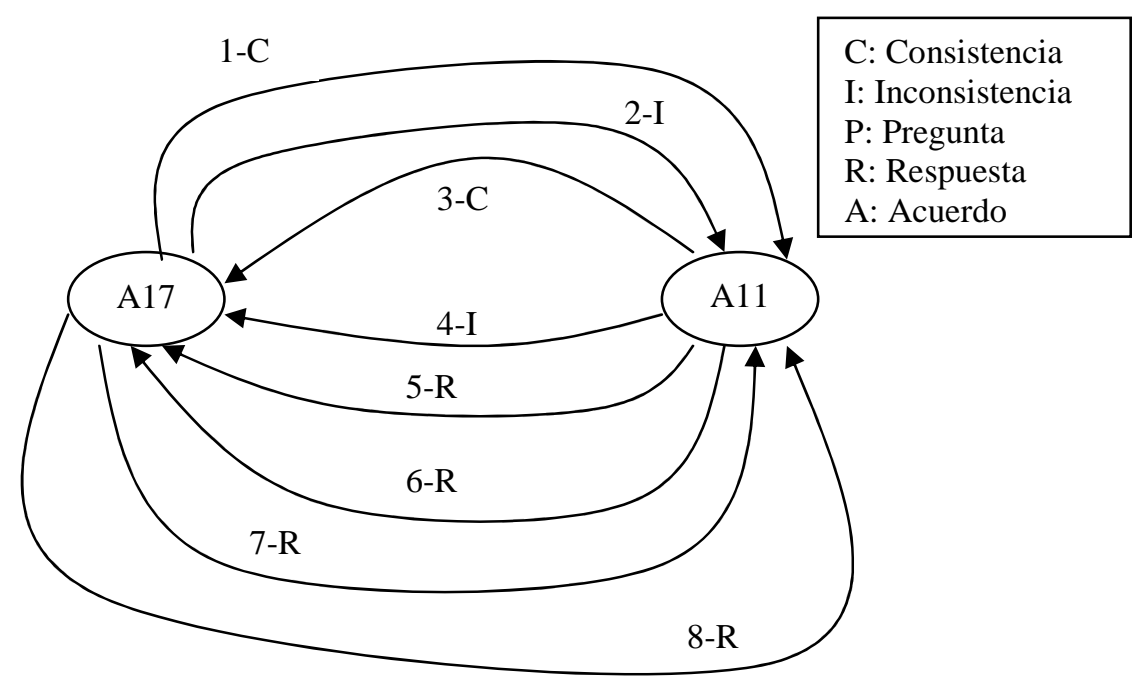

Figura 6.11: Diagrama de flujo de las interacciones entre los participantes del foro Violeta-Act4, indicando orden, dirección y tipo de mensaje.

Funcionamiento de Grupo: Categorías e Indicadores

\begin{tabular}{|c|c|}
\hline \multicolumn{2}{|r|}{ Categoría Gestión de Grupo } \\
\hline Indicadores & Ejemplos \\
\hline $\begin{array}{c}\text { Compartir } \\
\text { interpretaciones }\end{array}$ & $\begin{array}{l}\text {.."En mi caso planteo una probable modificación de las prácticas pero en } \\
\text { función de resultados generales, no sólo de las calificaciones. Un objetivo no } \\
\text { cumplido puede determinar cambios sin que haya calificaciones de por } \\
\text { medio"... A17 } \\
\text {.."Mi opinión personal, creo que hay que definir bien los conceptos y podría } \\
\text { estar acompañada de una explicación o de notas, pero no definir conceptos de } \\
\text { este estilo, no quedan claro al momento de leer un mapa.”... Al1 }\end{array}$ \\
\hline Argumentar & $\begin{array}{l}\text {... Yo opté por la segunda opción porque creo que es una herramienta más del } \\
\text { proceso de enseñanza aprendizaje, y que éste no está orientado específicamente } \\
\text { a la evaluación como meta final”... Al7 }\end{array}$ \\
\hline
\end{tabular}




\begin{tabular}{|c|c|}
\hline \multicolumn{2}{|r|}{ Categoría Gestión de Grupo } \\
\hline Indicadores & Ejemplos \\
\hline Acordar & $\begin{array}{l}\text {.."Creo que el mapa de Al1 y el mío comparten la multiplicidad de opciones } \\
\text { válidas para usar a la hora de evaluar, que no se limitan sólo al } \\
\text { "exámen"....A17 } \\
\text {.." a la hora de evaluar a un alumno, se tienen varias maneras de realizar la } \\
\text { misma, esto queda claro en el mapa de A17 tanto como en el mío"... All }\end{array}$ \\
\hline \multicolumn{2}{|c|}{$\begin{array}{l}\text { No se registran en la categoría gestión de grupo los indicadores consultar al grupo, secuenciar, presentar } \\
\text { alternativas, presentar síntesis de lo acordado, evaluar el avance del trabajo, tomar decisión, pedir } \\
\text { aclaración, formular propuesta de trabajo. }\end{array}$} \\
\hline \multicolumn{2}{|r|}{ Categoría Integración Social } \\
\hline Indicadores & Ejemplos \\
\hline Motivar & ..."en algo estamos de acuerdo jejeje." A11 \\
\hline $\begin{array}{l}\text { Contestar a un } \\
\text { compañero }\end{array}$ & $\begin{array}{l}\text {..” Está bueno que otro lea la producción de uno porque ayuda a clarificar. A } \\
\text { ver, aquí va la respuesta:"... A17 }\end{array}$ \\
\hline $\begin{array}{l}\text { Manifestar } \\
\text { compromiso con la } \\
\text { tarea grupal }\end{array}$ & ¡Perdón por la demora! A17 \\
\hline NI corocintran on lo & cador \\
\hline
\end{tabular}

Tabla 6.8: Funcionamiento de grupo. Ejemplos del SA 0.4 - Grupo Violeta.

\section{Fases en la construcción activa del conocimiento (Gunawardena y col., 1997)}

De acuerdo a lo expuesto en el Capítulo 4 "Metodología", para el análisis de la interacción relacionada a los procesos de construcción social de conocimiento y elaboración de síntesis se utiliza el modelo de Gunawardena y col (1997) "Interaction analysis model for examining social construction of knowledge in computer conferencing", el cual considera que la construcción activa del conocimiento progresa a través de las siguientes etapas:

- Fase I: Compartiendo/ Comparando información

- Fase II: Descubrimiento y exploración de disonancias e inconsistencias entre ideas, conceptos o sentencias

- Fase III: Negociación de significados/ Co-construcción de conocimiento

- Fase IV: Evaluación y modificación de síntesis propuesta o co-construcción

- Fase V: Sentencias de acuerdo/ Aplicación de los nuevos significados construidos

Los mensajes publicados en el Foro del grupo para esta actividad se representan en la Figura 6.12: 


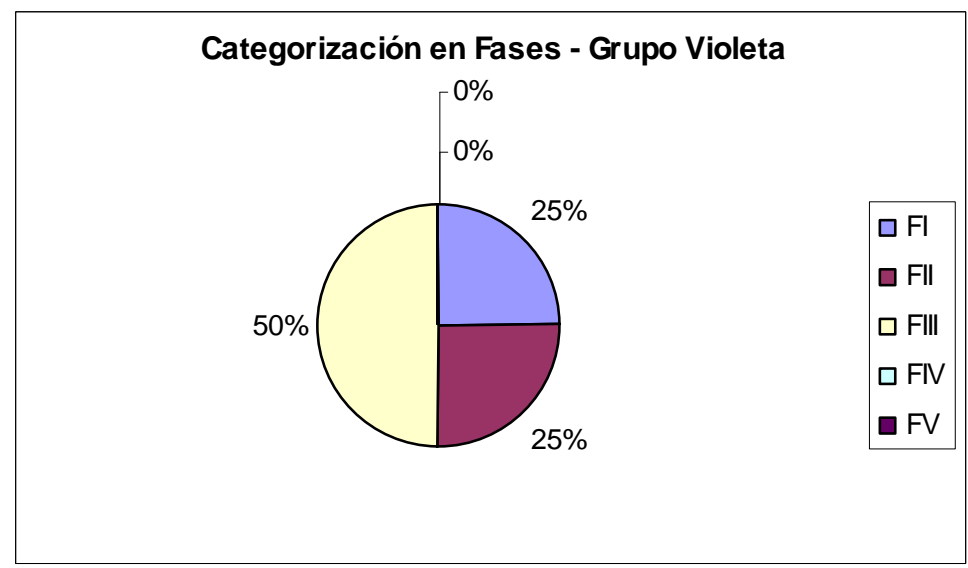

Figura 6.12: Categorización de los mensajes en fases (Gunawardena y col, 1997) del foro Violeta-Act4.

En este grupo no se encuentran contribuciones correspondientes a las fases IV y V. Se observa una distribución homogénea entre las dos primeras etapas (Fase I y II) correspondientes a mensajes en los cuales se expresan opiniones, acuerdos y se establecen zonas de desacuerdo:

..."Consistencias:

-Los puntos en común que se tiene con mi mapa conceptual son:

..." a la hora de evaluar a un alumno, se tienen varias maneras de realizar la misma, esto queda claro en el mapa de A17 tanto como en el mío”... Al1 (FI)

..."-El vinculo "consistente en" que relaciona el concepto "Acreditación" y "Trabajos prácticos, informes, pruebas escritas u orales, actividades en general que den cuenta del proceso de enseñanza aprendizaje", no tiene una buena definición de lo que es acreditación, a mi entender la acreditación es un resultado tanto numérico o con otro tipo de valor que se le quiera dar a cualquier evaluación como por ejemplo: bien, muy bien, satisfactorio, participación en clase, 10, etc. ”... A11 (FII)

Se distingue que gran parte de los mensajes contribuyen a la negociación y clarificación de significados de términos, identificándose además áreas de acuerdo:

..."conceptos dados: es verdad, en realidad los tuve en cuenta y luego los incluí en el mapa en el sentido que me pareció más conveniente pero sin preocuparme mucho por ver si estaban todos. Es más, error y tiempo los dejé afuera a propósito. Es que error no entre en mi idea de evaluación, y el tiempo, la verdad es sólo para dar una magnitud de referencia (evaluar el último cuatrimestre, por ejemplo). También me pareció secundario, y así como se podía agregar conceptos yo decidí ignorar algunos.”... A17 (FIII) 


\section{Grupo Rosa}

\section{Diagrama de flujo de interacciones}

El diagrama permite establecer la secuencia en el tiempo de los mensajes (Figura 6.13), observando además de acuerdo a la clasificación propuesta (C, I, P, R, A), la calidad del contenido de las interacciones. Se observa a partir de una pregunta formulada por A14 (3-P) A9 interviene, y responde aportando además su acuerdo a lo expresado por su compañero (4-R, A).

Se destaca la asimetría que se produce en el flujo de los mensajes. El alumno A1 recibió comentarios sobre su mapa conceptual pero no respondió ni participó de acuerdo a lo que proponía la actividad. De esta manera, no respetó las reglas del sistema afectando el progreso de la actividad y su objetivo en lo concerniente a promover el desarrollo de estrategias de gestión de grupo e integración social y favorecer el uso del foro como herramienta para la discusión, negociación y consenso de conceptos entre varias personas.

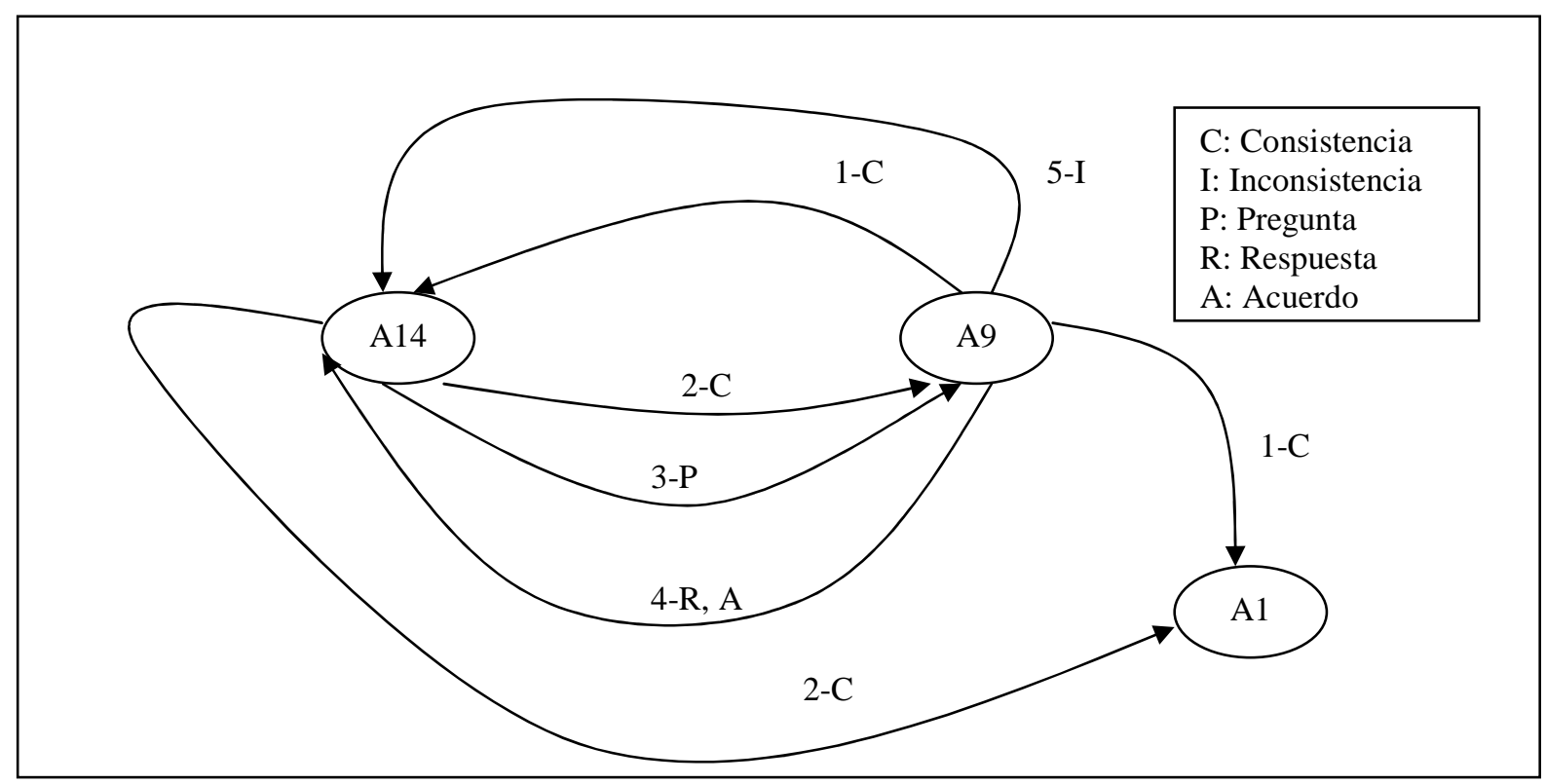

Figura 6.13: Diagrama de flujo de las interacciones entre los participantes del foro Rosa-Act4, indicando orden, dirección y tipo de mensaje.

Funcionamiento de Grupo: Categorías e Indicadores 


\begin{tabular}{|c|c|}
\hline \multicolumn{2}{|r|}{ Categoría Gestión de Grupo } \\
\hline Indicadores & Ejemplos \\
\hline Consultar al grupo & ..."creo que es un punto sobre el que podemos dialogar"... A14 \\
\hline $\begin{array}{c}\text { Compartir } \\
\text { interpretaciones }\end{array}$ & $\begin{array}{l}\text {.." Con esto quiero decir que al nodo de proceso de enseñanza aprendizaje (que } \\
\text { queda como nodo principal) le faltan muchos otros conectores"... A9 } \\
\text {..."Considero que si bien la idea está expresada de un modo distinto, en } \\
\text { definitiva, plasman como el proceso de E/A puede "medirse", y hasta agrego } \\
\text { modificarse por la evaluación"... A9 }\end{array}$ \\
\hline Argumentar & $\begin{array}{l}\text {..."En el mapa que elaboré coloqué el nodo proceso de enseñanza aprendizaje } \\
\text { por encima del de evaluación porque considero que es más general y por lo } \\
\text { tanto debe estar en un nivel jerárquico superior"...A9 } \\
\text {..."mientras que yo considero que la evaluación, sólo a veces implica } \\
\text { acreditación.”... A9 }\end{array}$ \\
\hline Acordar & $\begin{array}{l}\text {.."Creo que esto acuerda con lo que Al establece en el suyo acerca de que se } \\
\text { facilita un encuentro entre educador y educando"... A9 } \\
\text {..."tanto en el mapa de Al como en el mío se presentan a alumnos, docentes y a } \\
\text { la escuela (educador, educando y escuela) como los distintos sujetos } \\
\text { involucrados en el proceso de evaluación"... Al4 }\end{array}$ \\
\hline \multicolumn{2}{|r|}{ Categoría Integración Social } \\
\hline
\end{tabular}

Tabla 6.9: Funcionamiento de grupo. Ejemplos del SA 0.4 - Grupo Rosa.

\section{Fases en la construcción activa del conocimiento (Gunawardena y col., 1997)}

En la Figura 6.14 se aprecia la categorización de los mensajes en las cinco fases de acuerdo al modelo de análisis propuesto:

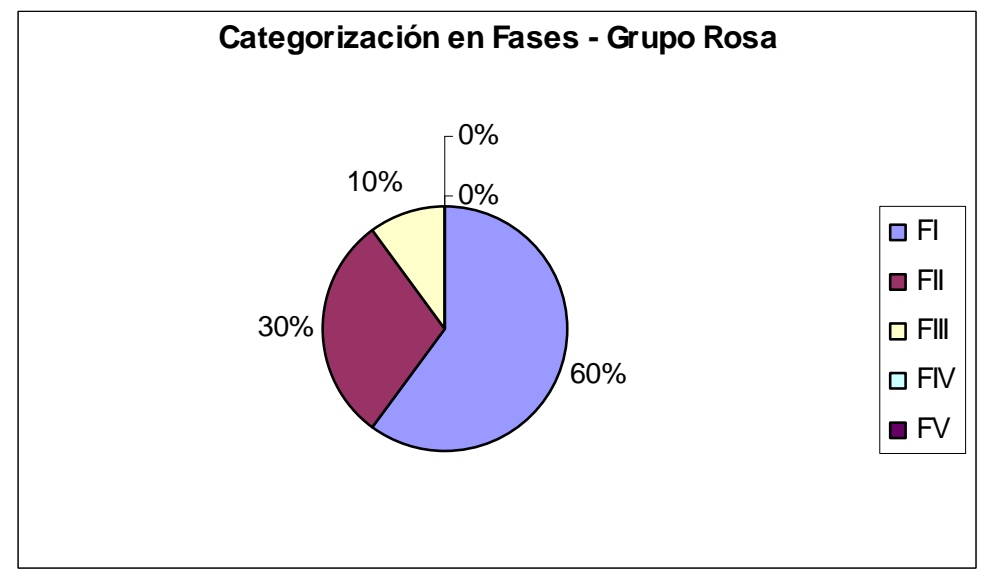

Figura 6.14: Categorización de los mensajes en fases (Gunawardena y col, 1997) del foro Rosa-Act4. 
Se observa en este foro que la mayoría de los mensajes corresponden a la Fase I, en los cuales se expresan sentencias de acuerdo y de opinión referidas al contenido de los mapas conceptuales.

Gran parte de las contribuciones restantes corresponden a la Fase II, en las cuales se identifican y establecen áreas de desacuerdo. Se las podría considerar como potenciales generadoras de mensajes para la etapa siguiente. En la Fase III se observa un solo mensaje destinado a negociar y clarificar el significado de términos.

No se registran contribuciones pertenecientes a las etapas IV y V.

Se detallan algunas de las contribuciones correspondientes a las etapas transitadas:

..." También puede observarse que tanto en el mapa de A9 como en el mío se manifiesta la detección de errores a partir de la evaluación.”... A14 (FI)

..."Una diferencia con el mapa de A14 creo que residiría en que, de acuerdo a lo que plantea, la acreditación y la calificación serían dos funciones de la evaluación, y por no relacionarse entre ellas, entiendo que funciones diferentes. En el mío, considero que son procesos que van de la mano, incluso que la acreditación se mide mediante una calificación”... A9 (FII)

..."Estaría de acuerdo con lo que plantea A14 acerca de que la evaluación es parte del proceso de enseñanza aprendizaje. En el mapa que elaboré coloqué el nodo proceso de enseñanza aprendizaje por encima del de evaluación porque considero que es más general y por lo tanto debe estar en un nivel jerárquico superior. $Y$ una manera de regularlo sería mediante la evaluación”... A9 (FIII)

\section{Grupo Gris}

\section{Diagrama de flujo de interacciones}

En este equipo se registra el menor flujo de mensajes (Fig. 6.15). Se observa que la participación de sus miembros en la actividad fue realizada en su totalidad fuera de término. En la elaboración del mapa conceptual el alumno A7 no consideró los conceptos que se proponían, lo que dificultó la búsqueda de consistencias e inconsistencias en la comparación de los mapas por parte de su compañero. 


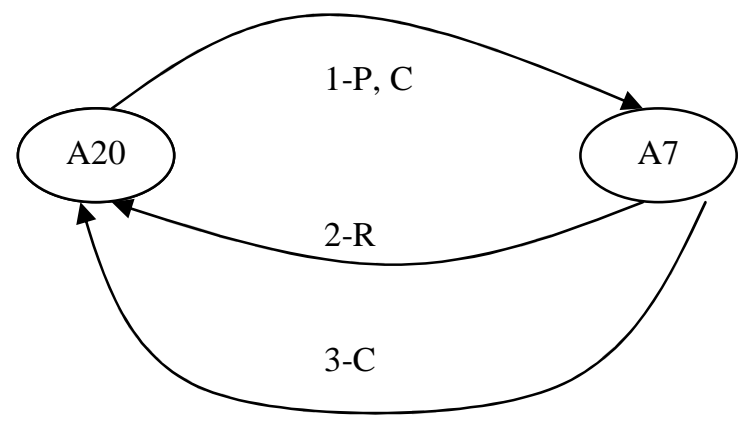

C: Consistencia

I: Inconsistencia

P: Pregunta

R: Respuesta

A: Acuerdo

Figura 6.15: Diagrama de flujo de las interacciones entre los participantes del foro GrisAct4, indicando orden, dirección y tipo de mensaje.

\section{Funcionamiento de Grupo: Categorías e Indicadores}

\begin{tabular}{|c|c|}
\hline \multicolumn{2}{|r|}{ Categoría Gestión de Grupo } \\
\hline Indicadores & Ejemplos \\
\hline $\begin{array}{l}\text { Compartir } \\
\text { interpretaciones }\end{array}$ & $\begin{array}{l}\text {.." Me pareció interesante la serie de preguntas, pero me pareció que la } \\
\text { actividad consistía en dar algunas respuestas, aunque sea iniciales.”... A20 } \\
\text {.."pero cuando hacía el mapa tenía la sensación de que faltaban los } \\
\text { fundamentos, la postura ideológica, el fundamento teórico en el sentido } \\
\text { pedagógico digo"... A7 }\end{array}$ \\
\hline Argumentar & $\begin{array}{l}\text {.."Creo que estas preguntas deben ser explícitas a la hora de la evaluación, } \\
\text { para saber realmente qué entendemos por evaluación y que decidimos } \\
\text { evaluar"...A7 }\end{array}$ \\
\hline Acordar & $\begin{array}{l}\text {.."También comparto que la evaluación DEBE tener como finalidad mejorar el } \\
\text { proceso de enseñanza aprendizaje”... A20 } \\
\text {..."Coincido con tu mapa, solo podría decir que la evaluación "debe” generar } \\
\text { revisión, más que "puede"”... A7 }\end{array}$ \\
\hline Pedir aclaración & $\begin{array}{l}\text {..."No termino de entender si pones como contrapuestas la evaluación como } \\
\text { instrumento de control y la evaluación reflexiva"... A20 }\end{array}$ \\
\hline \multicolumn{2}{|c|}{$\begin{array}{l}\text { No se registran en la categoría gestión de grupo los indicadores consultar al grupo, secuenciar, presentar } \\
\text { alternativas, presentar síntesis de lo acordado, evaluar el avance del trabajo, tomar decisión, formular } \\
\text { propuesta de trabajo. }\end{array}$} \\
\hline \multicolumn{2}{|r|}{ Categoría Integración Social } \\
\hline Indicadores & Ejemplos \\
\hline $\begin{array}{l}\text { Contestar a un } \\
\text { compañero }\end{array}$ & $\begin{array}{l}\text {.." respondo a tus interrogantes, a mi modo de ver los conceptos recomendados } \\
\text { para realizar el mapa son todos ellos conceptos técnicos"... A7 }\end{array}$ \\
\hline stran en & $\begin{array}{l}\text { goría integración social los indicadores motivar, involucrar al grupo, manifestar } \\
\text { grupal. }\end{array}$ \\
\hline
\end{tabular}

Tabla 6.10: Funcionamiento de grupo. Ejemplos del SA 0.4 - Grupo Gris. 


\section{Fases en la construcción activa del conocimiento (Gunawardena y col., 1997)}

En la Figura 6.16 se exhibe la categorización de los mensajes en las cinco fases de acuerdo al modelo de análisis propuesto. Se debe tener en cuenta para su interpretación la escasa participación de los integrantes del grupo.

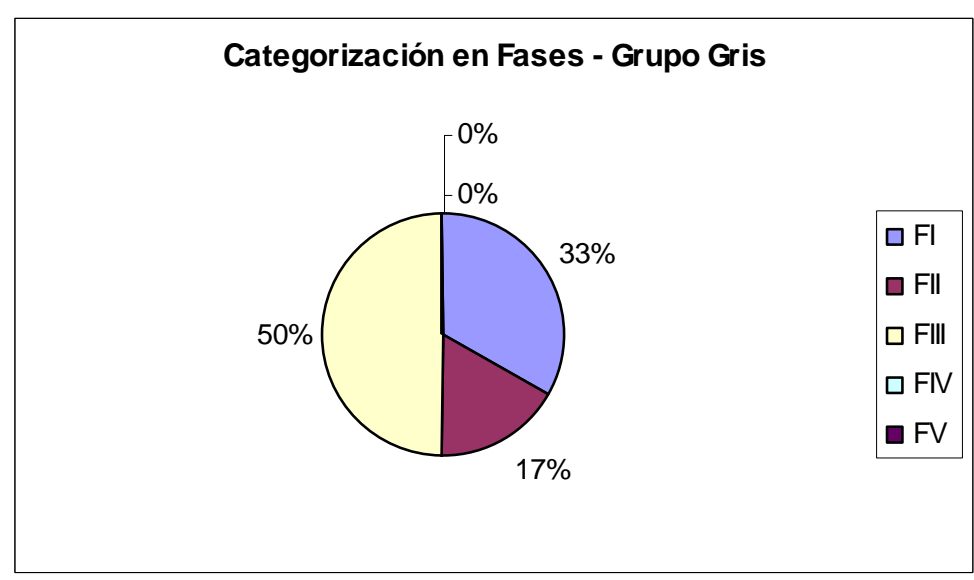

Figura 6.16: Categorización de los mensajes en fases (Gunawardena y col, 1997) del foro Gris-Act4.

En el foro desarrollado por este grupo se observan mensajes correspondientes a la Fase I portadores de acuerdos y opiniones personales.

...”Y bueno, me pareció que con este mapa se podía ampliar la discusión”... A7

Se distingue a partir de la identificación de áreas de desacuerdo (FII) la generación de contribuciones destinadas a la negociación y clarificación de los significados de los términos cuestionados (FIII):

...”Me pareció interesante la serie de preguntas, pero me pareció que la actividad consistía en dar algunas respuestas, aunque sea iniciales.

No termino de entender si pones como contrapuestas la evaluación como instrumento de control y la evaluación reflexiva"... A20 (FII)

..."Creo que estas preguntas deben ser explícitas a la hora de la evaluación, para saber realmente qué entendemos por evaluación y que decidimos evaluar. Digamos que el temor más grande sería estar evaluando sin haber pensado nunca en estas preguntas y que entonces se nos estén escapando posibilidades por desconocimiento, que no sería lo mismo que optar por convencimiento y conocimiento"... A7 (FIII)

\section{Grupo Naranja}

Diagrama de flujo de interacciones 
Se observa a través del flujo de mensajes (Fig. 6.17) el desarrollo de la regla en la que se indica "Proponer, discutir, valorar y negociar significados a partir de las formulaciones de un par". Esto es, a partir de la propuesta de consistencias e inconsistencias por parte de un compañero el otro publica un mensaje dando una respuesta o expresando su acuerdo.

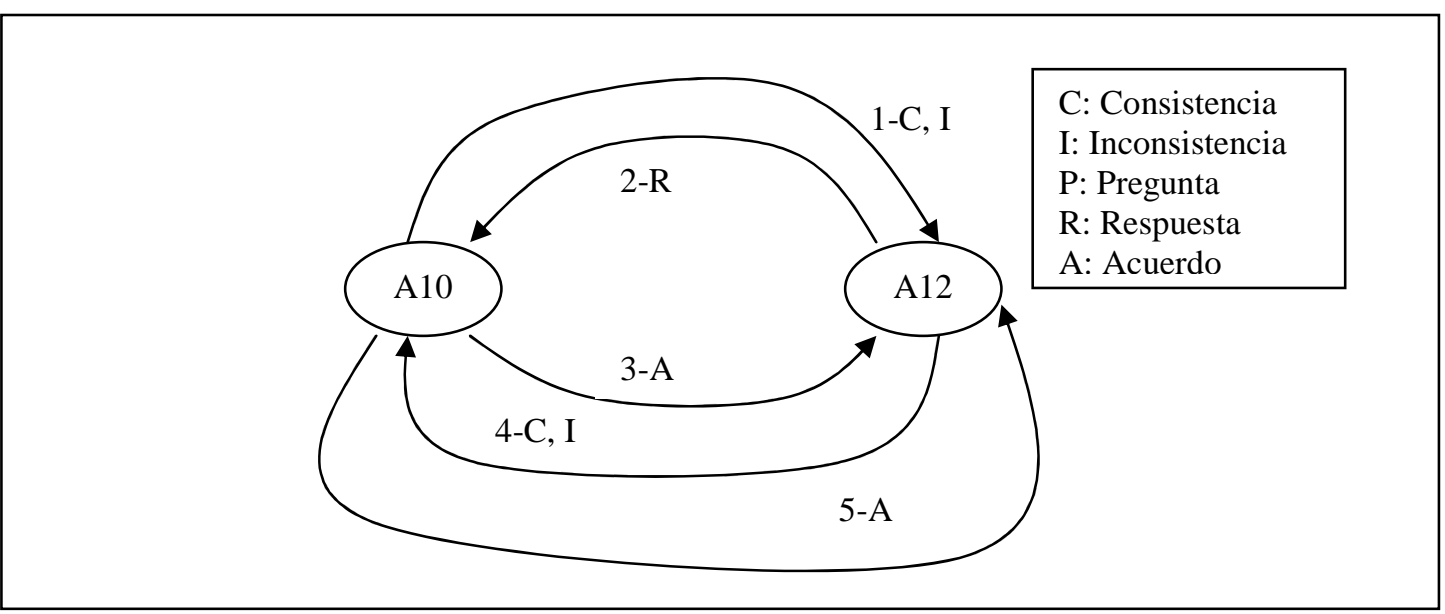

Figura 6.17: Diagrama de flujo de las interacciones entre los participantes del foro Naranja-Act4, indicando orden, dirección y tipo de mensaje.

Funcionamiento de Grupo: Categorías e Indicadores

\begin{tabular}{|c|c|}
\hline \multicolumn{2}{|r|}{ Categoría Gestión de Grupo } \\
\hline Indicadores & Ejemplos \\
\hline Consultar al grupo & ...”Espero rta....... al mio le vi varias cosas ... las vemos después”... A10 \\
\hline Argumentar & $\begin{array}{l}\text {..."yo escribí como concepto "función" porque considero que tiene status de } \\
\text { concepto y no de conector, debido a que la evaluación tiene para mi dos } \\
\text { funciones importantes la social y la pedagógica"... A12 }\end{array}$ \\
\hline Acordar & $\begin{array}{l}\text {.."Bien, creo que hay tantos mapas como representaciones mentales } \\
\text { instantáneas tengamos. Dadas tus razones y aceptadas"... Al0 }\end{array}$ \\
\hline Pedir aclaración & $\begin{array}{l}\text {..."Me cuestiono la proposición: la evaluación que actúa como función } \\
\text { pedagógica su objetivo es lograr calificaciones. ( no es más administrativo?.”... } \\
\text { A10 } \\
\text {..."No tendría que ser Evaluación- tiene como función- (conector) y que salgan } \\
\text { los otros dos conceptos: Social Pedagógico .......???”... A12 }\end{array}$ \\
\hline $\begin{array}{l}\text { No s } \\
\text { secu } \\
\text { decis }\end{array}$ & $\begin{array}{l}\text { egoría gestión de grupo los indicadores compartir interpretaciones, argumentar, } \\
\text { ernativas, presentar síntesis de lo acordado, evaluar el avance del trabajo, tomar } \\
\text { esta de trabajo. }\end{array}$ \\
\hline
\end{tabular}




\begin{tabular}{|c|l|}
\hline \multicolumn{2}{|c|}{ Categoría Integración Social } \\
\hline Indicadores & Ejemplos \\
\hline $\begin{array}{c}\text { Contestar a un } \\
\text { compañero }\end{array}$ & $\begin{array}{l}\text {..”Respuesta de A12 a Alo. } \\
\text { Ella cuestiona que la evaluación”... A12 }\end{array}$ \\
\hline $\begin{array}{l}\text { No se registran en la categoría integración social los indicadores motivar, involucrar al grupo, manifestar } \\
\text { compromiso con la tarea grupal. }\end{array}$ \\
\hline
\end{tabular}

Tabla 6.11: Funcionamiento de grupo. Ejemplos del SA 0.4 - Grupo Naranja.

\section{Fases en la construcción activa del conocimiento (Gunawardena y col., 1997)}

En la Figura 6.18 se representa la cantidad de contribuciones correspondientes a las distintas fases propuestas en el modelo de análisis:

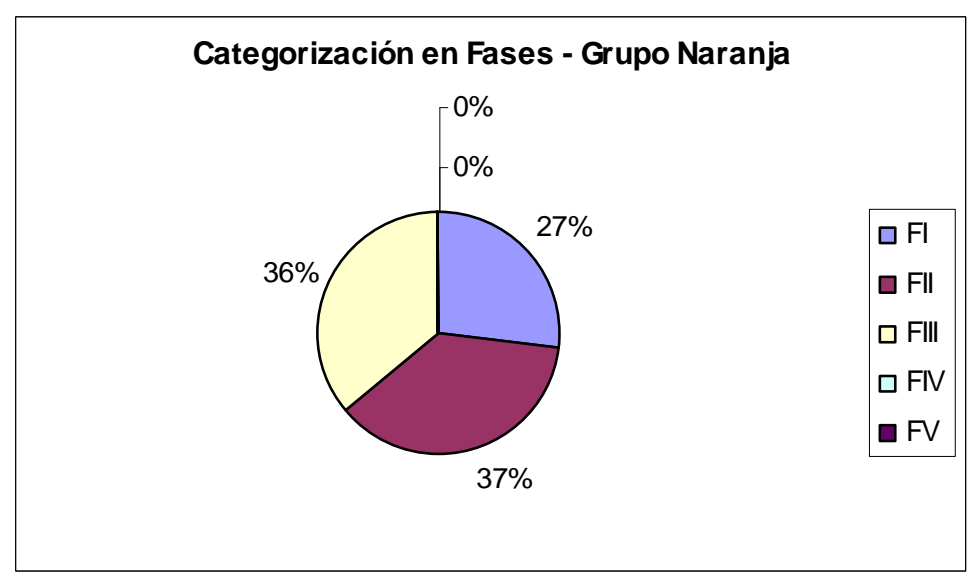

Figura 6.18: Categorización de los mensajes en fases (Gunawardena y col, 1997) del foro Naranja-Act 4 .

Se distingue una distribución equitativa entre las Fases I, II y III, no advirtiéndose contribuciones en las Fases IV y V.

Los mensajes correspondientes a la Fase I denotan acuerdos entre los participantes:

\section{..."Consistencias:}

- La evaluación como parte del proceso de enseñanza y aprendizaje.

- La evaluación como instrumento para diagnosticar errores y ser considerados en el proceso de enseñanza y aprendizaje”... A12 (FI)

Las contribuciones correspondientes a la Fase II se orientan al descubrimiento y exploración de disonancias e inconsistencias:

..."Otra inconsistencia podría ser que se les da rango de conceptos(están en rectángulos)"en el" "función" No tendría que ser Evaluación- tiene como función(conector) y que salgan los otros dos conceptos: Social Pedagógico .......???”... A10 (FII) 
Se observan sentencias de negociación y clarificación del significado de términos (Fase III):

..."- Respecto a la segunda incosistencia, yo escribí como concepto "función" porque considero que tiene status de concepto y no de conector, debido a que la evaluación tiene para mí dos funciones importantes la social y la pedagógica”... A12 (FIII)

\section{Grupo Lila}

\section{Diagrama de flujo de interacciones}

Se observa que ambos participantes intervinieron comunicando consistencias e inconsistencias encontradas en el mapa del compañero (Fig. 6.19). A21 publicó sus mensajes fuera de término lo que impidió al A8 responder a las inconsistencias planteadas por su compañero. La regla en la que se propone discutir, valorar y negociar significados a partir de las formulaciones de un par fue directamente afectada por el no cumplimiento de la regla que enuncia intervenir en al lapso de tiempo.

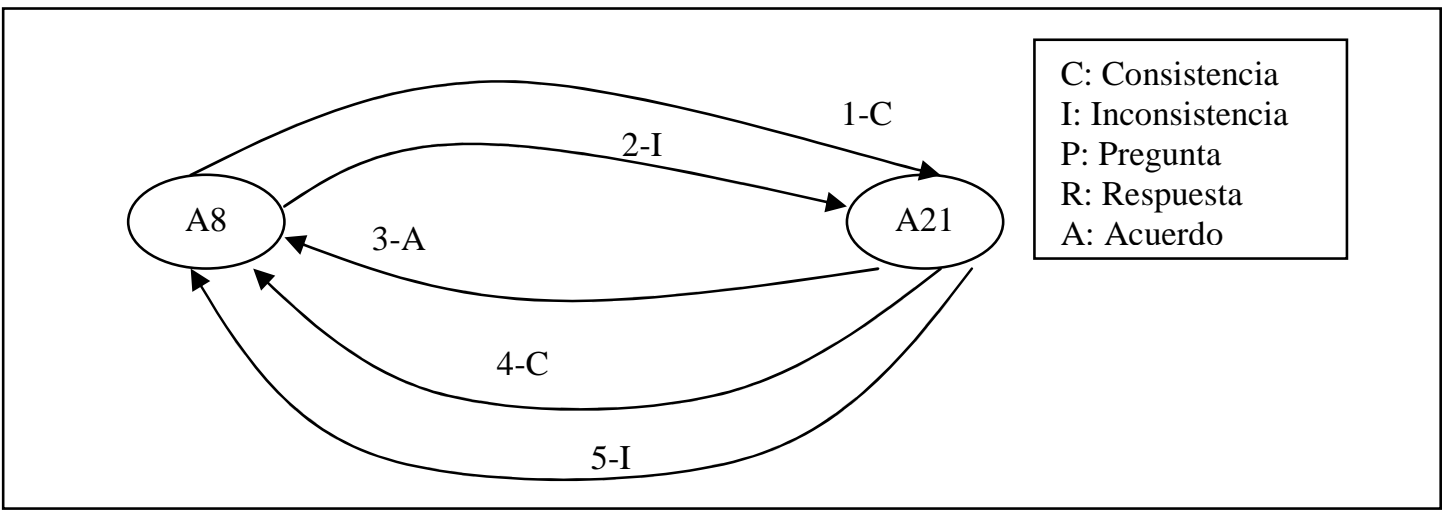

Figura 6.19: Diagrama de flujo de las interacciones entre los participantes del foro Lila-Act4, indicando orden, dirección y tipo de mensaje.

\section{Funcionamiento de Grupo: Categorías e Indicadores}

\begin{tabular}{|c|l|}
\hline \multicolumn{2}{|c|}{ Categoría Gestión de Grupo } \\
\hline Indicadores & Ejemplos \\
\hline Consultar al grupo & $\ldots$ ”Espero comentarios. A8 \\
\hline $\begin{array}{c}\text { Compartir } \\
\text { interpretaciones }\end{array}$ & $\begin{array}{l}\text { como sinónimos"...A8 } \\
\text { contiendo que las nociones de seguimiento y regulación pueden asumirse } \\
\text {.. Creo que lo que tienen en común los dos mapas es que toman la evaluación } \\
\text { como un proceso y no como un mero resultado”... A21 }\end{array}$ \\
\hline
\end{tabular}


significados de los conceptos involucrados en los mapas conceptuales.

El descubrimiento y exploración de disonancias o inconsistencias (Fase II) a partir de la interpretación de los mapas conceptuales registra la misma cantidad de contribuciones que en la Fase I. Estas contribuciones son generadoras de los mensajes correspondientes a la siguiente etapa (Fase III), donde los integrantes del grupo identifican áreas de acuerdo y avanzan hacia procesos de co-construcción de conocimiento.

A continuación se detallan ejemplos correspondientes a las fases mencionadas:

..."Otro aspecto que estos mapas comparten es que en ambos, está presente una mirada dinámica (o temporal) del proceso de enseñanza y aprendizaje. En el mapa de A21 se alude a analizar la adquisición de competencias, procesos, conocimientos, es decir se supone (implícitamente) alguna modificación o cambio de un estado anterior. En mi caso, intenté poner de manifiesto que la evaluación permite analizar la evolución que experimentan los conocimientos"... A8 (FI)

...”El lugar en que (dentro de cada mapa) se ha colocado la palabra Evaluación. Miro el mapa realizado por Gabriela y no puedo dejar de reconocer que ha hecho un trabajo centrado en el tema del curso, precisamente la evaluación.

Mi mapa, presenta a la evaluación inmersa dentro de la estructura más general de la escuela”.. A8 (FII)

..." Creo que la mayor diferencia que presentan los cuadros es la perspectiva desde la que se ha considerado la evaluación. Por lo que yo entiendo, A8 ubica a la inmersa en el proceso para alcanzar, a largo plazo, objetivos institucionales. Sin embargo, yo consideré la evaluación para alcanzar objetivos del área”... A21 (FIII)

\subsubsection{Análisis holístico del SA 0.4 (Compartir y discutir mapas conceptuales)}

Analizando el desempeño de los grupos en la actividad se observa en referencia a la participación, la deserción de participantes en todos los grupos, aún habiendo elaborado y publicado el mapa conceptual. Esto afecta al SA en el cual se habían definido como sujeto de la actividad grupos de por lo menos tres personas.

Se observa en el grupo gris una dificultad con la herramienta foro, surgida a partir de la intención de publicar un mensaje extenso que requirió de la intervención del tutor para solucionarlo. En los demás grupos los integrantes pudieron llevar adelante la actividad sin inconvenientes.

En la mayoría de los grupos se publicó una cantidad de contribuciones cercana a 
la establecida por la regla "Realizar por lo menos dos intervenciones en el lapso de tiempo prefijado". No se respetó el intervalo de tiempo destinado al desarrollo de la actividad, lo que afectó la evolución de procesos para "Proponer, discutir, valorar y negociar significados a partir de las formulaciones de un par”, propuestos en otra regla .

Con respecto a las interacciones generadas en el grupo, se detallan en la Tabla 6.2 algunos ejemplos de indicadores correspondientes a las dos categorías de la dimensión funcionamiento de grupo para los distintos equipos:

Uno de los objetivos del SA 0 es: promover en los docentes el desarrollo de estrategias y habilidades que favorezcan la evolución de procesos colaborativos de aprendizaje online.

El SA 0.4 contribuye a su logro a través del desarrollo de procesos guiados por la meta propia de este sistema: promover el desarrollo de estrategias de gestión de grupo e integración social.

Se puede observar la evolución de los diferentes grupos en la Tabla 6.8. En cuanto a la categoría gestión de grupo se registraron en la mayoría de los equipos mensajes pertenecientes a los indicadores consultar al grupo, compartir interpretaciones, argumentar, acordar y en algunos, contribuciones referidas a pedir aclaración señalando la presencia estrategias y habilidades que favorecen procesos de colaboración.

La categoría integración social presenta en los grupos gris, naranja y violeta mensajes correspondientes a las categorías motivar, contestar a un compañero y manifestar compromiso con la tarea grupal.

\begin{tabular}{|c|c|c|c|c|c|}
\hline \multicolumn{6}{|c|}{ Categoría: Gestión de grupo } \\
\hline \multirow[b]{2}{*}{ Indicadores } & \multicolumn{5}{|c|}{ Ejemplos de los grupos } \\
\hline & Violeta & Rosa & Gris & Naranja & Lila \\
\hline Consultar al grupo & & $\begin{array}{l}\text {..."creo que es } \\
\text { un punto sobre } \\
\text { el que podemos } \\
\text { dialogar"... }\end{array}$ & & $\begin{array}{l}\text {..."Espero } \\
\text { rta....... al mío le } \\
\text { vi varias cosas ... } \\
\text { las vemos } \\
\text { después"... }\end{array}$ & $\begin{array}{l}\text {..."Espero } \\
\text { comentarios." }\end{array}$ \\
\hline $\begin{array}{l}\text { Compartir } \\
\text { interpretaciones }\end{array}$ & $\begin{array}{l}\text {...”En mi caso } \\
\text { planteo una } \\
\text { probable } \\
\text { modificación de } \\
\text { las prácticas } \\
\text { pero en } \\
\text { función"... }\end{array}$ & $\begin{array}{l}\text {..."Con esto } \\
\text { quiero decir que } \\
\text { al nodo de } \\
\text { proceso de } \\
\text { enseñanza } \\
\text { aprendizaje (que } \\
\text { queda como } \\
\text { nodo principal) } \\
\text { le faltan muchos } \\
\text { otros } \\
\text { conectores"... }\end{array}$ & $\begin{array}{l}\text {...”Me pareció } \\
\text { interesante la } \\
\text { serie de } \\
\text { preguntas, pero } \\
\text { me pareció que } \\
\text { la actividad } \\
\text { consistía en dar } \\
\text { algunas } \\
\text { respuestas, } \\
\text { aunque sea } \\
\text { iniciales.”... }\end{array}$ & & $\begin{array}{l}\text {...”Entiendo que } \\
\text { las nociones de } \\
\text { seguimiento y } \\
\text { regulación } \\
\text { pueden asumirse } \\
\text { como } \\
\text { sinónimos"... }\end{array}$ \\
\hline
\end{tabular}




\begin{tabular}{|c|c|c|c|c|c|}
\hline \multicolumn{6}{|c|}{ Categoría: Gestión de grupo } \\
\hline \multirow{2}{*}{ Indicadores } & \multicolumn{5}{|c|}{ Ejemplos de los grupos } \\
\hline & Violeta & Rosa & Gris & Naranja & Lila \\
\hline Argumentar & $\begin{array}{l}\text {...”porque creo } \\
\text { que es una } \\
\text { herramienta más } \\
\text { del proceso de } \\
\text { enseñanza } \\
\text { aprendizaje”... }\end{array}$ & $\begin{array}{l}\text {..." porque } \\
\text { considero que es } \\
\text { más general y } \\
\text { por lo tanto debe } \\
\text { estar en un nivel } \\
\text { jerárquico } \\
\text { superior"... }\end{array}$ & $\begin{array}{l}\text {...”Creo que } \\
\text { estas preguntas } \\
\text { deben ser } \\
\text { explícitas a la } \\
\text { hora de la } \\
\text { evaluación, para } \\
\text { saber realmente } \\
\text { qué entendemos } \\
\text { por evaluación y } \\
\text { que decidimos } \\
\text { evaluar"... }\end{array}$ & $\begin{array}{l}\text {..."porque } \\
\text { considero que } \\
\text { tiene status de } \\
\text { concepto y no de } \\
\text { conector, debido } \\
\text { a que la } \\
\text { evaluación tiene } \\
\text { para mi"... }\end{array}$ & $\begin{array}{l}\text {..."por cuanto } \\
\text { regular significa } \\
\text { hacer ajustes con } \\
\text { miras a lograr } \\
\text { una cierta } \\
\text { meta"... }\end{array}$ \\
\hline Acordar & $\begin{array}{l}\text {..."Creo que el } \\
\text { mapa de A11 y } \\
\text { el mío } \\
\text { comparten la } \\
\text { multiplicidad de } \\
\text { opciones"... }\end{array}$ & $\begin{array}{l}\text {...'Creo que } \\
\text { esto acuerda con } \\
\text { lo que A1 } \\
\text { establece en el } \\
\text { suyo acerca de } \\
\text { que se facilita un } \\
\text { encuentro entre } \\
\text { educador y } \\
\text { educando"... }\end{array}$ & $\begin{array}{l}\text {...’También } \\
\text { comparto que la } \\
\text { evaluación } \\
\text { DEBE tener } \\
\text { como finalidad } \\
\text { mejorar el } \\
\text { proceso de } \\
\text { enseñanza } \\
\text { aprendizaje"... }\end{array}$ & \begin{tabular}{|l|}
...'Bien, creo \\
que hay tantos \\
mapas como \\
representaciones \\
mentales \\
instantáneas \\
tengamos. Dadas \\
tus razones y \\
aceptadas"...
\end{tabular} & $\begin{array}{l}\text {...'Estoy de } \\
\text { acuerdo con A8 } \\
\text { en este } \\
\text { comentario"... }\end{array}$ \\
\hline Pedir aclaración & & & $\begin{array}{l}\text {...”No termino } \\
\text { de entender si } \\
\text { pones como } \\
\text { contrapuestas la } \\
\text { evaluación como } \\
\text { instrumento de } \\
\text { control y la } \\
\text { evaluación } \\
\text { reflexiva"... }\end{array}$ & \begin{tabular}{|l|}
...”Me cuestiono \\
la proposición: \\
la evaluación \\
que actúa como \\
función \\
pedagógica su \\
objetivo es \\
lograr \\
calificaciones.( \\
no es más \\
administrativo?" \\
\end{tabular} & \\
\hline \multicolumn{6}{|c|}{$\begin{array}{l}\text { No se registran en la categoría gestión de grupo los indicadores secuenciar, presentar alternativas, } \\
\text { presentar síntesis de lo acordado, evaluar el avance del trabajo, tomar decisión, formular propuesta de } \\
\text { trabajo. }\end{array}$} \\
\hline \multicolumn{6}{|c|}{ Categoría: Integración social } \\
\hline \multirow{2}{*}{ Indicadores } & \multicolumn{5}{|c|}{ Ejemplos de los grupos } \\
\hline & Violeta & Rosa & Gris & Naranja & Lila \\
\hline Motivar & $\begin{array}{l}\text {...'en algo } \\
\text { estamos de } \\
\text { acuerdo jejeje." }\end{array}$ & & & & \\
\hline $\begin{array}{l}\text { Contestar a un } \\
\text { compañero }\end{array}$ & $\begin{array}{l}\text {...’Está bueno } \\
\text { que otro lea la } \\
\text { producción de } \\
\text { uno porque } \\
\text { ayuda a } \\
\text { clarificar. A ver, } \\
\text { aquí va la } \\
\text { respuesta:"... }\end{array}$ & & $\begin{array}{l}\text { "respondo a tus } \\
\text { interrogantes, a } \\
\text { mi modo de ver } \\
\text { los conceptos } \\
\text { recomendados } \\
\text { para realizar el } \\
\text { mapa son todos } \\
\text { ellos conceptos } \\
\text { técnicos"... }\end{array}$ & $\begin{array}{l}\text {...'Respuesta de } \\
\text { A12 a A10. } \\
\text { Ella cuestiona } \\
\text { que la } \\
\text { evaluación"... }\end{array}$ & \\
\hline $\begin{array}{l}\text { Manifestar } \\
\text { compromiso con la } \\
\text { tarea grupal }\end{array}$ & $\begin{array}{l}\text { ¡Perdón por la } \\
\text { demora! }\end{array}$ & & & & \\
\hline
\end{tabular}

Tabla 6.13. Funcionamiento de grupo. Ejemplos de SA 0.4 
En este SA dentro de las metas que se plantean se encuentran dos que están fuertemente relacionados a los objetivos del SA general:

-En base a los conocimientos previos, reflexionar sobre los conceptos de evaluación, calificación y acreditación en el proceso enseñanza y aprendizaje.

-Favorecer el uso del Foro como herramienta para la discusión, negociación y consenso de conceptos entre varias personas.

Para avanzar hacia el logro de estas metas, se propuso a partir de los mapas conceptuales individuales hacer explícitas las consistencias e inconsistencias halladas en los trabajos de los compañeros en relación al propio. Tratando de generar de esta manera un debate, donde se provean distintas perspectivas y se favorezca la reflexión, considerándolo como un entorno propicio para el desarrollo de procesos que soporta la construcción de conocimiento colaborativa a través de la negociación social (Gunawardena y col, 1997). En referencia al modelo propuesto por los autores Gunawardena y col. (1997), se puede observar que en la mayoría de los grupos las contribuciones de la Fase I, en las que se comparte información, opiniones y acuerdos, alcanza cerca de un $30 \%$ de los mensajes. Destacándose en el grupo rosa aproximadamente el doble de contribuciones para esta etapa.

Las contribuciones de la Fase II, señalan posibles inconsistencias de ideas, estableciendo las áreas de desacuerdo. Se observa en todos los grupos una distribución homogénea de la cantidad de contribuciones, distinguiéndose el grupo gris con un bajo porcentaje de mensajes en esta etapa.

En la Fase III, los participantes negocian y clarifican el significado de términos, llegando en algunos casos a la identificación de áreas de acuerdo. Se distingue un alto porcentaje de contribuciones en esta etapa.

El paso de las diferentes fases propuestas por los autores revelarían procesos, originados en las interacciones entre los miembros del grupo (McInnerney y Roberts, 2004), en los cuales se compartiría, negociaría, clarificaría y acordarían significados de los términos del debate. No se identificaron contribuciones en las Fases IV y V, referidas a evaluación, síntesis y aplicación de lo trabajado, si bien los participantes podrían haber transitado estas etapas, el SA no contemplaba en sus objetivos el desarrollo de las mismas. El avance en estas dos últimas etapas se ha previsto para el desarrollo de la actividad final (SA 0). 
La evolución del SA fue perturbado por el surgimiento de las siguientes contradicciones: sujeto - reglas, sujeto - objeto y sujeto - herramienta.

Las tensiones generadas entre las componentes sujeto - reglas y sujeto - objeto se encuentran muy relacionadas, ya que el no cumplimiento de las reglas afecta directamente al logro del objetivo propuesto en la dimensión referida a los procesos colaborativos.

Los conflictos en la relación sujeto - herramienta afectan directamente al desarrollo de la actividad, ya que pueden retrasar la participación e inhibir posibles interacciones. Este conflicto fue detectado anteriormente en el SA 0.3, proponiéndose modificaciones en el rol del tutor que debía contemplar la asistencia en este tipo de inconvenientes. A7 del equipo gris, por ejemplo, presentó dificultades para publicar sus mensajes debido a restricciones en cuanto al tamaño de las contribuciones soportado por la herramienta foro:

“Hola Gabriela.

Escribo para comentarte que no he podido agregar mi actividad 4 al foro. Probé en varias oportunidades"...

..."Sigo los pasos correctamente y aunque clickeo en publicar no aparece.

Mi apuro es porque me demoré con esta actividad y no querría que se cerrara la discusión y dejar a mi compañera sin respuesta”... A7

El tutor pidió que le enviara la contribución, y luego de resolver el inconveniente generado a partir de limitaciones de la herramienta utilizada (desconocida por el tutor), la publicó en el foro en nombre del alumno:

“A7, no podías publicar el mensaje por el tamaño. Lo dividí en dos partes, pero después de varios intentos lo publiqué”...

El alumno A10 del grupo naranja presentó en el comienzo de la actividad dificultades en el manejo de la plataforma que le impiden realizar la actividad. Lo comunica a través del Webmail y el espacio "Preguntas y respuestas de interés":

...”Ya consulté lo mismo por el lado de preguntas frecuentes.

Estoy explorando la plataforma. Se me está tornando áspera. No encuentro los mapas conceptuales publicados de mis compañeras del grupo naranja”...

El tutor respondió a través de "preguntas y respuestas de interés" para socializar la respuesta entre los miembros del curso. 


\subsection{Sistema de Actividad 0.5 (Reflexionar, negociar y acordar conceptos de evaluación)}

Los sistemas 0.5.1 y 0.5.2 que forman parte del SA 0.5, se desarrollaron simultáneamente para contribuir a los objetivos del sistema que integran. Se propuso a los participantes el siguiente enunciado que contempla al SA 0.5 y sus actividades componentes:

\section{Actividad 5:}

\section{1/10/06 al 15/11/06}

-Leer la bibliografía recomendada y la Disposición Nº11/2006 (el material se encuentran en la fotocopiadora del Colegio).

-Durante el tiempo de lectura se habilitará un foro general para compartir comentarios y aclarar dudas entre ustedes y/o los tutores.

-Resolver individualmente la siguiente actividad:

En el espacio "Archivos y apuntes" se ha publicado el archivo "Dos situaciones de Enseñanza y Aprendizaje", explique y argumente en base a la bibliografía "cómo piensa que haría el docente para calificar en cada caso de los propuestos en el artículo". Si fuera necesario, aclare condiciones, restricciones y límites que considera en su propuesta.

La resolución de esta actividad debe ser enviada al tutor vía Webmail.

Para promover el desarrollo de la actividad 0.5.1 se planteó en el foro "comentarios y dudas", abierto a todos los participantes en general, dos propuestas con la intención de favorecer una lectura crítica y reflexiva del material:

Queremos proponerles comenzar a revisar las lecturas. Para esto les planteamos dos cuestiones:

- Qué decisiones podríamos tomar cuando un alumno "no acierta" con la "respuesta correcta".

- Evaluar y poner notas ¿es lo mismo?

Esperamos comentarios

\footnotetext{
${ }^{4}$ Ver Anexo II
} 


\subsubsection{Análisis de los factores que caracterizan el desarrollo de procesos colaborativos (Ingram y Hathorn, 2004)}

\subsubsection{Participación}

En el SA 0.5.1 participaron cuatro alumnos de un total de diez en la actividad anterior y de los cuales se esperaran posibles contribuciones. Tres de los alumnos publicaron un mensaje y sólo uno contribuyó en dos oportunidades.

Teniendo en cuenta el lapso de tiempo previsto para la actividad, dos de los mensajes fueron publicados fuera de término.

\subsubsection{Interacción}

\section{Diagrama de flujo de interacciones}

Se observa que todos los participantes hicieron aportes generales al grupo (Fig. 6.21), y todos menos A8 expresaron su acuerdo con un mensaje publicado por otro compañero, dando indicios de haber leído las contribuciones anteriores antes de participar.

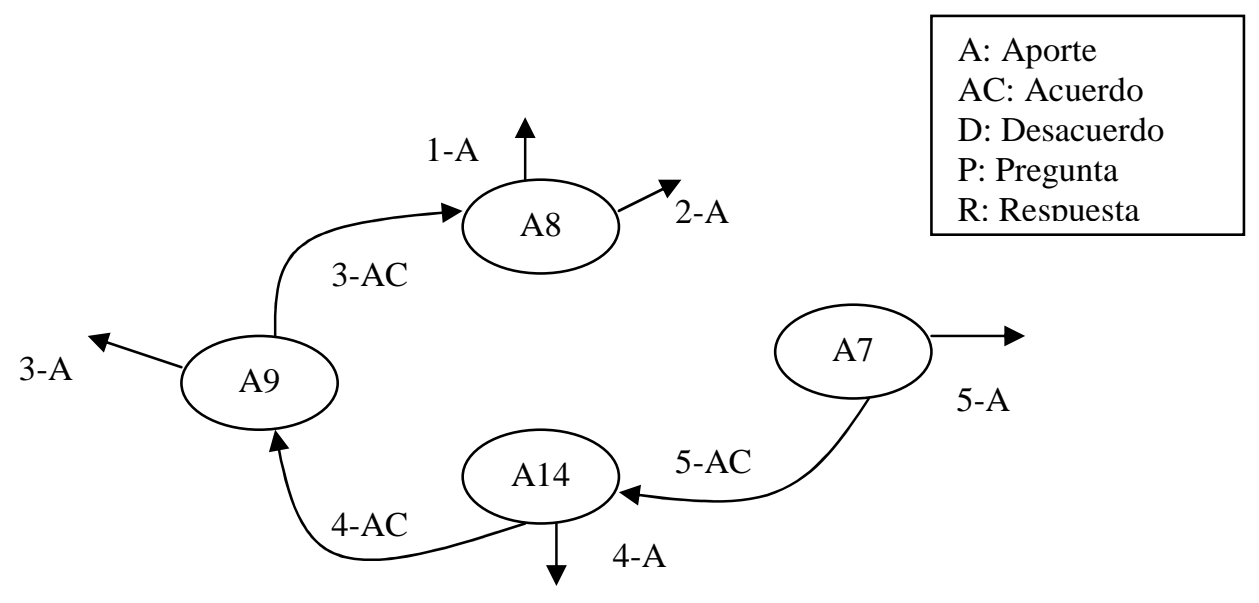

Figura 6.21: Diagrama de flujo de las interacciones entre los participantes del foro "Comentarios y dudas", indicando orden, dirección y tipo de mensaje. 


\section{Funcionamiento de Grupo: Categorías e Indicadores}

\begin{tabular}{|c|c|}
\hline \multicolumn{2}{|r|}{ Categoría Gestión de Grupo } \\
\hline Indicadores & Ejemplos \\
\hline $\begin{array}{l}\text { Compartir } \\
\text { interpretaciones }\end{array}$ & $\begin{array}{l}\text {... Creo que las decisiones que podemos tomar están relacionadas con el } \\
\text { análisis que hagamos de la situación particular y dependerá de muchos } \\
\text { factores."... A14 }\end{array}$ \\
\hline Argumentar & $\begin{array}{l}\text {..."Las lecturas ofrecidas ponen de manifiesto que el término evaluar tiene } \\
\text { connotaciones que superan ampliamente el reduccionismo que necesariamente } \\
\text { impone transformar un proceso (el educativo) en un número.”... A8 }\end{array}$ \\
\hline Acordar & $\begin{array}{l}\text {..."Claramente no es lo mismo evaluar que poner notas. Ya A8 lo detalla muy } \\
\text { bien"... A9 }\end{array}$ \\
\hline \multicolumn{2}{|c|}{$\begin{array}{l}\text { No se registran en la categoría gestión de grupo los indicadores consultar al grupo, secuenciar, presentar } \\
\text { alternativas, presentar síntesis de lo acordado, evaluar el avance del trabajo, tomar decisión, pedir } \\
\text { aclaración, formular propuesta de trabajo. }\end{array}$} \\
\hline \multicolumn{2}{|r|}{ Categoría Integración Social } \\
\hline Indicadores & Ejemplos \\
\hline Motivar & ..."Me enganché tarde, pero me gustaron las cuestiones planteadas. ”... A7 \\
\hline \multicolumn{2}{|c|}{$\begin{array}{l}\text { No se registran en la categoría integración social los indicadores involucrar al grupo, contestar a un } \\
\text { compañero, manifestar compromiso con la tarea grupal. }\end{array}$} \\
\hline
\end{tabular}

Tabla 6.14: Funcionamiento de grupo. Ejemplos del SA 0.5.1

Fases en la construcción activa del conocimiento (Gunawardena y col., 1997)

En la Figura 6.22 se representan las contribuciones de los participantes de acuerdo al modelo propuesto:

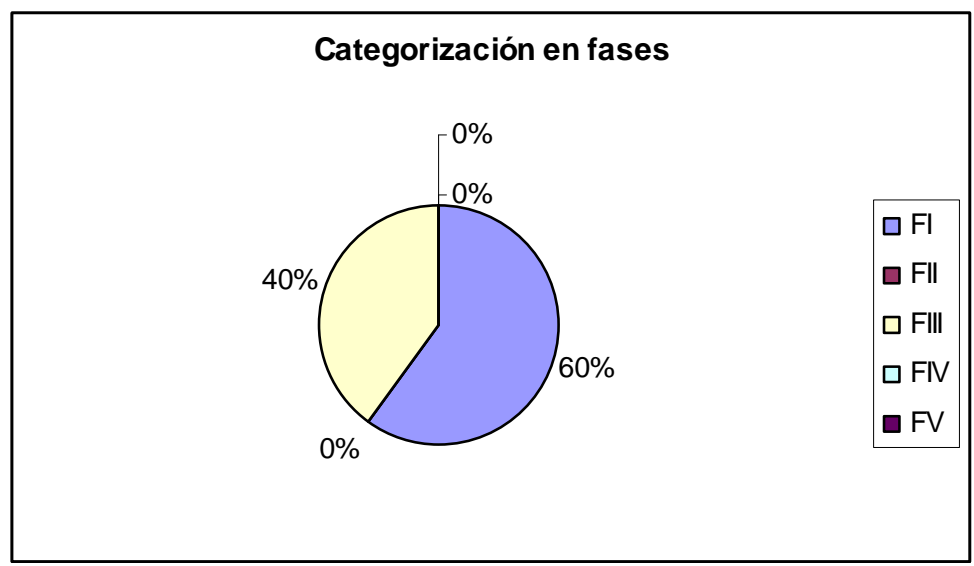

Fig. 6.22: Categorización de los mensajes en fases (Gunawardena y col, 1997) del foro "Comentarios y dudas". 
Se observa que la mayoría de las contribuciones corresponden a la Fase I, las cuales manifiestan sentencias de opinión y clarificación de significados.

Se distinguen mensajes correspondientes a la Fase III, orientados al establecimiento de áreas de acuerdo y clarificación del significado de términos. No se registran contribuciones en las otras etapas.

A continuación se presentan algunos ejemplos de mensajes correspondientes a las fases mencionadas:

..."Si detrás de ese "poner una nota" somos capaces de registrar:

- cuál es la evolución que nuestros estudiantes han sido capaces de desarrollar (esto supone conocer desde dónde han comenzado),

- qué dificultades hay cuando la evolución no es tal,

- cuánto de ese "parate en la evolución" puede tener que ver con nuestra propia tarea, con nuestras ausencias o nuestra incapacidad de ver que aquello que creemos hacer resulta que no es tal como lo estamos pensando, entonces

podría ser más probable que la nota reflejara la evaluación del proceso que ha seguido"... A8 (FI)

..."- Tratar de encontrar el porqué del "no acierto", de esta manera estaríamos considerando la información para detectar cuál fue la causa y poder, de esta manera, ajustar el proceso. Como dijo A9, la evaluación no debería terminar con la detección del error sino que éste nos debería servir para investigar y actuar en función de ello"... A14 (FIII)

\subsubsection{Análisis holístico del SA 0.5 (Reflexionar, negociar y acordar conceptos de evaluación)}

A partir de la disminución de la participación de alumnos en la actividad anterior, se decidió modificar el sujeto de los sistemas 0.5 y 0.5.1, el cual pasó de ser el grupo de trabajo a redefinirse como el grupo de todos los alumnos del curso.

La evolución de la actividad fue afectada principalmente por una contradicción sujeto-reglas, cuya manifestación se observa en la deserción y la escasa participación de los alumnos. Lo que compromete el logro del objeto definido:

-Reflexionar, negociar y acordar los conceptos de evaluación, calificación y acreditación en el proceso enseñanza y aprendizaje en el aula. 
-Promover el desarrollo de estrategias de Gestión de grupo e Integración social.

-Favorecer el uso del Foro como herramienta para la discusión, negociación y consenso de conceptos entre varias personas.

-Promover la interactividad entre el alumno y el material del curso.

Las dos actividades componentes se propusieron en forma simultánea, ya que se vinculaban para favorecer el logro del objeto del SA 0.5 .

La actividad 0.5.2 debía resolverse en forma individual y remitir la solución vía webmail a los tutores. En base a la bibliografía sugerida se debía proponer cómo podría ser planteada la evaluación por el docente de cada una de las situaciones presentadas.

Sólo tres alumnos presentaron sus soluciones al problema planteado, de los cuales dos lo hicieron fuera de término.

Durante el desarrollo de las actividades se enviaron mails a los alumnos que no habían ingresado a la plataforma desde el mes de octubre, informándoles sobre las actividades en curso y ofreciéndoles ayuda en el caso de que hubieran tenido algún inconveniente para participar. Cinco contestaron que no habían cumplido con el cronograma de tareas por no disponer de tiempo debido a concursos o exámenes, problemas personales o de salud. De esta manera, se pone de manifiesto que existirían factores contextuales que influirían en el desarrollo de la actividad y para lo cual sería necesario obtener información utilizando como instrumento una entrevista semiestructurada para indagar la influencia de estos factores.

\subsection{Sistema de Actividad 0}

Al mantenerse la situación que originó la modificación del sujeto del SA anterior, se decide eliminar el SA 0.6 y realizar la actividad final considerando sujeto todos los alumnos del curso.

Los inconvenientes presentados en la actividad anterior originaron la extensión del plazo, afectando la evolución del SA 0 ya que el nuevo lapso abarcaba los últimos días del período escolar.

Se comunica a los alumnos la actividad a desarrollar: 
Actividad Final:

22/11/06 al 18/12/06

Deberán elaborar de manera conjunta un documento Word donde sinteticen pautas acordadas sobre evaluación, tratando de abarcar tanto la dimensión que atañe al proceso de enseñanza y aprendizaje como a aquella que se relaciona con los compromisos institucionales con el fin de mejorar las prácticas evaluativas en el colegio.

Para lograr esta síntesis les proponemos participar en un foro, donde nos convocará el siguiente tema: "Cómo mejoraría las prácticas de evaluación, teniendo en cuenta dos dimensiones: pedagógica y administrativa, institucional y social”.

La actividad se desarrollará a partir del 22 de noviembre hasta el 18 de diciembre, y el grupo de trabajo estará compuesto por todos los participantes del curso.

Esperamos una participación activa de todos aportando desde su experiencia y las actividades que consideren importante compartir con sus colegas e invitarlos a debatir las propuestas de otros compañeros. Intentaremos en este espacio reflexionar y elaborar algunas pautas sobre evaluación tratando de abarcar tanto la dimensión que atañe al proceso de enseñanza y aprendizaje como a aquélla que se relaciona con los compromisos institucionales con el fin de mejorar las prácticas evaluativas en el colegio.

La metodología de trabajo deberán acordarla también en el foro, ya que aquellas pautas que vayan consensuando deberán formar parte del documento final que elaborarán entre todos. Ustedes decidirán cómo elaborar el documento, si establecerán una figura de moderador, si todos podrán acceder al documento en edición, y cuál será el espacio para compartirlo.

En el período previsto para la actividad se registraron cinco mensajes correspondientes a tres alumnos, no logrando llevar a cabo la actividad. Ante esta situación, y considerando la época del año, se comunica por mail a los alumnos la siguiente propuesta:

\section{Hola a todos!}

Estamos terminando el año, hemos llegado a los plazos previstos y queremos comentarles una nueva propuesta.

El desarrollo del curso fue muy satisfactorio, los aportes realizados muy interesantes, declinando la participación hacia el final, lo que impidió llevar a cabo la actividad final. Esta actividad reviste singular importancia porque posibilitaría llegar a acuerdos consensuados y contextualizados en el ámbito del colegio sobre el tema objeto del curso: las prácticas evaluativas. La intención es favorecer el diálogo a partir de lo trabajado en el desarrollo del curso, por eso pensamos en extenderlo hasta marzo del año que viene para permitir por un lado, completar las actividades individuales, y por otro, establecer un nuevo período para llevar a cabo la actividad final. Esto demandaría un esfuerzo adicional para el cual necesitamos que nos confirmen su compromiso.

El nuevo cronograma sería el siguiente: 
Hasta el 30 de marzo: entrega de actividades individuales adeudadas.

Del 19 de marzo hasta el 30 de marzo: desarrollo de la actividad final

Por favor comuníquense con nosotras para hacernos conocer su opinión.

\subsubsection{Análisis de los factores que caracterizan el desarrollo de procesos colaborativos (Ingram y Hathorn, 2004)}

\subsubsection{Participación}

Los tutores recibieron la confirmación de proseguir con el curso el año entrante de ocho alumnos vía mail. Sin embargo, sólo participaron de la actividad tres publicando un mensaje cada uno. Las contribuciones se realizaron antes de la fecha de cierre de la actividad.

\subsubsection{Interacción}

\section{Diagrama de flujo de interacciones}

La Fig. 6.23 muestra que todos los participantes publicaron aportes y en el caso de A14 y A8 manifiestan acuerdo con lo expresado por A21. A pesar de que los mensajes fueron publicados en término, ningún participante hizo una segunda contribución lo que limitó la dinámica de las interacciones.

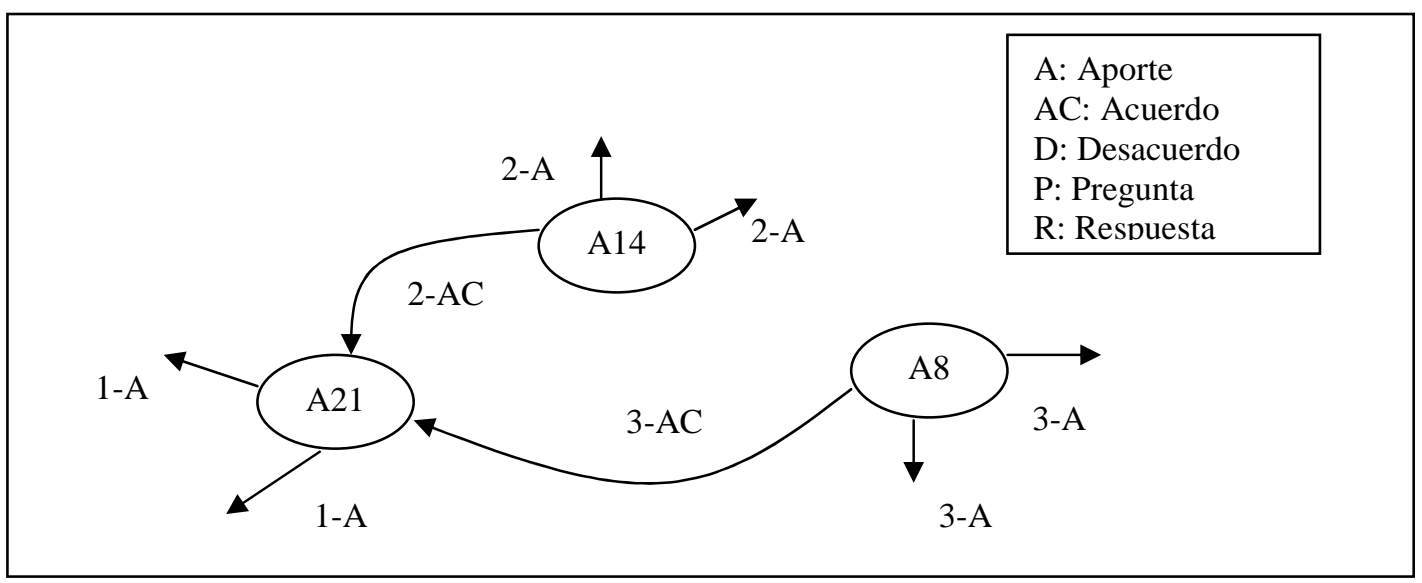

Figura 6.23: Diagrama de flujo de las interacciones entre los participantes del foro de la Actividad Final, indicando orden, dirección y tipo de mensaje. 


\section{Funcionamiento de Grupo: Categorías e Indicadores}

\begin{tabular}{|c|c|}
\hline \multicolumn{2}{|r|}{ Categoría Gestión de Grupo } \\
\hline Indicadores & Ejemplos \\
\hline Consultar al grupo & $\begin{array}{l}\text {.."me parece importante acordar criterios en lo que denominamos NOTA } \\
\text { CONCEPTUAL en la que muchos docentes evaluamos solo algunas actitudes"... } \\
\text { A21 } \\
\text {.."Por último me parece muy interesante que pudiéramos debatir sobre los } \\
\text { puntos que sugiere este autor en la sección } 5 \text { "... Al4 }\end{array}$ \\
\hline $\begin{array}{c}\text { Compartir } \\
\text { interpretaciones }\end{array}$ & $\begin{array}{l}\text {...” En cuanto a la dimensión pedagógica, creo que se debe atender muy bien al } \\
\text { proceso y al objetivo de la evaluación.”... A21 } \\
\text {..”Continuando con la dimensión pedagógica creo que debemos considerar que } \\
\text { la evaluación debe formar parte del proceso de aprendizaje y que debe servir } \\
\text { como guía para su desarrollo”... A14 }\end{array}$ \\
\hline Argumentar & $\begin{array}{l}\text {.."Resaltando, como dice Alvarez. Méndez, el carácter formador del proceso } \\
\text { educativo en la medida en que cuando un sujeto aprende, simultáneamente } \\
\text { evalúa, discrimina, valora, critica, opina, razona, fundamenta, decide, enjuicia, } \\
\text { opta"... Al4 }\end{array}$ \\
\hline Acordar & $\begin{array}{l}\text {..."Coincido con A21 en cuanto a la importancia que tenemos que dar a la } \\
\text { evaluación como parte del proceso."... A14 } \\
\text {..."Acuerdo con A21 en la importancia de atender al proceso de la } \\
\text { evaluación"... A8 }\end{array}$ \\
\hline \multicolumn{2}{|c|}{$\begin{array}{l}\text { No se registran en la categoría gestión de grupo los indicadores secuenciar, presentar alternativas, } \\
\text { presentar síntesis de lo acordado, evaluar el avance del trabajo, tomar decisión, pedir aclaración, formular } \\
\text { propuesta de trabajo. }\end{array}$} \\
\hline \multicolumn{2}{|r|}{ Categoría Integración Social } \\
\hline No se registran en & $\begin{array}{l}\text { goría integración social los indicadores motivar, involucrar al grupo, contestar } \\
\text { ar compromiso con la tarea grupal. }\end{array}$ \\
\hline
\end{tabular}

Tabla 6.15: Funcionamiento de grupo. Ejemplos del SA 0

Fases en la construcción activa del conocimiento (Gunawardena y col., 1997)

En la Fig. 6.24 se observa que la mayoría de las contribuciones pertenece a la Fase I, indicando que los participantes exponen sus ideas con el objetivo de compartirlas. Los mensajes en la Fase III se refieren a áreas de acuerdo, en las cuales los participantes realizan nuevos aportes. 


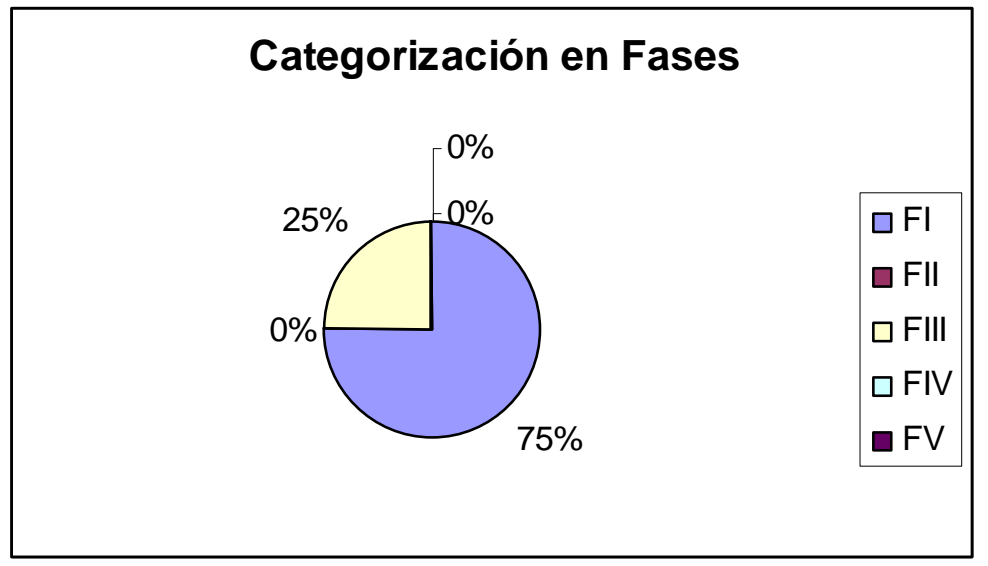

Figura 6.24: Categorización de los mensajes en fases (Gunawardena y col, 1997) del foro de la Actividad Final.

Los siguientes son ejemplos de las fases mencionadas:

..." me parece importante acordar criterios en lo que denominamos NOTA CONCEPTUAL en la que muchos docentes evaluamos sólo algunas actitudes ( como participación en clase, responsabilidad - que a veces se limita a cumplimiento de tareas- o disciplina) omitiendo además otras que a mi entender son muy valiosas como actitud frente a los desafios o la aplicación de estrategias, por nombrar algunas."... A21 (FI)

..."Acuerdo con A21 en la importancia de atender al proceso de la evaluación. Eso significa tener en cuenta la evolución que los estudiantes van experimentando durante cierto tiempo teniendo como referentes los objetivos que se han previsto."... A8 (FIII)

\subsubsection{Síntesis}

En el desarrollo del curso los alumnos han avanzado en procesos de negociación a través de interacciones que han permitido compartir nuevos significados. Si bien en la actividad final no elaboraron una síntesis con los acuerdos consensuados sobre evaluación, calificación y acreditación en la práctica del aula, se observa que las contribuciones expresan síntesis de los temas trabajados en las actividades del curso. En los mensajes del foro se distingue que las contribuciones categorizadas en el punto anterior como Fase III, además de acordar sobre un tema clarifican y exponen ideas relacionadas enriqueciendo y afianzando los conceptos consensuados.

A continuación se presentan algunos ejemplos sobre las ideas compartidas y consensuadas por los alumnos que fueron tomadas por los tutores para elaborar el documento síntesis de esta actividad. 
Los alumnos refirieron que en la evaluación se deberían considerar no sólo los resultados sino el proceso de aprendizaje:

..."En cuanto a la dimensión pedagógica, creo que se debe atender muy bien al proceso y al objetivo de la evaluación. El primero porque va a ser el que dé realmente la pauta que muestra si los conocimientos han sido verdaderamente aprendidos o si sólo se han incorporado momentáneamente para resolver determinadas problemáticas en una situación particular”... A21

..." Coincido con A21 en cuanto a la importancia que tenemos que dar a la evaluación como parte del proceso. Valorando además de los conocimientos aprendidos los factores que influyen en este proceso como por ejemplo la metodología utilizada para evaluar y su relación con la metodología de enseñanza, la situación particular en la que se desarrolle la evaluación (tipo de evaluación), el momento de la secuencia en el que nos encontramos, si fue acordada o no, etc. Los alumnos deberían conocer con anticipación los aspectos que se valorarán en el proceso y al finalizar el mismo conocer también el resultado global de estas valoraciones"... A14

..."Acuerdo con A21 en la importancia de atender al proceso de la evaluación. Eso significa tener en cuenta la evolución que los estudiantes van experimentando durante cierto tiempo teniendo como referentes los objetivos que se han previsto. Para tener indicadores de esa evolución creo que sería necesario acordar qué se va a mirar frente a cada instancia de evaluación respecto de un determinado contenido. Se me ocurren algunas cosas:

- empleo de lenguaje específico;

- grado en que se acerca/aleja de las respuestas esperadas (cómo discrimina, compara, establece relaciones, etc.);

- capacidad de interpretación;

- capacidad de síntesis.

Desde luego ésto requiere de varias instancias de evaluación si justamente a lo que se aspira es tener noticias sobre la continuidad del proceso para poder, desde nuestro rol, modificar aquello que sea posible”... A8

\subsubsection{Análisis holístico del SA 0}

Este SA representa al curso formación colaborativo online "La Evaluación: reflexionando en nuestra práctica docente”. Estudiar su evolución comprende reconocer los progresos de cada actividad componente, sus relaciones con el sistema en general y el contexto en el cual se desarrollaron.

El objeto del SA 0 define dos ejes fundamentales, uno relacionado al tema conceptual que se desarrolla durante el transcurso del curso y otro vinculado a favorecer el desempeño de los alumnos en situaciones de aprendizaje colaborativo: 
-Reflexionar, negociar y acordar los conceptos de evaluación, calificación y acreditación en el proceso enseñanza y aprendizaje en el aula, en dos dimensiones: una pedagógica y otra institucional y social.

-Promover en los docentes el desarrollo de estrategias y habilidades que favorezcan la evolución de procesos colaborativos de aprendizaje online.

La presentación del SA 0 a los alumnos del curso se realizó en forma presencial, se explicaron los objetivos y la metodología de trabajo. Se lograron los resultados propuestos para el SA 0.1:

-Definición de los objetivos del curso.

-Primeras experiencias en la utilización de las herramientas mediadoras del curso.

Los sistemas 0.2 y 0.3 desarrollados en forma simultánea, evolucionaron hacia el logro de los objetivos sin presentar obstáculos para el progreso del sistema en general, agregando en forma explícita tareas al rol de tutor. Se reconocen avances tanto en la dimensión referida a los conceptos sobre evaluación como al desempeño en procesos colaborativos que se ponen de manifiesto en la identificación de indicadores correspondientes a las categorías gestión de grupo e integración social en las interacciones entre los participantes.

En la actividad 0.4.1 se observa que participan trece alumnos finalizando diez la actividad 0.4, lo que afecta la dinámica de los grupos ya que se reducen a dos alumnos por equipo. Por esta razón, se modifica el sujeto de la actividad siguiente, redefiniéndolo como el grupo de los diez participantes que realiza el curso.

Se reconocen indicadores de funcionamiento de grupo que permiten identificar procesos de negociación de significados y aquellos inherentes al aspecto social del grupo que contribuirían al desarrollo de procesos colaborativos. La aplicación del modelo de Gunawardena y col (1997) permite observar que los participantes de los diferentes grupos desarrollaron procesos de negociación, clarificación y acuerdo de significados, transitando las Fases I, II y III en concordancia con los objetivos propuestos.

El desarrollo del sistema 0.5 fue afectado principalmente por una contradicción sujeto - reglas, observándose que cuatro alumnos intervienen en la actividad 0.5.1, presentando sólo tres los resultados del SA 0.5.2. Al ser indagados al respecto, explican 
no disponer de tiempo debido a la presentación a concursos o exámenes, tener problemas personales o de salud. De esta manera, se interpreta que la perturbación del sistema tiene su origen en el contexto en el cual se desarrolla, influyendo la época del año y los compromisos asumidos por los participantes en esa fecha.

Debido a que el sujeto de la actividad se define como todo el grupo de participantes del curso, deja de tener sentido la realización del SA 0.6, eliminándolo del SA 0. Así, se pasa a desarrollar la actividad final que no se puede concluir en diciembre de 2006 debido a la falta de participación. En consideración de los problemas contextuales existentes se consulta a los alumnos acerca de su interés por realizar esta actividad a comienzos del año próximo. Si bien contestaron en forma afirmativa ocho alumnos, sólo tres participaron de la actividad en el nuevo período.

Al finalizar el curso se entrevistó a los alumnos con el objeto de indagar acerca del funcionamiento del grupo en la e-formación desde la perspectiva personal en base a la experiencia realizada (ver Anexo I). Al preguntarles sobre su participación, ponen de manifiesto que al principio ingresaban periódicamente a la plataforma pero que luego su intervención fue afectada por diversos factores: época del año (finalización del ciclo lectivo), dos alumnas transitaban el final de su embarazo, problemas laborales. Esta información corrobora la problemática contextual del sistema planteada a los tutores a través del mail durante el desarrollo del curso. A continuación se detallan algunos textos extraídos de las entrevistas a los alumnos:

...”No te podría especificar frecuencia, seguro que tres veces por semana o más... la semana que no lo hice fue porque en algún momento en el medio de esto no estuve en Tandil y entonces ingresar desde afuera era para ver exclusivamente si había cuestiones de trabajo pero no para estudiar un curso"... A8

..."este final de licencia que tuve del fin del ciclo 2006 sólo entraba una vez por semana"... A10

...”No pude participar en esta etapa final por el extenso trabajo, se me desplazó el cronograma, estuve a cargo de todo lo que es estrategias de ingreso en veterinarias, más todo el inicio de los exámenes finales"... A10

..."Al principio empecé los fines de semana, en general falta de tiempo mío. Estaba haciendo otras cosas a la vez y estaba con una licenciatura, estoy con proyectos y era como que a lo mejor entraba, miraba como para ir pensando en todo lo que tenía que hacer pero bueno, a veces me faltaba tiempo"... A21

..."Por lo tiempos supongo. Porque se juntaron muchas cosas y por ahí era lo último que empecé y dije bueno ésto lo dejo pero no tuvo que ver con la organización ni con la temática ni con nada, era el tiempo para sentarse a leer. Y también el hecho de que era extra completamente"... A7 
..."Que no tuve tiempo. No de cantidad de tiempo sino, del momento en que se largó el curso y en que se empezó a poner complicado cuando se nos complicaba el año escolar por ahí”... A17

..." Cuando avanza mi embarazo empiezo a tener problemas porque me caí. Me dieron reposo absoluto"... A12

Los participantes no realizan un documento con la síntesis de lo desarrollado en el foro, por lo cual se modificó el resultado de la actividad. Los tutores, en base a la lectura del trabajo realizado en el foro, elaboraron un documento resaltando las ideas acordadas y algunas pautas para mejorar las prácticas de evaluación desde las dimensiones pedagógica y administrativa, institucional y social. El documento fue publicado en la plataforma como resultado de la actividad final. Sin embargo, el análisis de las participaciones del foro permite observar que los participantes no sólo exponen sus ideas sino que además de acordar con un compañero contribuyen a la negociación y coconstrucción de significados, reflejando una síntesis de lo desarrollado durante todo el curso. En consideración de la evolución del curso como un proceso dinámico al que contribuyeron los distintos sistemas componentes, se identifican procesos de colaboración a partir del análisis detallado acerca de la participación, interacción y síntesis, los cuales contribuyeron a los objetivos generales:

-Reflexionar, negociar y acordar los conceptos de evaluación, calificación y acreditación en el proceso enseñanza y aprendizaje en el aula, en dos dimensiones: una pedagógica y otra institucional y social.

-Promover en los docentes el desarrollo de estrategias y habilidades que favorezcan la evolución de procesos colaborativos de aprendizaje online

En el siguiente capítulo se presentan las conclusiones y proyecciones futuras del presente trabajo. 
CAPÍTULO VII

CONCLUSIONES 


\subsection{Presentación general de resultados}

El objetivo principal de esta propuesta, que se encuadra en la problemática de proyectos de cursos e-learning para formación en organizaciones educativas, consiste en delinear un modelo de diseño de enseñanza basado en una visión constructivista social del aprendizaje que permita promover el aprendizaje colaborativo en un entorno virtual.

A través del desarrollo de las actividades $0.1,0.2,0.3$ y 0.4 se avanzó hacia los objetivos propuestos tanto en la dimensión referida a los conceptos de evaluación como al desempeño de los docentes en procesos colaborativos.

El desarrollo de la actividad 0.5 se vió afectado por la disminución del número de alumnos debido a diferentes factores: época del año, dos alumnas transitaban el final de su embarazo, problemas laborales, exámenes, compromisos. Al interpretar esta situación a la luz de la Teoría de la Actividad se la reconoció como una contradicción sujeto-reglas que afectó el equilibrio del SA y fué considerada como fuerza de cambio y desarrollo, influyendo en la evolución del curso al causar la eliminación del SA 0.6.

A partir del estudio del diseño y evolución del curso de formación docente colaborativo online desarrollado en este trabajo, se definen las fases componentes del modelo "Diseño de propuestas de e-formación colaborativa", contribuyendo con un instrumento a la elaboración de cursos colaborativos online sobre la base de los referentes teóricos. El modelo construído permite interpretar la visión socio constructivista del aprendizaje en un entorno virtual desde una perspectiva didáctica.

Utilizar la TA para el diseño de un curso de formación colaborativo online permitió concebir el diseño como un conjunto de fases modificables a partir de la evolución del curso definido como un SA. De esta manera no se interpreta al diseño como una etapa inicial, aislada y estática definida fuera del contexto de la actividad por personas ajenas a la práctica educativa, sino que se concibe como un proceso que se retroalimenta y modifica en la evolución de la actividad como consecuencia de la evaluación de los procesos involucrados por parte del profesor y del tutor. La propuesta consiste en un modelo de diseño flexible, orientativo y coherente con el marco teórico de referencia. Debido a la naturaleza dinámica de las interrelaciones de los elementos del sistema, las fases de diseño no siguen una secuencia preestablecida sino que forman parte de un proceso iterativo incremental (Reigeluth, 2000; Miranda, 2003). Así, una 
primera propuesta puede ser modificada al comenzar a trabajar en las fases e incluso puede existir simultaneidad en el desarrollo de una o más etapas.

Las cinco fases del modelo "Diseño de propuestas de e-formación colaborativa" que se describen a continuación, se proponen como guías u orientaciones que pueden contribuir tanto a mejorar la práctica de los docentes que desarrollan cursos online, como a promover la implementación de propuestas similares en la formación docente de grado.

\subsection{Modelo de "Diseño de propuestas de e-formación colaborativa"}

En este trabajo se han articulado diferentes campos de conocimiento -educación, psicología social, informática y comunicación- con el objeto de contribuir a la innovación de la formación en las organizaciones escolares.

El modelo de e-formación resulta de la integración y síntesis interdisciplinaria alcanzada durante el proceso de investigación, bajo el supuesto de que el problema a abordar es una "actividad humana" de naturaleza social, histórica y contextual, que abarca aprendizajes, pensamientos y prácticas.

El análisis de los datos permitió inferir la estructura y funcionalidad del modelo de e-curso que se distingue por favorecer no sólo la adquisición de conocimientos específicos sino competencias para la práctica profesional y la comunicación en espacios virtuales de manera complementaria a los actuales espacios institucionales.

\section{-Definición del propósito del SA}

Definir el propósito del SA dentro del marco de este trabajo, significa explicitar una propuesta de formación colaborativa online como posible solución a un problema real planteado en una organización educativa. De esta manera, se construye un objeto provisorio, incompleto y dúctil que se resignifica en la evolución del SA del curso.

Los teóricos de la actividad atribuyen el status de objeto a manifestaciones físicas, sociales y culturales, incluyendo fenómenos tales como las expectativas y las afinidades. El propósito de actuación sobre un objeto es el principio base de todo SA y 
delimita el espacio de la acción (Gay y Hembrooke, 2004).

\section{-Delimitación del contexto del SA}

El diseño de un curso online se verá afectado por las características propias de la organización educativa, los sujetos (sus objetivos, conocimientos previos, normas de relación y comunicación) y los artefactos (mentales, físicos) que utilizan. Concebir el curso como un SA permite situar la actividad colaborativa en un contexto determinado destacando la dimensión social en la que se desarrolla (Barros y col., 2004).

\section{- Definición de los elementos del SA según el modelo de Engeström (1987)}

La utilización de la TA como heurística para el diseño del curso permite incorporar una visión sistémica que constituye una de las fortalezas del modelo que aquí se presenta, que posibilita una interpretación holística por parte de profesores y tutores de los principios socio constructivistas en el diseño e implementación de un e-curso colaborativo. Adoptar esta perspectiva permitió concebir el modelo de diseño no como una prescripción de un conjunto tareas a realizar, sino como orientaciones para el diseño del curso como un SA.

En esta etapa se identifican y describen los componentes de la actividad, estableciendo las interrelaciones que los conectan.

El sujeto es el grupo de personas que participan como alumnos del curso online. Es un componente fundamental del sistema, ya que el sujeto es quien conduce el sistema hacia el logro del objeto (Jonassen y Rohrer-Murphy, 1999).

El objeto es el propósito y motivo que define la actividad, estableciendo explícita y claramente los objetivos de enseñanza en relación con los núcleos conceptuales a desarrollar durante la actividad, planteando además objetivos vinculados a competencias y estrategias colaborativas requeridas.

El resultado surge como la proyección del objeto, motiva y da significado a las acciones del grupo (Engeström, 1987). Se aspira la obtención de un producto externo elaborado por el grupo, y un producto interno, inherente a cada uno de los miembros, considerando la internalización del producto elaborado. El producto final creado por el grupo representa una síntesis de ideas y aportes de todos los miembros, volviéndose 
dificultoso identificar las contribuciones individuales. Así, el resultado es más que la suma de las partes, creando un producto diferente de otro que los individuos podrían haber producido solos (Ingram y Hathorn, 2004). Los procesos por los que el grupo llega al resultado agrega a los aprendizajes individuales el desarrollo de capacidades para nuevas formas de comunicación con las tecnologías.

La comunidad está formada por el grupo de personas que comparten el objeto común de la actividad (Hew y Cheung, 2003): alumnos del curso, el profesor y los tutores que guiarán la actividad. Debido a que los grupos de aprendizaje no son jerárquicos, la toma de decisiones requieren un alto grado de negociación y compromiso (Graham y Misanchuk, 2004). En el desarrollo del proceso de colaboración será necesario fomentar habilidades de negociación y comunicación (Ferry y col., 2000) que permitan al grupo tomar decisiones y llegar al consens. Si la idea de un miembro es aceptada por el grupo se integrará a la estructura conceptual compartida, posibilitando la creación de conocimiento grupal e individual vinculados por una fuerte interdependencia (Gunawardena y col., 1997).

En la división del trabajo se distinguen generalmente los siguientes roles: alumno, profesor y tutor. Definir la división de tareas entre los integrantes de la comunidad es importante porque actúa como mediadora en la relación entre la comunidad de aprendizaje y el objeto (Jonassen y Rohrer-Murphy, 1999).

Debido a que la actividad a resolver radica en un problema real, las tareas del alumno consisten en contribuir a la definición del problema y a la elaboración de una posible solución. Las del profesor en observar el desarrollo de la actividad, evaluar el proceso colaborativo y el desempeño individual de los miembros, intervenir proveyendo feedback si fuese necesario y evaluar el resultado obtenido. El profesor actúa como facilitador cuya función principal es ayudar a los estudiantes a convertirse en participantes activos y realizar conexiones significativas entre los conocimientos previos, el nuevo conocimiento y los procesos involucrados en el aprendizaje. La responsabilidad del proceso enseñanza y aprendizaje es compartida por el profesor y los alumnos. Para poder llevar adelante esta tarea es necesario que el tutor comprenda los objetivos del aprendizaje colaborativo desde un enfoque pedagógico basado en el constructivismo social (Scagnoli, 2005).

Las interacciones entre los distintos componentes del sistema de actividad son 
mediadas por las herramientas (Jonassen y Rohrer-Murphy, 1999), que conectan a las personas no sólo con el mundo de los objetos, sino con otras personas (Leont'ev citado en Jonassen y Rohrer-Murphy, 1999). En el uso de herramientas informáticas como mediadoras es necesario considerar la posibilidad de que los participantes del curso no conozcan los instrumentos o los hayan utilizado en otros contextos para otros fines, y de esta manera la herramienta se convierta a la vez en objeto de estudio en sí misma.

Las reglas son normas explícitas e implícitas que la comunidad impone a los sujetos, cumplen un rol muy importante en la evolución del sistema ya que contribuyen a regular el funcionamiento del mismo.

\section{- Definición de la estructura interna del SA}

La tarea de definición de la estructura interna del SA se relaciona fuertemente con el tipo de problema "mal estructurado" que se intenta resolver, requiriendo la identificación y la definición de las actividades componentes y sus interrelaciones en el sistema general. Dado que cada actividad tendrá asociado un conjunto de acciones, para la selección de las herramientas de mediación es adecuado considerar las características de las acciones implicadas. Una actividad puede responder a varios objetivos que podrían dar origen a actividades componentes. En un diseño inicial se consideran las actividades más globales, para luego elaborar los sistemas de actividad componentes de acuerdo a los requerimientos del proceso de diseño. En la relación entre dos actividades el resultado de la primera puede que se constituya en una herramienta de mediación para la segunda, estableciendo una dependencia entre ambas (Barros y col, 2004).

En virtud de la dinámica del proceso, si alguno de los objetivos planteados no fueran alcanzados, influirá en la definición del siguiente sistema de actividad.

Para orientar el diseño de las actividades componentes conservando una visión global del e-curso, se elaboró un instrumento para la representación gráfica del SA con el fin de facilitar la elaboración del diseño, favoreciendo la comunicación entre profesor y tutor durante el proceso. En el mismo se representó al SA del e-curso con la figura de un triángulo, conteniendo en su interior los SA componentes representados por triángulos más pequeños y ubicados de izquierda a derecha según el desarrollo en el tiempo previsto para cada sistema. 


\section{-Evaluación integral del SA}

La evaluación es un proceso continuo en el diseño del sistema de actividad, que plantea la necesidad de rever y reajustar el producto parcial a medida que se avanza generando feedback entre las diferentes fases, favoreciendo la reflexión sobre el funcionamiento del SA y la toma de decisiones en el proceso de diseño.

Desde una visión holística del sistema, algunos componentes no pueden ser definidas de antemano en una forma completa, debido a que el diseño se realiza sobre un caso real, respondiendo a las características más generales de los problemas "mal estructurados" y haciendo necesaria una evaluación que contemple la evolución del sistema en forma iterativa (Nash y col., 2004).

En el marco de esta propuesta evaluar el SA significa indagar y reflexionar acerca de la calidad de los procesos colaborativos que tienen lugar en el desarrollo de la actividad, para lo cual se propone estudiar los factores participación, interacción y síntesis. Para el análisis de la participación de los alumnos en su grupo se analizaron la cantidad de intervenciones y su relación con las reglas del sistema. Para indagar acerca de la calidad de las interacciones se elaboraron dos instrumentos que constituyen un aporte a la evaluación de procesos de aprendizaje colaborativo. La herramienta "funcionamiento de grupo: categorías e indicadores" permite valorar las interacciones entre los participantes del grupo desde las dimensiones gestión de grupo e integración social y el "diagrama de flujo de interacciones" visualizar de manera gráfica las interacciones y su contenido con el fin de facilitar su interpretación por parte del profesor y el tutor. El estudio de la calidad de las interacciones se completa en la dimensión construcción de conocimiento a través de la utilización del instrumento "Interaction analysis model for examining social construction of knowledge in computer conferencing" (Gunawardena y col 1997). Las interacciones entre los miembros del grupo facilitan el desarrollo de los procesos de colaboración, indagar acerca de su calidad desde el funcionamiento de grupo y la construcción de conocimiento consideramos es la principal fortaleza de este trabajo ya que permitió profundizar el estudio de los procesos desarrollados. El factor síntesis fue estudiado a partir de la identificación por parte del profesor y tutor, de acuerdos consensuados en el desarrollo de la actividad. 


\subsection{Supuestos que sustentan la propuesta}

En el desarrollo del presente trabajo se destaca la adopción de un marco teórico que dió sustento a la toma de decisiones durante el proceso de diseño, permitiendo a través de acciones coherentes y consistentes con la perspectiva teórica; generar las fases para el diseño de un curso colaborativo online. Se destaca el rol del profesor socio constructivista que en la consideración de Applefield, Huber y Moallem (2001) requeriere reconocer cuatro características principales del proceso de aprendizaje: los alumnos construyen su propio aprendizaje, la dependencia del nuevo aprendizaje con el conocimiento previo, el rol crítico de la interacción social y la necesidad de tareas auténticas de aprendizaje para promover aprendizajes significativos en el alumno.

La utilización de estas pautas para la realización de proyectos de formación online requiere de los profesores comprender los alcances de la propuesta teórica para, desde esta perspectiva, poder generar experiencias que potencien el aprendizaje colaborativo y la integración de las Tics en la formación organizacional. 


\subsection{Proyección de este trabajo}

El trabajo presentado constituye un primer avance en el campo del diseño de cursos colaborativos online. Se presentan a continuación posibles líneas de investigación (I) e investigación y desarrollo (I+D) que podrían contribuir a la comprensión y a la definición de líneas de acción para intervenir en situaciones reales de colaboración:

- Mejorar los instrumentos utilizados en este trabajo para evaluar los elementos participación, interacción y síntesis (y proponer nuevos), con el fin de indagar la calidad de los procesos colaborativos que se desarrollan en cursos de este tipo.

- Elaborar representaciones gráficas de la información del SA para que permitan realizar un estudio pormenorizado del funcionamiento del sistema.

- Diseñar estrategias de formación docente en el diseño y seguimiento de cursos colaborativos online en base a los resultados de investigaciones.

- Desarrollar investigaciones para estudiar el "cómo" evaluar los aprendizajes individuales alcanzados mediante metodologías de aprendizaje colaborativo online.

El estudio de caso planteado en este trabajo se desarrolló en el ámbito de la formación docente permanente; sería de gran interés promover investigaciones en otros contextos como la formación de grado y postgrado, así como en la formación en entornos educativos no formales (estado, ONG, empresas, etc.). 
ANEXOS 


\section{Curso de capacitación docente online}

“La evaluación: reflexionando en nuestra práctica docente”

\section{Entrevista}

\section{1- Apreciación personal}

¿Cómo te resultó la experiencia? En relación con:

- Forma de capacitarse

- Cambios en tus prácticas

- Interacción con colegas

\section{2- Plataforma}

- ¿Pudo comprender fácilmente el funcionamiento de la plataforma?

- ¿Encontró inconvenientes al utilizarla? ¿Cuáles?

- ¿Utilizó el power point "Guía para el alumno" del CD entregado como parte del material del curso?

\section{3- Participación}

- ¿Con qué frecuencia ingresó a la plataforma en busca de novedades?

- Todos los días

- 3 veces por semana

- 1 vez por semana

- Períodos más largos

¿Por qué?

- Su participación se vio afectada por inconvenientes

- Tecnológicos

- Tiempo disponible

- Contenido del curso

- Metodología del curso

Explicar

- ¿Participó en la actividad final? ¿Por qué?

\section{4- Interacción}

Utilizó para comunicarse con sus pares sólo la plataforma u otros medios? Cuáles? 
5- Metodología y tecnología

Comente ventajas y desventajas que encontró en el desarrollo del curso en relación a un curso presencial en referencia a:

- Metodología de trabajo (Grupo, Actividades)

- Materiales (CD, Bibliografía, Esquema, Disposición ¿la conocía?)

- Herramientas tecnológicas (plataforma, Cmap)

- Participación (asistencia en presencial, resolución de actividades)

- Tutoría (qué hubiese necesitado? Se sintió perdido en algún momento? Que hizo?)

\section{6- Objetivos del curso}

¿El desarrollo del curso influyó en sus reflexiones acerca del concepto de evaluación y su propia práctica?

¿Qué actividades contribuyeron a esto?

\section{7- Sugerencias para una próxima edición del curso}


ANEXO II: Planteo de la situación problemática (SA 0.5.2)

\section{"Dos situaciones de Enseñanza y Aprendizaje"}

Texto extraído y adaptado del artículo "Constructivism in Theory and Practice: Toward a Better Understanding”, James. M. Applefield, Richard Huber y Mahnaz Moallem. The High School Journal, 84 (2) Dec 2000/Jan 2001.

Los siguientes relatos describen una clase típica de ciencias naturales de noveno año. El objetivo de la clase es comprender la diferencia entre circuito en paralelo y circuito en serie, un objetivo de ciencia física común en este año.

La clase está compuesta por un grupo heterogéneo de veinticinco estudiantes, quienes varían ampliamente en sus conocimientos, habilidades intelectuales, competencias para el aprendizaje independiente y habilidades básicas de escritura, lectura y reglas aritméticas.

\section{Situación 1:}

Los alumnos se sientan en filas ordenadas en frente del pizarrón y la profesora guía la clase parada en el frente del salón. La mayoría de las veces, después de terminar la clase los estudiantes tienen pequeños exámenes u hojas de trabajo individuales para realizar y evaluar lo que se espera que aprendan de la clase(s).

El entorno de la clase parece placentero, ya que el salón está limpio y ordenado destacándose posters de ciencia, no dejando dudas que aquí se enseña ciencias. En la clase los estudiantes no se comportan mal, aunque las interrupciones sean bastante comunes. Los estudiantes con más dificultades a menudo se distraen durante la clase; se pueden observar distracciones y conversaciones y ocasionalmente entretienen o molestan a otros estudiantes durante la clase. La profesora utiliza diferentes estrategias para modificar estos comportamientos de los estudiantes improductivos y a menudo perjudiciales, con frecuencia les pide que se queden quietos y que escuchen.

En sus interacciones con los estudiantes, la profesora tiende a mencionar, considerar y elogiar a quienes frecuentemente dan "buenas respuestas". Les da tareas más fáciles y cortas a los estudiantes con menos probabilidades de realizarlas y presta menos atención a los detalles de sus esfuerzos. Los resultados de las calificaciones de las pruebas revelan que algunos estudiantes no están teniendo buenos progresos en el dominio de 
los contenidos básicos del currículo de ciencia naturales, y hay evidencias que indican que se están retrasando respecto de sus compañeros de clase también en otras ciencias. La profesora dibujó un circuito completo en el pizarrón y les dijo a los estudiantes que escuchen cuidadosamente la descripción que realizaba de las características de un circuito completo. Su ejemplo comparaba un circuito en serie con uno en paralelo. La profesora explicó el movimiento de cargas en ambos dibujos, advirtió lo que sucedería en el circuito en serie si una de las lamparitas se quemara, e identificó las principales diferencias entre los dos esquemas. Entonces les pidió a algunos estudiantes que pasaran al frente y marcaran el punto en el circuito donde pondrían un interruptor. Para señalar la utilidad de tal predicción, ella demostró como se podía determinar que tipo de circuito (serie o en paralelo) se había realizado en la conexión del salón removiendo uno de los fluorescentes. Seguidamente, les dijo a los estudiantes que dibujaran y nombraran un circuito en paralelo y uno en serie en sus cuadernos.

Después de la demostración, los estudiantes fueron sentados en grupos, se les dio cables, pilas y lamparitas y se les indicó construir un circuito en serie y otro en paralelo como el mostrado en el pizarrón. Se les dieron las pautas para trabajar juntos y registrar los resultados en sus hojas de trabajo. La profesora supervisaba mientras los estudiantes comenzaban a trabajar. En cada uno de los grupos, uno o dos estudiantes conectaban los cables mientras los otros tres miembros del grupo observaban o charlaban entre ellos. Los estudiantes trabajaron en la tarea durante 15 minutos y, como la clase terminaba, se les dio tarea para el hogar que requería identificar circuitos en serie y en paralelo en varios gráficos

\section{Situación 2:}

La clase de 9no año se puede distinguir de otras clases tanto por su aspecto como por sus sonidos. Recorriendo los corredores escuchamos de la clase del final del pasillo una serie de voces y sonidos como zumbidos, conversaciones y ocasionales "lo tengo" y a veces expresiones de frustración. Desde la puerta del salón vemos grupos de alumnos trabajando con varios objetos. De hecho, si no fuera por la edad de la profesora, sería difícil identificar quién es el maestro en este salón. La profesora está hablando con uno de los grupos cerca de la puerta y dice, “¿Por qué seleccionaron ese diseño y colocaron la lamparita allí? ¿Trabajaría igual si se coloca en este otro lugar? Discútanlo y volveré a pasar luego." Se dirigió al siguiente grupo, se sentó entre ellos y observó cómo los estudiantes continuaban trabajando con baterías y lamparitas. Ellos parecían no notar la 
presencia de la profesora y continuaban hablando unos con otros, mientras ella se sonríe a medida que los observa.

Entramos al salón... No podemos encontrar el escritorio de la profesora, pareciera que está en el fondo del salón, aunque es dificultoso decir cuál es el fondo y cuál el frente del salón de clase. Notamos que varios estudiantes se han frustrado porque no logran que las lamparitas se enciendan y consultan con los compañeros del grupo más cercano. Uno opina que la lamparita está quemada. Les prestan una lámpara que en el circuito de ellos si ha encendido, pero tampoco funciona. Los alumnos del segundo grupo, que si han logrado hacer funcionar el circuito, se acercan e intentan buscar la causa del problema. Así se inicia una discusión entre los miembros de ambos grupos: dan diferentes razones, proponen cambios de elementos (pilas, llaves, resistencias, lamparitas), del diseño del circuito. Un alumno que quiere terminar la actividad les propone que hagan el mismo diseño que a ellos les funcionó. Pero un alumno del primer grupo se niega, quiere saber porque su diseño no funciona. Como no se ponen de acuerdo, otro alumno llama a la profesora: -Señora!, ¿puede venir? Cuando la profesora se acerca al grupo, con alboroto comienzan a hablar varios alumnos a la vez. No funciona -dice uno con desaliento. La lamparita no está quemada y pusimos pila nueva le advierte otro, para que no piense que es un problema trivial. Quieren mostrarle que han estado pensado pero no encuentran el problema. La profesora intenta calmar la ansiedad del grupo y les alcanza un multímetro para que busquen el problema. Ya les había explicado su funcionamiento en una clase anterior. ¿Recuerdan este instrumento? ¿Para qué y cómo se utiliza?. Podemos medir la corriente -se adelanta uno. O la diferencia de potencial - agrega otro. $\mathrm{Si}$, -dice la profesora- de acuerdo, ahora busquen dónde está el problema. Luego de un rato se escuchan exclamaciones de entusiasmo, han solucionado el problema. La profesora desde el otro extremo del salón, repara en el alboroto, se acerca, los felicita por el logro y les pide que expliquen que estaba mal, como encontraron el problema y como lo solucionaron. Un alumno que es muy callado y en general participa poco en clase, se anima y con entusiasmo cuenta la solución, otros alumnos aportan detalles y le muestran como lo hicieron.

Luego, la profesora mira el reloj, faltan solo 10 minutos para finalizar la clase. Entonces, pide que el vocero de cada grupo explique las dificultades para armar el circuito, como las fueron sorteando y la conclusión que extraen de dicho trabajo. 
BIBLIOGRAFÍA 
Adell Segura, J. y Sales Ciges, A. (online) Enseñanza online: elementos para la definición del rol del profesor. Consultada 3 de Agosto de 2007 en http://tecnologiaedu.us.es/edutec/2libroedutec99/libro/3.4.htm

Applefield J., Huber R., Moallem M. (2001). Constructivism in Theory and Practice: Toward a Better Understanding. The High School Journal, 84 (2), 35-53.

Barros B., Vélez J. y Verdejo M. (2004). Aplicaciones de la Teoría de la Actividad en el desarrollo de Sistemas Colaborativos de Enseñanza y Aprendizaje. Experiencias y Resultados. Inteligencia Artificial, 8 (24), 67-76.

Barros B., Verdejo M. (2000). DEGREE: un sistema para la realización y evaluación de experiencias de aprendizaje colaborativo en enseñanza a distancia. Revista Iberoamericana de Inteligencia Artificial, Vol 9, 27-37.

Biesenbach-Lucas, S. (2004). Asynchronous web discussions in teacher training courses: Promoting collaborative learning—or not? AACE Journal, 12 (2), 155-170.

Booch, G., Rumbaugh, J. y Jacobson, I. (2000). El lenguaje unificado de modelado. España: Addison Wesley Iberoamericana.

Bowles, M. (2004). Relearning to E-learn: Strategies for Electronic Learning and Knowledge. Australia: Melbourne University Press.

Brown J., Collins A., Duguid P. (1989). Situated Cognition and the Culture of Learning. Educational Researcher, 18 (1), 32-42.

Burbules, N. y Callister, T. (h) (2001). Riesgos y promesas de las Nuevas Tecnologías de la Información. Buenos Aires: GRANICA - Educación.

Cabero, J. (2006). Bases pedagógicas del e-learning. Revista de Universidad y Sociedad del Conocimiento (RUSC), 3 (1), 1-10.

Cañas, A. y col. (2005). Concept Maps: Integrating Knowledge and Information Visualization . En S.-O. Tergan and T. Keller (Eds.): Knowledge and Information Visualization, Alemania: Springer-Verlag Berlin Heidelberg, 205 - 219.

Castorina J., Ferreiro E., Kohl M., Lerner D. (1999). Piaget-Vigotsky: contribuciones para replantear el debate. Argentina: Paidós Educador.

Cenich, G. y Santos, G. (2006). Aprendizaje Colaborativo Online: Indagación de las Estrategias de Funcionamiento, Revista Iberoamericana de Tecnología en Educación y Educación en Tecnología (TE\&ET), 1(1), 79-86.

Chacón, F. (1996). Aproximación Histórica a las Tecnologías de la Educación a Distancia. Ponencia presentada en el 1 Seminario Internacional de Nuevas Tecnologías en Educación organizado por CEDIPROE. Bs. As.

Dirkx J. y Smith R. (2004). Thinking Out of a Bowl of Spaghetti: Learning to Learn in Online Collaborative Groups, en T. Roberts (ed). Online Collaborative Learning: Theory and Practice. USA: Idea Group Inc., 132-159.

Duggleby, J. (2001). El tutor online. La enseñanza a través de INTERNET. Barcelona: Ediciones DEUSTO S. A.

Engeström Y., Miettinen R. y Punamäki R. (eds.) (1999). Perspectives on Activity Theory. New York-USA: Cambridge University Press. 
Engeström, Y. (1987). Lerning by expanding: An activity-theoretical approach to developmental research. Helsinki, Orienta-Konsultit.

Fainholc, B. (1994). Reflexiones en Torno a la comunicación. La interactividad en le Educación a Distancia, en Litwin E., Maggio M. y Roig H., Comp. La Educación a distancia en los 90. Desarrollos, problemas y perspectivas. Buenos Aires: FFYL. UBA XXI. UBA, 130-136.

García Peñalvo, F. (2005). Estado actual de los sistemas e-learning. Revista Teoría de la Educación, 6 (1).

Gay G. y Hembrooke H. (2004). Activity - Centered Design. An Ecological Approach to Designing Smart Tools and Usable Systems. USA: MIT Press.

Ghezzi, C., Jazayeri M. y Mandrioli, D. (1991). Fundamentals of Software Engineering. USA: Prentice-Hall.

Graham C. y Misanchuk M. (2004). Computer-Mediated Learning Groups: Benefits and Challenges to Using Groupwork in Online Learning Environments, en T. Roberts (ed).

Online Collaborative Learning: Theory and Practice. Hershey-USA: Idea Group Publishing, 181-202.

Gunawardena, C. N., Lowe, C. A. \& Anderson, T. (1997). Analysis of a global online debate and the development of an interaction analysis model for examining social construction of knowledge in computer conferencing. Journal Educational Computing Research, 17(4), 397- 431.

Hasan, H. (2003). An Activity-based Model of Collective Knowledge. Proceedings of the 36th Annual Hawaii International Conference on System Sciences, 6-9 January 2003, 9p.

Hasu, M. y Engeström, Y. (2000), Measurement in Action: An Activity-theoretical Perspective on Producer-user Interaction. Human-Computer Studies (53), 61-89.

Hew, K. F. and Cheung, W. S. (2003). Models to evaluate online learning communities of asynchronous discussion forums. Australian Journal of Educational Technology, 19 (2), 241-259.

Huberman, S. (2000). Cómo se forman los capacitadores. Arte y saberes de su profesión. Bs. As.-Argentina: Ed. Paidós.

Hung, D. (2002). Situated Cognition and Problem-Based Learning: Implications for Learning and Instruction with Technology. Journal of Interactive Learning Research 13 (4), 393-414.

Ingram, A. y Hathorn L. (2004). Methods for Analyzing Collaboration in Online Communications, en T. Roberts (ed). Online Collaborative Learning: Theory and Practice. USA: Idea Group Inc. 215-241.

Johnson D. y Johnson F. (1999). Aprender Juntos y Solos. Aprendizaje cooperativo, competitivo e individualista. Brasil: Aique Grupo Editor S. A.

Jonassen, D. (online). Technology as Cognitive Tools: Learners as Designers.

Consultado 28 de marzo de 2006 en:

http://itech1.coe.uga.edu/itforum/paper1/paper1.html 
Jonassen, D. (2000). El diseño de entornos constructivistas de aprendizaje. En C. Reigeluth (Eds), Diseño de la instrucción. Teorías y modelos. Madrid: Aula XXI Santillana, 225-249.

Jonassen, D. y Rohrer-Murphy, L. (1999). Activity Theory as a Framework for Designing Constructivist Learning Environments. ETR\&D, 47 (1), 61-79.

Jonassen, D., Carr, C. y Yueh H. (1998) Computers as Mindtools for Engaging Learners in Critical Thinking.TechTrends, 43 (2), 24-32.

Jonassen, D. (1997). Instructional Desing Models for Well-Structure and Ill- Structure Problem-Solving Learning Outcomes. Educational Technology: Research and Development, 45 (1), 65-95.

Kanuka, H. y Anderson, T. (1998). Online Social Interchange, Discord, and Knowledge Construction. Journal of Distance Education, 13 (1), 57-75.

Karagiorgi Y., Symeou L. (2005). Translating Constructivism into Instructional Design: Potential and Limitations. Educational Technology \& Society, 8 (1), 17-27.

Lee, C. (1999). Problem-solving in a Constructivist Environment. Educational Technology \& Society, 2 (4).

Leont'ev, A. (1978). Activity, consciousness and personality. Englewood Cliffs, NJ: Prentice Hall.

Lewis, R. (2001). Grupos de trabajo en comunidades virtuales. Jornadas de la red FREREF NTIC. Consultada el 21 de Septiembre de 2007 en http://www.uoc.edu/web/esp/art/uoc/lewis0102/lewis0102.html

Lewis, R. (1998). Trabajo y aprendizaje en comunidades distribuidas. En C. Vizcarro y J. A. León (Eds), Nuevas tecnologías para el aprendizaje. Madrid: Pirámide, 191-219.

Litwin, E. (Compiladora) (2000). La Educación a Distancia. Temas para el debate en una nueva agenda educativa. Bs. As.-Argentina: Amorrortu.

Lugo, M. y Schulman, D. (1999). Capacitación a distancia: acercar la lejanía. Herramientas para el desarrollo de programas a distancia. Argentina.: Magisterio del Río de La Plata.

Marsh II G., Ketterer J. (2005). Situating the Zone of Proximal Development. Online Journal of Distance Learning Administration, 8 (2).

McInnerney, J. y Roberts T., (2004). Collaborative or Cooperative Learning?, en T. Roberts (ed). Online Collaborative Learning: Theory and Practice. USA: Idea Group Inc., 203-214.

McLoughlin, C. (2002). Computer supported teamwork: An integrative approach to evaluating cooperative learning in an online environment. Australian Journal of Educational Technology, 18(2), 227-254.

Mergendoller J. y col. (2006). Pervasive Management of Project Based Learning: Teachers as Guides and Facilitators, en Evertson C. y Weinstein S. (ed.). Handbook of classroom management. Research, Practice and Contemporary Issues. N.J.: Lawrence Erlbaum Associates, 583-616.

Moallem, M. (2003). An Interactive Online Course: A Collaborative Design Model, Educ Technol Res Dev 51(4), 85-103. 
Moore, M. (1990). Contemporary Issues in American Distance Education. Great Britain: Pergamon Press. BPCC Wheatons Ltd. Exeter.

Nardi, B. (1996). Context and Consciousness: activity Theory and Human-Computer Interaction. USA: The MIT Press.

Nash, J., Richter, C., Heidrun, A. (2004). Drawing on Design to Improve Evaluation of Computer Supported Collaborative Learning: Two Complementary Views, en T. Roberts (ed). Online Collaborative Learning: Theory and Practice. USA: Idea Group Inc., 281-310.

Neo, M. \& Neo, T. (2001). Innovative teaching: Using multimedia in a problem-based learning environment. Educational Technology \& Society, 4(4).

Novak, J. y Gowin, D. (1988). Aprendiendo a aprender. Barcelona: Sirven Grafic.

Ortiz, L. (2007). Campus Virtual: la educación más allá del LMS. Revista de Universidad y Sociedad del Conocimiento (RUSC), 4 (1).

Paz Dennen, V. (2000). Task structuring for online problem based learning: A case study. Educational Technology \& Society, 3(3), 329-336.

Petraglia, J. (1998). The Real World on a Short Leash: The (Mis)Application of Constructivism to the Design of Educational Technology. ETR\&D, 46 (3), 53-65.

Prieto Castillo, D. (1999). La comunicación en la educación. Argentina: Ed. Ciccus, La Crujía.

Reigeluth, C. (2000). La Teoría Elaborativa: orientación para la toma de decisiones sobre el alcance y la secuenciación, en Reigeluth, C. (eds), Diseño de la Instrucción. Teorías y modelos. Madrid: Aula XXI Santillana, 449-479.

Roberts, T. (2004). Online Collaborative Learning: Theory and Practice. Hershey-USA: Idea Group Publishing.

Rodríguez Gómez, G., Gil Flores, J. y García Jímenez, E. (1999), Metodología de la investigación cualitativa. Málaga: Ediciones Aljibe.

Rodriguez Illera, J. (2004). El aprendizaje virtual. Argentina: Homo Sapiens Ediciones.

Ronteltap F. \& Eurelings A. (2002). Activity and Interaction of Students in an Electronic Learning Environment for Problem-Based Learning. Distance Education, 23 (1), 11-22.

Rosenberg, M. (2001), E-Learning, USA: Mc Graw-Hill.

Rourke L., Anderson T., Garrison D. y Archer W. (1999). Assessing social presence in asynchronous text-based computer conferencing. Journal of Distance Education, 14 (2). Consultado 7 de Abril de 2006 en http://cade.athabascau.ca/vol14.2/rourke_et_al.html

Russell, D. L. y Schneiderheinze A. (2005), Understanding Innovation in Education Using Activity Theory. Educational Technology \& Society, 8(1), 38-53.

Salomon, G., Perkins, D. y Globerson, T. (1992). Coparticipando en el conocimiento: la ampliación de la inteligencia humana con las tecnologías inteligentes. Revista Comunicación, lenguaje y educación, 13, 6-22.

Sánchez Ilabaca, J. (2004). Bases constructivistas para la integración de TICs. Revista Enfoques Educacionales, 6 (1), 75-89. 
Sangrà Morer, A. (2002). Educación a distancia, educación presencial y usos de la tecnología: una tríada para el progreso educativo. EDUTEC, Revista Electrónica de Tecnología Educativa, 15. Consultado 10 de Setiembre de 2007 en http://www.uib.es/depart/gte/edutec-e/revelec15/albert_sangra.htm

Scagnoli, N. (2005). Estrategias para motivar el aprendizaje colaborativo en cursos a distancia. Consultado 20 de Abril de 2008 en http://students.ed.uiuc.edu/scagnoli/pubs/scagnoli-CL.pdf

SEC (2000) 1832, Memorándum sobre el aprendizaje permanente, Comisión de las Comunidades Europeas, Bruselas.

Sorensen, E. (2004). Reflection and Intellectual Amplification in Online Communities of Collaborative Learning, en T. Roberts (ed). Online Collaborative Learning: Theory and Practice. USA: Idea Group Inc, 242-261.

Spector, J. y Wang, X. (2002), Integrating Technology into Learning and Working: Promising Opportunities and Problematic Issues. Educational Technology \& Society, 5 (1), 1-7.

Tam, M. (2000). Constructivism, Instructional Design, and Technology: Implications for Transforming Distance Learning. Educational Technology \& Society, 3 (2).

Treleaven L. (2004). A New Taxonomy for Evaluation Studies of Online Collaborative Learning, en T. Roberts (ed). Online Collaborative Learning: Theory and Practice. USA: Idea Group Inc., 160-180.

Tu, C-H. y Corry M., (2001). Research in Online Learning Community. E-Journal Instructional Science and Technology, 5(1). Consultado el 1 de Marzo de 2007 en http://www.usq.edu.au/electpub/e-jist/docs/old/full_papers_5.htm.

Vidal Puga, M. (2004). Uso y evaluación de la plataforma de enseñanza-aprendizaje virtual "Blackboard". Revista de medios y educación Píxel - Bit, 24.

Vygotsky, L. (1930/ 1978). El desarrollo de los procesos psicológicos superiores. Barcelona: Crítica.

Wang, X. (2002). Integrating technology into learning and working: A promising future. Educational Technology \& Society, 5(2), 142-146.

Wentling, T y col (2000). e-learning - A Review of Literature . Consultado 20 de Agosto 2007 en learning.ncsa.uiuc.edu/papers/elearnlit.pdf

Williams, M.; Paprock, K.; Covington, B. (1999). Distance Learning: The Essential Guide. London: SAGE Publications, 1-34. 